\title{
Process evaluation of community mobilization activities
}

Zakir Hussain Shah

Follow this and additional works at: https://knowledgecommons.popcouncil.org/departments_sbsr-rh

Part of the Community-Based Research Commons, Community Health Commons, Community Health and Preventive Medicine Commons, International Public Health Commons, Public Health Education and Promotion Commons, and the Women's Health Commons How does access to this work benefit you? Let us know!

\section{Recommended Citation}

Shah, Zakir Hussain. 2010. "Process evaluation of community mobilization activities." Islamabad: Population Council. 

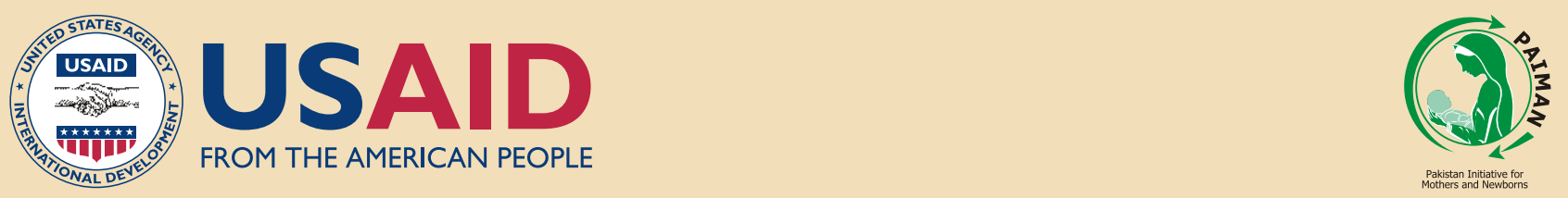

\section{Process Evaluation of Community Mobilization Activities}

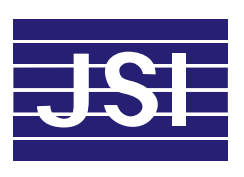

1 Population Council 

Pakistan Initiative for Mothers and Newborns (PAIMAN)

\section{Process Evaluation of Community Mobilization Activities}

Dr. Zakir H. Shah 


\section{(1) Population Council}

The Population Council, an international, non-profit, non-governmental organization established in 1952, seeks to improve the well-being and reproductive health of current and future generations around the world and to help achieve a humane, equitable, and sustainable balance between people and resources.

The Council analyzes population issues and trends; conducts research in the reproductive sciences; develops new contraceptives; works with public and private agencies to improve the quality and outreach of family planning and reproductive health services; helps governments design and implement effective population policies; communicates the results of research in the population field to diverse audiences; and helps strengthen professional resources in developing countries through collaborative research and programs, technical exchange, awards, and fellowships.

The Population Council reserves all rights of ownership of this document. No part of this publication may be reproduced, stored or transmitted in any form by any means-electronic, photocopying, recording or otherwise-without the permission of the Population Council.

\section{For inquiries, please contact:}

Population Council

\# 7, Street 62, F-6/3, Islamabad, Pakistan

Tel: 92518445566

Fax: 92512821401

Email:pcpak@popcouncil.org

Web: http://www.popcouncil.org

$\underline{\text { http://www.paiman.org.pk }}$

Layout and Design: Ali Ammad

Published: April, 2010

\section{Disclaimer}

"This study/report is made possible by the generous support of the American people through the United States Agency for International Development (USAID). The contents are the responsibility of JSI Research \& Training Institute, Inc and do not necessarily reflect the views of USAID or the United States Government." 


\section{Table of Contents}

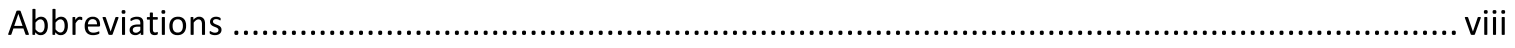

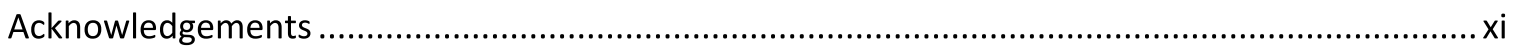

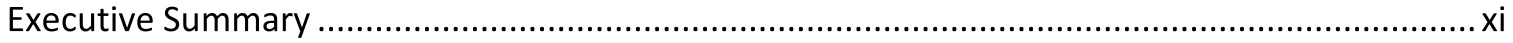

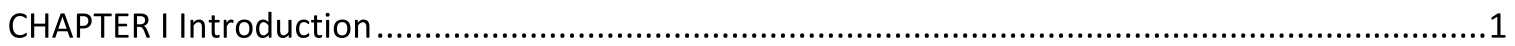

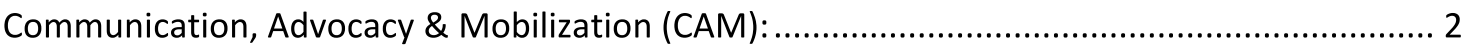

Activities under Communication, Advocacy \& Mobilization (CAM) ..................................... 3

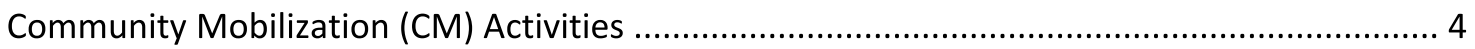

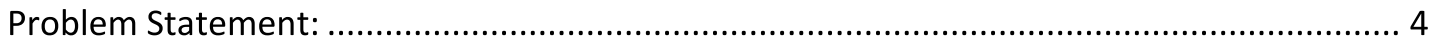

Rationale for selecting $\mathrm{CM}$ activities for Process Evaluation: .............................................. 5

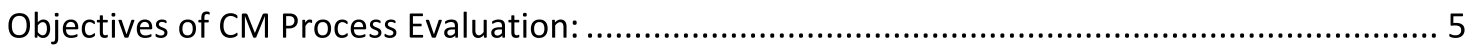

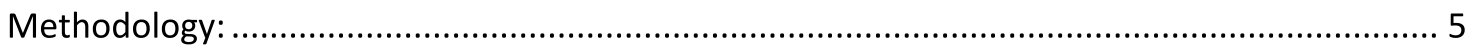

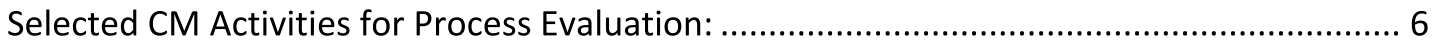

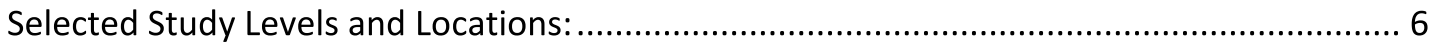

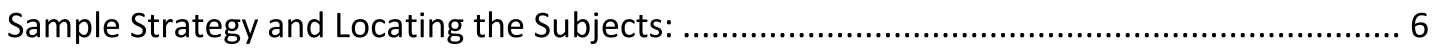

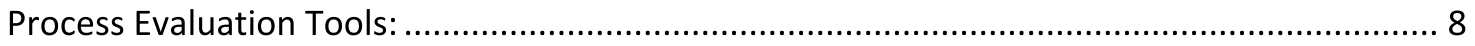

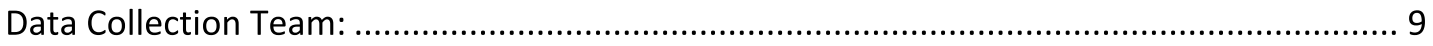

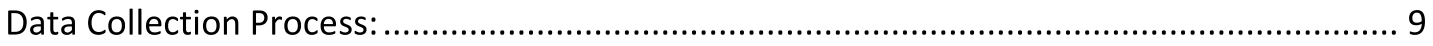

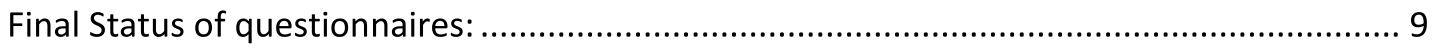

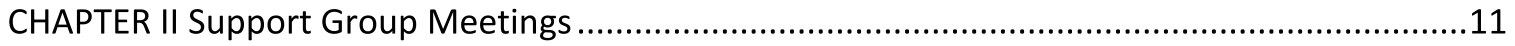

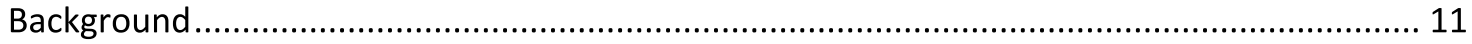

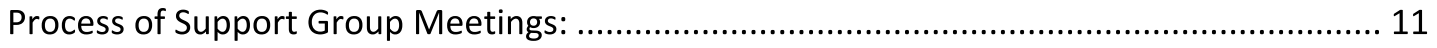

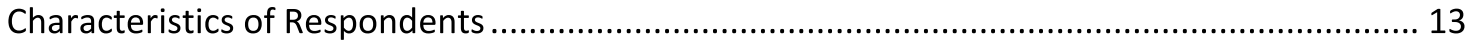

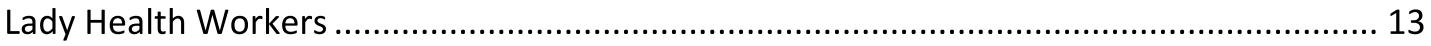

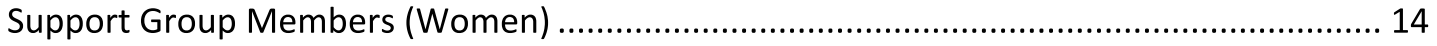

Findings Training of LHWs in Support Group Methodology: ...................................................17

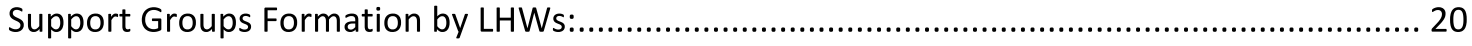

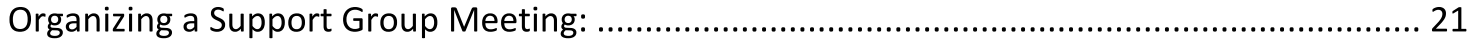

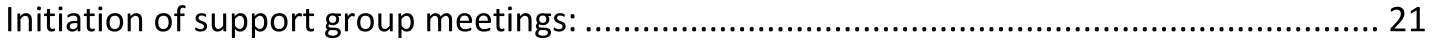

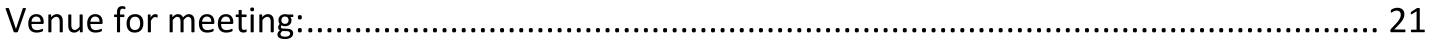

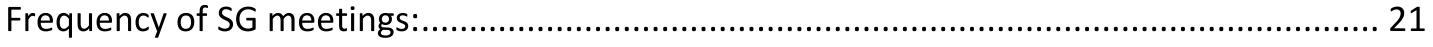

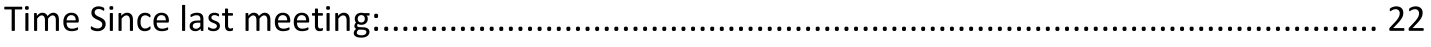

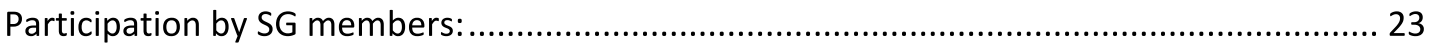




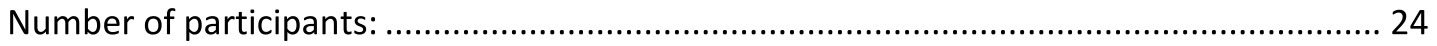

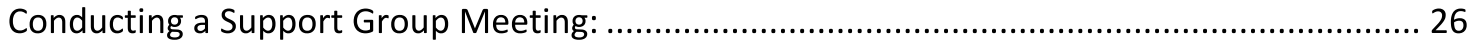

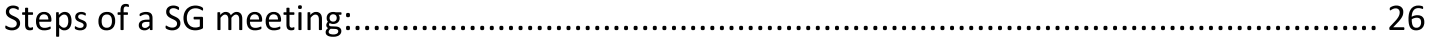

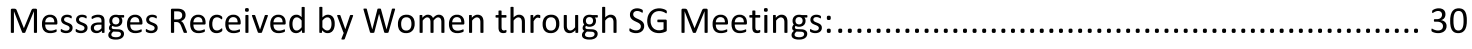

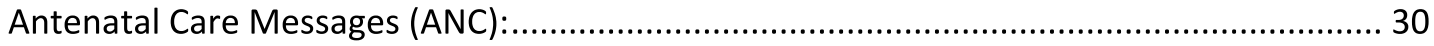

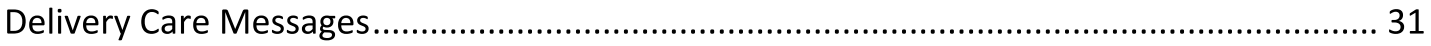

Postnatal care (PNC) messages received by women.......................................................... 32

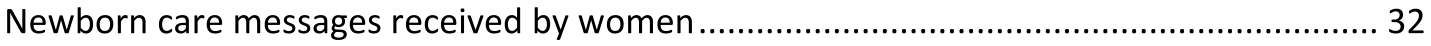

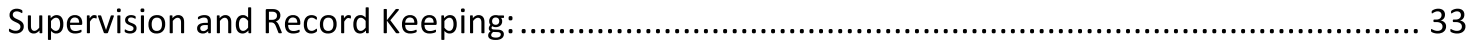

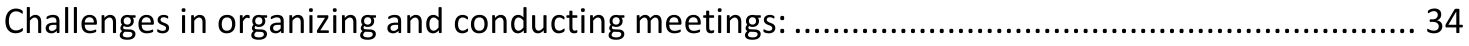

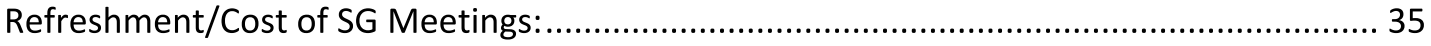

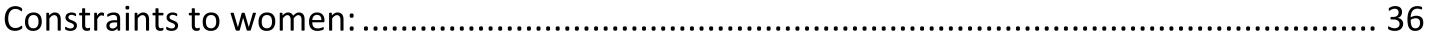

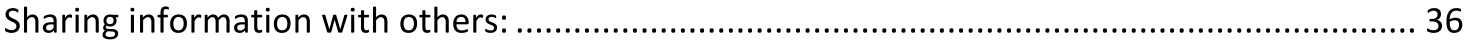

Views of women and LHWs about community and SG meetings ........................................ 37

Conclusions

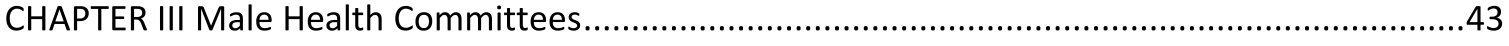

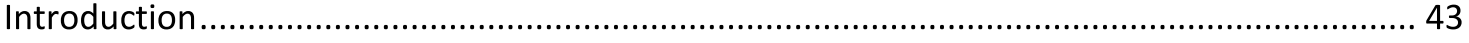

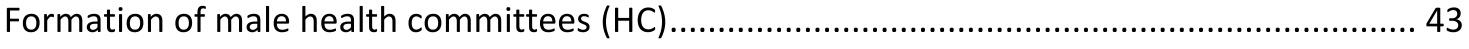

Organizing the Health Committee meeting ……..................................................................... 44

Frequency of Health Committee Meetings: ......................................................................... 44

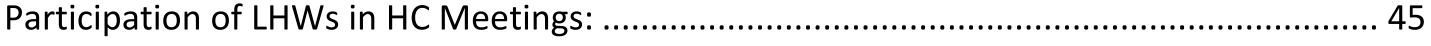

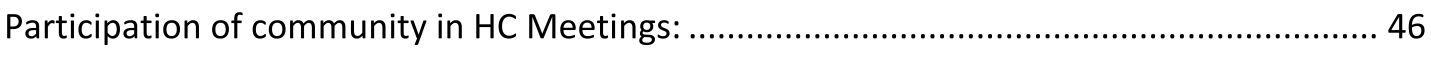

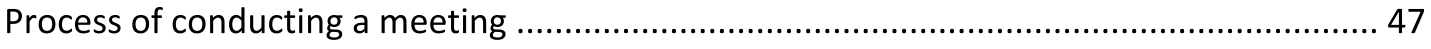

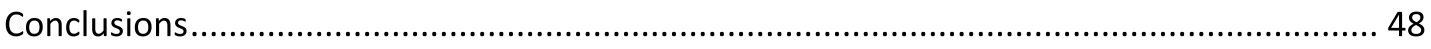

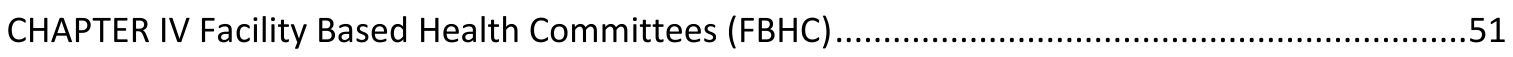

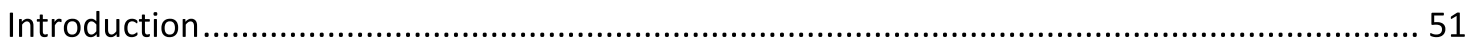

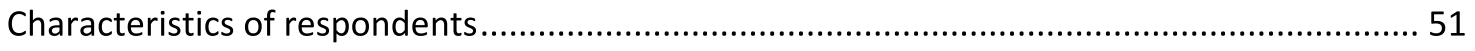

Organization of facility based health committee ............................................................. 53

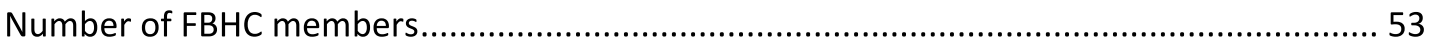

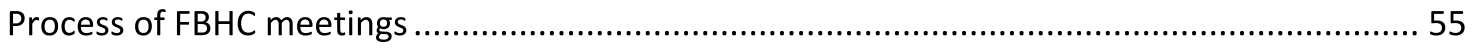

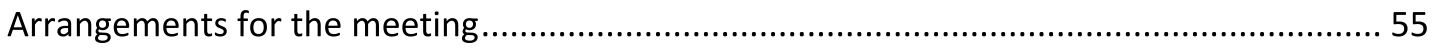

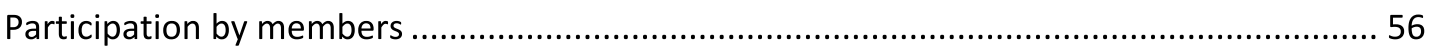

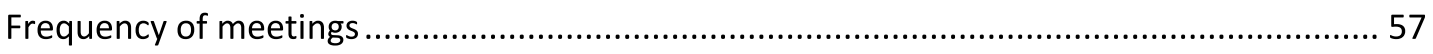

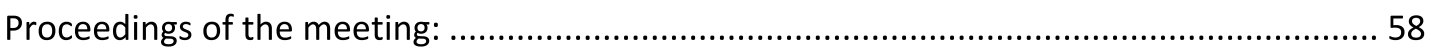




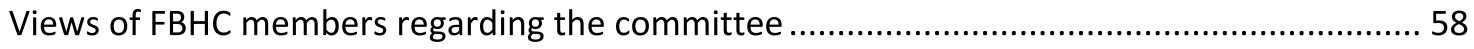

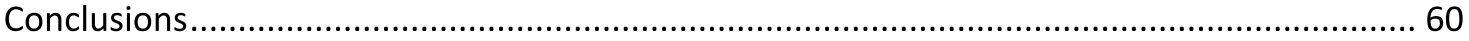

ANNEXURE

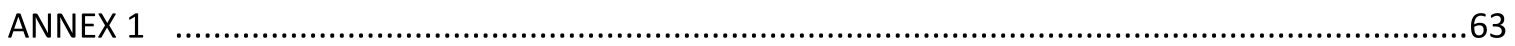

Team formation for fieldwork of process evaluation community mobilization ...................... 63

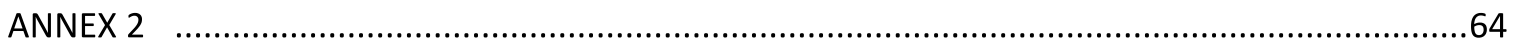

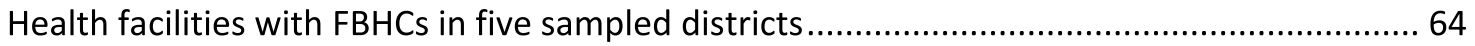

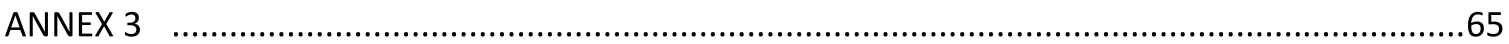

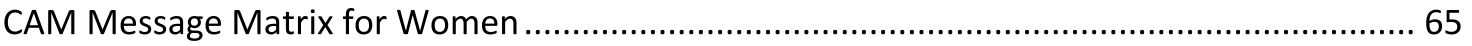

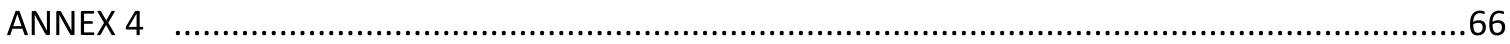

MNH messages given to women during SG meetings, as reported by LHWs and women....... 66

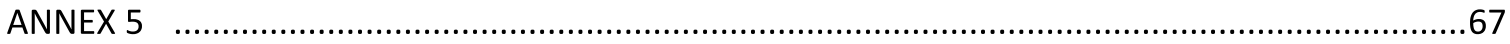

Steps followed during SG meetings as reported by LHWs \& Observed .................................. 67

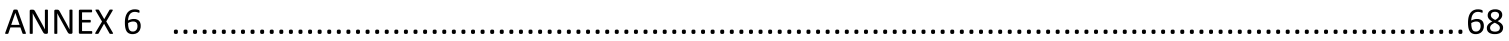

Percent women by number of SG meetings attended, as reported by women ....................... 68

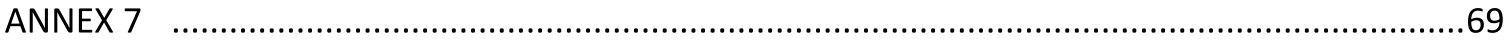

Messages Matrix for Husbands, Family Members and Community Leaders ..........................69 69

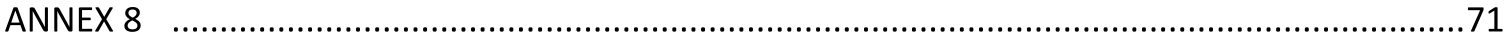

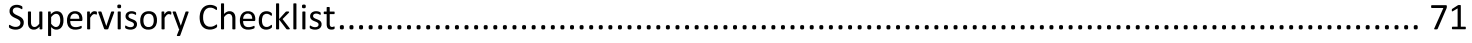

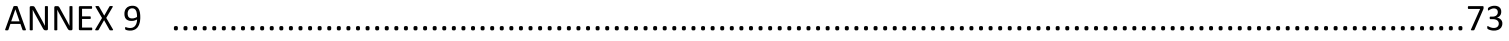

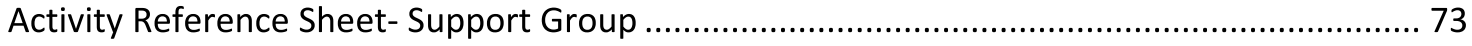

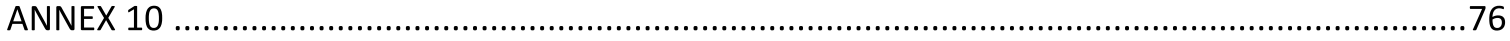

Mean Number of members in FBHC by district as reported by members FBHC …................. 76 


\section{List of Figures}

Figure 2.1: Percent LHWs by year of receiving training in SG methodology, as reported by LHWs.

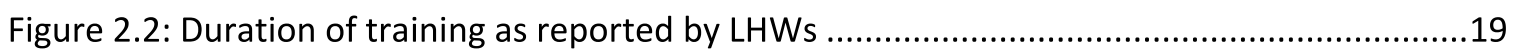

Figure 2.3: Topics discussed during the LHW's support group training, as reported by LHWs .....19

Figure 2.4: Frequency of SG meetings as reported by LHWs and women ...................................22

Figure 2.5: Percent women by number of meetings attended, as reported by women $(\mathrm{N}=286)$

Figure 2.6: Number of participants in the last attended meeting, as reported by LHWs, women and observed.

Figure 2.7: Steps followed by LHWs during the introductory session of SG meeting, as observed

Figure 2.8: Steps followed by LHWs during the main session of SG meeting, as observed...........28

Figure 2.9: Steps followed by LHWs during the closing session of SG meeting as observed.........29

Figure 2.10: Topics of discussion, as reported by LHWs and women .......................................30

Figure 2.11: ANC messages received by women of community, as reported by women ............31

Figure 2.12: Delivery Care messages received by women, as reported by women .....................31

Figure 2.13: Postnatal care messages received by women, as reported by women ...................32

Figure 2.14: Newborn care messages received by women, as reported by women ..................33

Figure 2.15: Problems encountered in organizing the SG meetings as reported by LHWs .........34

Figure 2.16: Cost of refreshment per SG meeting as reported by LHWs ......................................35

Figure 2.20: Improvements made by SG meetings in maternal health, as perceived by LHWs

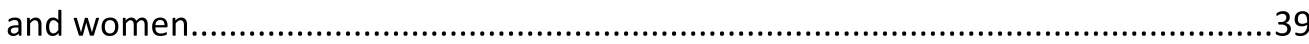

Figure 2.21: Improvements made by SG meetings in newborn health, as perceived by LHWs

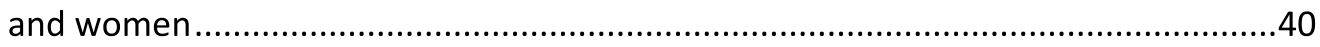

Figure 3.1: Number of male health committee meetings, as reported by LHWs $(\mathrm{N}=56)$............44

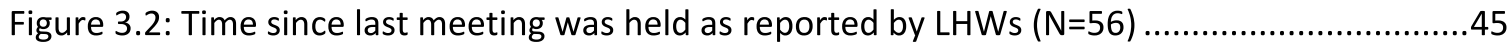

Figure 3.3: Facilitator of HC meetings as reported by LHWs ..................................................46

Figure 3.4: Number of participants in last held meeting as reported by LHWs ............................46

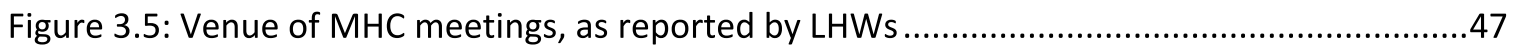

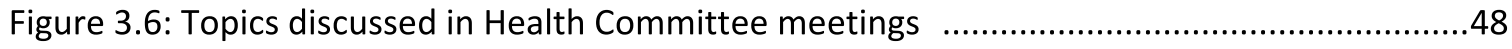

Figure 4.1: Distribution of respondents by education (FBHC) ................................................52

Figure 4.2: Maternal health problems in the community as perceived by the FBHC members ....54

Figure 4.3: Newborn health problems in the community as perceived by the FBHC

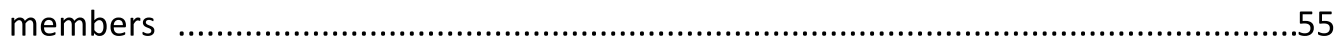

Figure 4.4: Time since last meeting attended as reported by FBHC members ...........................57

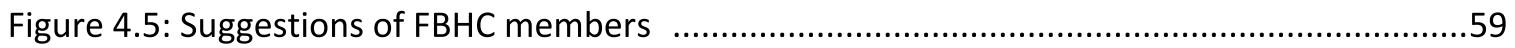




\section{List of Tables}

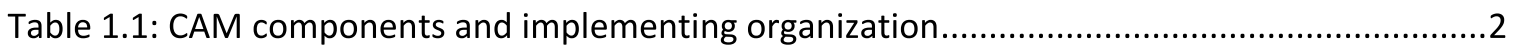

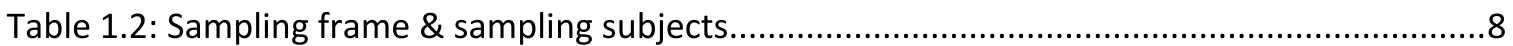

Table 1.3: Number of data collection instruments applied in each of five districts .......................9

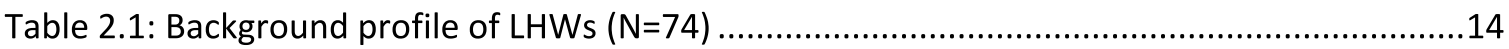

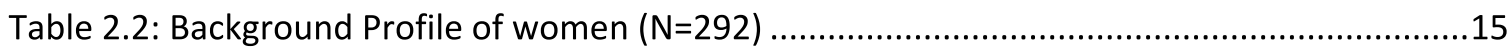

Table 2.3: Frequency of last SG meetings as reported by LHWs and women............................23

Table 2.4: Percent women who reported to have ever attended SG meeting by District

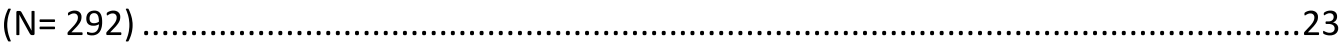

Table 3.1: Duration of last male HC meeting, as reported by LHWs .............................................47

Table 4.1: Distribution of respondents across districts by gender............................................52

Table 4.2: Distribution of respondents by age group and number of children.............................53

Table 4.3: Number of members in FBHC, as reported by respondents ......................................53

Table 4.4: Arrangements for FBHC meetings, as reported by members .....................................56

Table 4.5: Frequency of meetings as reported by FBHC members ............................................58 


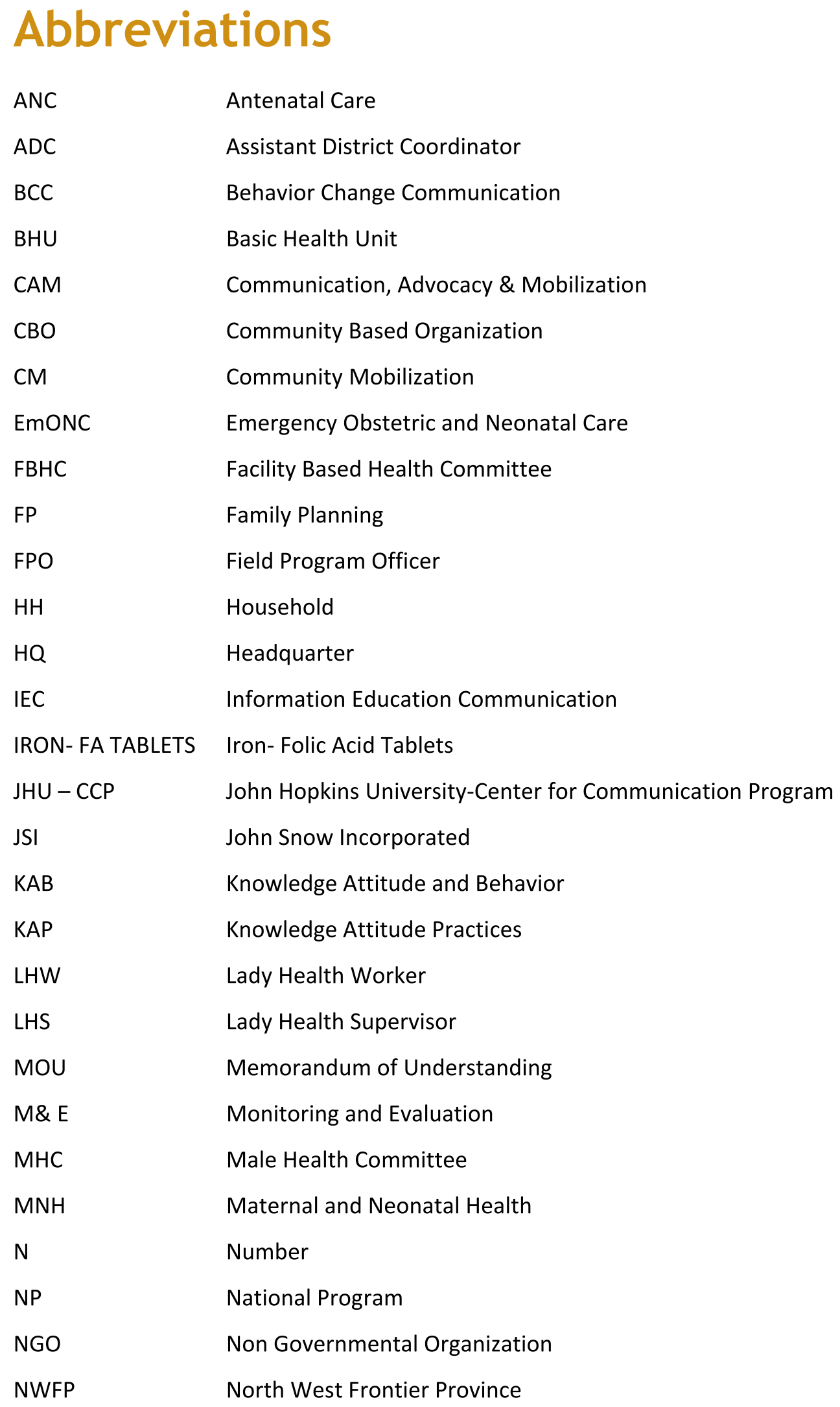




$\begin{array}{ll}\text { PAIMAN } & \text { Pakistan Initiative for Mothers and Newborns } \\ \text { PAVHNA } & \text { Pakistan Voluntary Health and Nutrition Association } \\ \text { PDQ } & \text { Partnership Defined Quality Process } \\ \text { PHC } & \text { Primary Health Care } \\ \text { PNC } & \text { Postnatal Care } \\ \text { RHC } & \text { Rural Health Centre } \\ \text { SBA } & \text { Skilled Birth Attendant } \\ \text { SG } & \text { Support Group } \\ \text { TBA } & \text { Traditional Birth Attendant } \\ \text { TT VACCINE } & \text { Tetanus Toxoid Vaccine } \\ \text { USAID } & \text { United States Agency for International Development } \\ \text { VHC } & \text { Village Health Committee }\end{array}$





\section{Acknowledgements}

PAIMAN would like to thank USAID for its generous funding and support for the project. We are extremely thankful to our community mobilization implementation partners; Save the Children US, Mercy Corps and PAVHNA, for providing the background information and support during the survey. We owe special thanks to National Program for Family Planning and Primary Health Care, who facilitated and allowed our teams to interview LHWs and to observe the support group meetings in five PAIMAN districts. We are also thankful to the District Health Departments Rawalpindi, Khanewal, Buner, Dadu and Lasbella for the facilitation during data collection and for permitting us to interview the members of facility based health committees (FBHC).

We are thankful to Dr Nabila Ali, Chief of Party PAIMAN, for her leadership role and guidance. We are thankful to Dr Zeba Sathar, Country Director Population Council and Dr. Arshad Mahmood, Director M\&E, who provided the technical guidance during the evaluation design, tools development, sampling and report writing. This report was initially edited by Dr. Sarah Khokhar, and final editing was carried out by Ms Momina Salim. We are thankful to both of them for providing useful feedback for improving the report.

Data collection teams who carried out excellent work under the able supervision of Ms. Lubna Mahmood, Mr. Abdur Rauf Khan and Ms. Nasreen Akhtar deserve full appreciation ${ }^{1}$. We owe our thanks to several Population Council colleagues who provided input during the completion of this report. These include Mr. Minhaj ul Haq, Ms. Nadia Abid, Dr. Munir Afridi and Ms. Saman Naz. Mr. Irfan Masood, Data Quality Officer, managed the data entry process. Mr. Abdur Rauf Khan deserves appreciation for his contribution in generating tables, graphs and typing the first draft of this report. Mr. Ali Ammad formatted and finalized the layout of this report. We are thankful to all the respondents of this survey, especially women of the communities who took time to answer our questions. We hope that this report will bring forward important information about the community mobilization experience of PAIMAN and be helpful in designing and implementing future programs.

\footnotetext{
1 Names of data collection team are given in Annex 1
} 



\section{Executive Summary}

This report presents the findings of the process evaluation of community mobilization activities implemented under the PAIMAN project. The data collection for this evaluation was conducted during May- June, 2008. The Pakistan Initiative for Mothers and Newborns (PAIMAN) is a sixyear program funded by the United States Agency for International Development (USAID). PAIMAN is a consortium led by JSI Research \& Training Institute. PAIMAN is committed to assisting the Government of Pakistan in implementing the full spectrum of interventions necessary to address maternal and newborn health, initially focusing on 10 districts throughout Pakistan. Later on, the initiative was expanded to include 14 more districts across Pakistan and Azad Jammu and Kashmir with an extended agenda that incorporates Child Health and Family Planning components. Therefore the total number of districts now being covered by PAIMAN is 24.

The project uses the "Pathway to Care and Survival" strategy to create an environment of increased awareness and informed decision making across all levels of the health systems. PAIMAN intends to reduce maternal, newborn, and child mortality in Pakistan, through viable and demonstrable initiatives, capacity building of existing programs and strengthening structures within health systems and communities to ensure improvements. It also supports linkages along with the continuum of health care for women from home to hospital. PAIMAN developed a comprehensive Communication, Advocacy and Mobilization (CAM) strategy to increase knowledge and awareness of harmful practices among women and their family and to improve their health seeking behaviors. The CAM roadmap acknowledges the importance of engaging communities in order to achieve behavior change and links clients with providers and services. Community Mobilization (CM) is an important sub-component of CAM that refers to the activities designed for individual behavior change (BCC).

For this process evaluation, we selected three CM activities; Support Group (SG) Meetings, Male Health Committees (MHC) and Facility Based Health Committees (FBHC), due to their innovative design, extent of application and intended impact on communities. The main objective of this evaluation was to assess the process of $\mathrm{CM}$ implementation and to identify its gaps in order to develop corrective strategies and guidelines for future component activities. Quantitative assessment methods were used to carry out the evaluation in 5 randomly selected districts of PAIMAN; Buner, Rawalpindi, Khanewal, Dadu and Lasbella. A total number of 74 sampled Lady Health Workers (LHWs), 292 female members of the SG and 60 members of FBHC were interviewed using structured questionnaires by trained interviewers. Proceedings of 52 SG 
meetings were also observed. In each sampled district, two health facilities (HFs) (among the BHUs and RHCs) were selected for interviewing all the members of FBHC of that facility. From each of the sampled HFs, 8 LHWs were randomly selected for interviews. Finally, 4 of the SG members (women) from each of the selected LHWs were sampled and interviewed.

\section{Support Group (SG) Meetings:}

A memorandum of understanding (MOU) was signed between PAIMAN and the National Program (NP) for Family Planning and Primary Health Care (FP \& PHC) whereby an LHW as a community outreach worker for health shall incorporate PAIMAN key MNH messages ${ }^{2}$ through an interactive and participatory technique with lactating mothers, pregnant and newlywed women, mothers-in-law, sisters-in-law, TBA and/or other women of child bearing age in her catchment area. The LHWs were initially trained through PAIMAN to formulate support groups (SG) and conduct SG Meetings of the women in the community. Later on, these trained LHWs had to formulate 4 support groups in their respective areas. Each SG comprised of 8 to 15 women. Finally, each LHW had to organize SG meetings in which women, who were members of the support group of that community, participated and became aware of $\mathrm{MNH}$ issues.

The evaluation results show that all LHWs attended the PAIMAN training to conduct and organize SG meetings. A majority (78\%) of LHWs received training during the year 2007 . These trainings were either conducted at RHCs or BHUs. After completion of training each LHW formed $4 \mathrm{SGs}$ in their communities, each comprising of 8 to 15 women. Although a majority of the LHWs were conducting two SG meetings in a month according to design, a large proportion (38\%) were conducting the SG meetings less frequently. A majority of the meetings were conducted at the house of one of the SG members and in most of the cases the LHW, rather than the women, decided where to conduct the meeting. One quarter of the interviewed women, who were SG members, had never attended the SG meeting. Interviews showed that typically up to 10 women attended the meetings, which is a low number by standards stated in the Activity Reference Sheet (ARS), designed by the CM implementing partners (see Annex 9).

The technical skills of the LHWs to conduct the SG meetings were generally appropriate according to the standards described in the LHWs book "Guide for lady health workers on support-groups" and in "Checklist of Support Group Meeting- for Lady Health Supervisor". The behavior of LHWs towards the participants of the meeting was positive. However, a majority of LHWs did not keep a record or make an attendance sheet of the participants. LHWs also

2 See Annex 3- CAM Message Matrix for women 
described difficulties in organizing SG meetings rather than in actually conducting the meetings. The research team found supervision to be a weak area of SG meetings. Only less than a fifth of the meetings were supervised (mainly by LHS). The LHWs were supposed to deliver messages related to ANC, delivery, PNC, newborn care and FP. In most SG meetings ANC, newborn care and delivery care were discussed, but PNC and family planning were not so frequently discussed. The topics less frequently discussed were: danger signs of pregnancy, arrangement for skilled birth attendant, and use of iron/folic acid tablets, arrangement of transport and money, post natal checkups, hygiene practices and FP during post natal period. The less frequently discussed newborn care messages were protecting newborn from heat and cold, danger signs of newborn illness, care of umbilical cord, exclusive breast feeding for first 6 months and immunization. Generally the attitude of the LHWs and women was positive towards the SG and they found it very useful for improving MNH. The main difficulties and problems mentioned by the LHWs were low attendance/participation and non-cooperation by women, beside difficulties in finding a suitable place for meeting, other duties and responsibilities of the LHWs and non-availability of funds for refreshment for participants of SG meeting. The results show that in a majority of meetings, refreshments were given to the participants; however, a large number of LHWs did not receive funds for refreshments. It was also found that a majority of the LHWs asked for an increase in refreshment amount. SG members shared the information, received through SG meetings with their family members and neighbors; sahaili/family friend, women in the neighborhood, husband and, in very few cases, with their mother in law. Women were generally reluctant to share the information with their husbands and mothers in law.

\section{Male Health Committee (MHC):}

PAIMAN also signed an MOU with the National Program for FP \& PHC (NP) whereby an LHW as a community outreach worker for health would incorporate PAIMAN key MNH messages through an interactive and participatory technique with fathers of newborns, husbands of pregnant women, influential people, religious leaders, teachers etc. through meeting of Health Committees. According to the criteria set by the NP, an LHW belonging to the local area, with formal education of grade 10 selects a focal person for herself. The same focal person seeks advice from LHWs and revitalizes LHWs Health Committee. There are 6-12 male members in each Health Committee representing her whole catchment population. As these members are representatives, they are expected to communicate the messages discussed during these meetings to other men who need the information. The facilitator and the participants of the Health Committee decide on the length and frequency of the meetings (number per month). The LHWs were trained through PAIMAN to revitalize Health Committees in their areas. 
Findings of the process evaluation have identified several areas which need improvement; nevertheless, Male Health Committees (MHC) had provided opportunities to mobilize the male proportion of the community, which is very vital. A quarter of LHWs never formed/revitalized the MHC in their area. Although a majority of the established committees had 6-10 members, slightly less than half the committees had fewer than 5 members, opposed to the set norm of 6-12 members in each committee. In most of the previously held meetings, attendance was at 5 or more members; however, attendance was less than 5 members in a third of the previous meetings. In the majority of the cases, more than 10 meetings were reportedly held since the formation of Health Committees a year ago, which indicates a satisfactory regularity of meetings. The above indicators showed appreciable differences between study districts. More than two third of the LHWs attended at least one MHC meeting. This is quite encouraging that a male meeting is being attended by a female. Most of the LHWs also facilitated the committee meeting, which is a very promising outcome of the LHW participation in MHC. In a majority of the previously held meetings, participation was 5 or more members. Approximately half of the meetings were held at LHW's health house, while duration of a majority of these meetings was 30 minutes to an hour. Although ANC, newborn care and immunization were discussed in most of the meetings, the focus on FP, PNC and delivery care needs to be enhanced.

\section{Facility Based Health Committees (FBHC):}

As part of the CM process, a Facility Based Health Committee (FBHC) was formed at each health facility (HF) that had been selected for improvement/up gradation in each district by PAIMAN. These committees were comprised of local notables, elected representatives, and community and religious leaders, TBAs, health care providers of the facility and other volunteers. FBHC members themselves determined the organizational structure and functions of these committees. Committee meetings play an important role throughout the community mobilization process. Small, focused meetings as well as larger, awareness raising meetings held at different junctures help motivate community leaders to take responsibility for the improvement of MNH facilities in their area, to make their village/union council/district a model for $\mathrm{MNH}$. Furthermore, the FBHCs are responsible for guiding the upgradation process of HFs, involving the community members and other organizations when needed, providing support to facilities, and mobilizing communities in various ways. Mobilization activities include but are not restricted to: generating emergency transport systems, emergency $\mathrm{MNH}$ funds (such as for obstetric emergencies), partner organizations for referral and providing transport to pregnant mother, information sharing sessions, male committees of the LHWs etc. 
The process evaluation results show that the average number of members in each committee was 13, including a mean number of 5 females in each committee. A quarter of the FBHC members had never attended a meeting. Out of the remaining, almost half had attended only one meeting. This shows very limited member participation. The research team also found that in a majority of the meetings, no prior agenda was prepared or circulated among the members. Similarly, meeting minutes were not sent to the members of FBHC. Maternal and newborn health, creating awareness on $\mathrm{MNH}$ and upgradation of HF were the topics of discussion during most of the meetings. Most of the members were able to share their views during the meetings and had a positive attitude towards FBHC, but a third of them thought that there was no benefit of having the committee. Those who were not in favor of FBHC replication, thought so because the $\mathrm{FBHC}$ had no legal power and no importance was given to the recommendations of the committee by the community. The members suggested that there should be regular, frequent, well organized and coordinated meetings of FBHC. They also suggested including more members in the committee to be truly representative.

The main findings of the evaluation show that;

- Despite some grey areas, most of the support group meetings were being implemented in PAIMAN districts according to design. Most of the gaps pertain to the areas of overall organization, management and logistics. However, limited but important deficiencies were also seen in the quality and supervision of support group meetings.

- The overall implementation process of male health committees was not as satisfactory as that of SG meetings. There was low coverage of health committees in PAIMAN districts. Although all the LHWs exhibited a positive attitude towards the health committees, more effort is required to fill the gaps in implementation, and make the health committees effective enough to mobilize the male section of the community.

- The process of implementing the steps of Facility Based Health Committees was not carried out as planned, in most of the districts. The coverage of FBHCs and participation by the members was very limited. There was a low frequency of FBHC meetings. A major effort is required to improve the prevailing situation of FBHC in PAIMAN districts. The alternate strategy could be to replace the FBHC with some innovative community mobilization activity. 


\section{Suggestions and Recommendations:}

- The reporting mechanism, use of IEC material and field practices need more consideration during the LHW's training on SG methodology.

- Supervision of SG meetings can be strengthened by supporting the LHS and also involving Assistant District Coordinator (ADC) of LHW Program in the process. Monitoring visits by Field Program Officer (FPO), district health office, and provincial office also need to be increased.

- Efforts should be made to have the messages reach husbands and mothers in law because they are the decision makers in most cases.

- The implementers need to review the implementation strategy of Male Health Committees and improve the monitoring and supervisory mechanism for the activity.

- The overall strategy and planning of the FBHC concept needs to be reviewed. The existing strategy could be replaced or modified with a process which is more participatory for the community and health facility representatives. 


\section{CHAPTER I Introduction}

Community mobilization is defined as a capacity-building process through which community individuals, groups, or organizations plan, carry out, and evaluate activities on a participatory and sustained basis to improve their health and other needs, either at their own initiative or stimulated by others. Community mobilization is a key strategy for increasing demand for and use of health services. It is a process that helps communities to identify their own needs and to respond to and address these needs. Gaining the participation of community members can help providers raise awareness both of health issues at the community level and of social and cultural issues that may promote or inhibit use of information and services, as well as improve clients' understanding of the methods or services being offered. Specific barriers to service access and use can be addressed and service utilization increased ${ }^{3}$.

Community mobilization is a proven approach for development that has helped people around the world identify and address pressing health care issues. The approach not only helps people improve their health and living conditions, but by its very nature strengthens and enhances the ability of the community to work together for any goal that is important to its members. It uses deliberate, participatory processes to involve local institutions, local leaders, community groups, and members of the community to organize for collective action toward a common purpose. Community mobilization is characterized by respect for the community and its needs ${ }^{4}$.

This report describes the result of the process evaluation of community mobilization activities implemented under the PAIMAN project. The Pakistan Initiative for Mothers and Newborns (PAIMAN) is a six-year program funded by the United States Agency for International Development (USAID). PAIMAN is committed to assist the Government of Pakistan to implement the full spectrum of interventions necessary to address maternal and newborn health, focusing on ten districts throughout Pakistan. Recently, the initiative has been expanded to include 14 more districts across Pakistan and Azad Jammu and Kashmir bringing the total number of districts to 24. The project uses the "Pathway to Care and Survival" strategy to create an environment of increased awareness and informed decision making across all levels of the health systems.

31 Howard-Grabman, L., and Snetro, G. 2003. How to mobilize communities for health and social change. Baltimore, MD: Health Communication Partnership.

4 http://www.hcpartnership.org/Publications/Field Guides/Mobilize/htmIDocs/introduction.htm on November 2, 2008 
PAIMAN is a consortium led by JSI Research \& Training Institute, which includes the Aga Khan University, Contech International Health Consultants, Greenstar Social Marketing, JHU-CCP, PAKISTAN Voluntary Health, \& Nutrition Association (PAVHNA), Population Council, and Save the Children, USA. PAIMAN intends to reduce maternal, newborn, and child mortality in Pakistan, through viable and demonstrable initiatives, capacity building of existing programs and strengthening structures within health systems and communities to ensure improvements. It also supports linkages along with the continuum of health care for women from home to hospital, in order to improve the maternal and newborn health status in Pakistan.

\section{Communication, Advocacy \& Mobilization (CAM):}

CAM (Communication, advocacy and community mobilization) is a strategy, which is often referred to as 'the demand generation component' of PAIMAN in the community. It seeks to increase the knowledge and awareness of harmful practices among women and their families and to improve their health seeking behaviors. Communication refers to the activities designed for individual behavior change (BCC), Advocacy refers to the activities that improve the environment for $\mathrm{MNH}$ and Mobilization refers to the community mobilization that brings together the messages and activities for action at the community level. In PAIMAN, responsibility of each component of CAM is being allocated to its partners according to their area of expertise and geographical presence, as mentioned in table 1.1

Table 1.1: CAM components and implementing organization

\begin{tabular}{ll}
\hline Component: & Organization: \\
\hline Communication: & JHU/ Center for Communication Programs. \\
Advocacy: & John Snow International, JHU/ Center for Communication Programs. \\
Mobilization: & Save the Children US, PAVHNA, Mercy Corps \\
\hline
\end{tabular}

The CAM roadmap for PAIMAN was developed by the partners in the first year of the project. It describes the CAM activities for increasing awareness and demand for MNH services through communication and information. It also empowers individuals and communities to seek and expect quality maternal and newborn health services from public and private health settings. The roadmap acknowledges the importance of engaging communities in order to achieve behavior change and links clients with providers and services. It is based on an ecological approach which assumes that health is shaped by many environmental subsystems, including family, community, workplace, cultural beliefs and traditions, economics, the physical world and the web of social relationships. Therefore, health promotion efforts must be comprehensive in addressing those systems that adversely affect a person's capacity for healthy living. 
Utilizing this approach, the CAM activities in PAIMAN have been implemented at several levels. At the national level, PAIMAN has improved advocacy efforts to create a more favorable environment. In addition, mass media activities have been conducted for the general public, to increase their awareness of MNH issues. At the provincial level, PAIMAN has advocated for more resources for communication activities and has focused on enhancing the capacity of health education managers. At the district level, PAIMAN has worked to build CAM capacity of the government and partner NGOs and is making an effort at the local level through community mobilization activities to encourage communities to take necessary action to save mothers and newborn.

\section{Activities under Communication, Advocacy \& Mobilization (CAM)}

The activities conducted under CAM are multifaceted and are perceived to generate a high level of community sensitization and involvement. Depending upon communication access, gender role, health KAP and availability of services and LHWs, each district developed a unique twophased strategy for disseminating information to its masses. In the first phase, general messages were communicated, through LHWs and mass media, with a purpose to sensitize families about $\mathrm{MNH}$ issues and to make pregnancy a special event. In the second phase, messages were disseminated through LHWs, mega events and media, to encourage communities to avail SBA and EMONC facilities in their region. The second phase was scheduled to start after these services and facilities were made available in the districts. For this purpose all mediums, including electronic media, print media and direct/ personal approach, were utilized to enhance the outcome of this component.

Not only were CAM activities employed to generate an understanding among communities on $\mathrm{MNH}$ issues, but they were also used to sensitize managers and decision makers at Provincial and National levels on the prevailing situation of maternal and newborn health in the region. Activities under CAM can be divided into three groups according to its components:

\section{Communication:}
a. Radio / TV drama
b. Radio / TV talk shows
c. Stage shows
d. Putli tamashas

\section{Advocacy:}

a. Mega events like village fairs and numaish

b. Community walks 
c. Seminars for Ulemas, members of Assemblies, local health departments, local leaders and local NGOs / CBOs

\section{Community Mobilization(CM)}

a. Women support groups

b. Revitalization of male health committees

c. Facility based health committees

d. Partner defined quality process (PDQ)

e. Interschool debate competition on maternal and newborn health

f. Inter-village sports matches, tehsil / district level healthy mother and baby shows

\section{Community Mobilization (CM) Activities}

CM activities were implemented in ten districts of PAIMAN by its community mobilization partners. In Punjab and NWFP, these activities were implemented by Save the Children US; in Baluchistan by Mercy Corps; and in Sindh by PAVHNA. Operational feedback from each district was gathered and disseminated to other partners to improve the impact of similar activities in other districts.

The activities which are performed under PAIMAN CM component include women support groups, revitalization of male health committees, facility based health committees, partnership defined quality process (PDQ) interschool debate competition on maternal and newborn health, inter-village sports matches, tehsil / district level healthy mother and baby shows.

\section{Problem Statement:}

In developing countries, communication, advocacy and community mobilization are the most important and critical components of any given program to improve the health status and health seeking behavior of the communities. In PAIMAN, an enormous amount of resources have been invested in this component to reach households, develop two-way communication, to build capacity of health care providers and to mobilize communities. This process leads to the development of two basic foundations of the program:

- Creating demand in the community for $\mathrm{MNH}$ related services

- Directing them towards health services delivery centers.

The impact and sustainability of this component is not possible if the process through which these activities were performed was not in accordance with given guidelines and standards. In addition to that, PAIMAN has diverse communities in 10 districts across Pakistan and a single 
strategy may not be sufficient enough to work well in these areas with different socio-cultural backgrounds. Thus it is pertinent not only to review the process of program implementation through the project, but also to identify prevailing gaps. In this way, lessons can be learnt and corrective strategies can be employed to rectify the shortcomings in future activities of the component.

\section{Rationale for selecting CM activities for Process Evaluation:}

We planned to evaluate activities from each of three components of CAM, but later focused on community mobilization activities in this round. Some of the activities under communication and advocacy were being evaluated by JHU. Some activities under advocacy were difficult to evaluate especially for process evaluation e.g. community walks and seminars. There were no records of participants available to contact those persons. Since the main objective of process evaluation was to focus on the steps of activity implementation and to give feedback for program improvement, we focused on concrete activities which reflect the overall situation of $\mathrm{CM}$ implementation in communities.

\section{Objectives of CM Process Evaluation:}

The objective of this evaluation was to assess the process of $\mathrm{CM}$ implementation and to identify its gaps in randomly selected PAIMAN districts, in order to develop corrective strategies and guidelines for future component activities.

\section{Methodology:}

Quantitative assessment methods were used to carry out the evaluation of the CM component. The evaluation process may be recapitulated in five steps:

1. The First step was to select the activities for evaluation from all activities performed under the $\mathrm{CM}$ component. The selection was based upon the significance of the activity for the overall objectives of PAIMAN and availability of resources to perform evaluation.

2. The Second step was to identify levels of implementation of $\mathrm{CM}$ activities in terms of its geographic location.

3. The Third was the identification of indicators for assessment.

4. The Fourth step was the identification, development and field-testing of evaluation tools.

5. The Final step was the training of interviewers, data collection, data analysis and report writing. 


\section{Selected CM Activities for Process Evaluation:}

The activities selected for evaluation were:

- Female Support Group Meetings(SG)

- Male Health Committees (MHC)

- Facility Based Health Committees (FBHC)

These three activities were focused on mobilizing communities on maternal and newborn health issues.

\section{Selected Study Levels and Locations:}

The evaluation was conducted at two levels:

1. The First level was the partners' head quarter office $(H Q)$ at the national level that consisted of data related to the actual dates of conducting activities and availability of their reports.

2. The Second was the community level to evaluate the process of actual implementation of activities in selected districts.

\section{Sample Strategy and Locating the Subjects:}

Following steps were carried out for sampling the subjects:

Step I: Five PAIMAN districts were randomly selected for the CM process evaluation; one district from upper Punjab, one from south Punjab and one each from the remaining 3 provinces. The following five districts were randomly selected:

1. Buner

2. Rawalpindi

3. Khanewal

4. Dadu

5. Lasbella

Step II: In each of the five districts, two health facilities (BHU, RHC) were randomly selected from the list provided by the implementing partners (See Annex 2, lists provided by partnersHealth facilities with $\mathrm{FBHC}$ ).

Step III: Out of all Lady Health Workers (LHWs) attached to each sampled health facility, 8 LHWs were randomly selected. In this way 16 LHWs from each district were sampled for interviews and observation. In district Buner, total number of LHWs attached to the sampled health facilities (HF) was 10 (five at each HF). Therefore all the available LHWs (10) were included in the sample. 
Step IV: Each LHW was supposed to form 4 support groups in her area. Two support groups of each selected LHW were randomly sampled. This sampling was done prior to the field work, so that the interviewing team knew whom to interview.

Step V: When the data collection teams met the LHW in the field, she was asked to provide the lists of women in each of the two selected support groups. From each of these selected LHW support groups, 2 females were randomly picked for an interview i.e. 4 females of each LHW were interviewed.

All the support group meetings, by the sampled LHWs, that were held during the research team's visit in the area (a week's time) were observed. In some cases the LHWs were especially requested to organize a support group meeting, to assess her skills in support group methodology.

A list of members of facility based health committee (FBHC) was obtained from the implementing partners. All available members of FBHC at the sampled health facilities were interviewed. Male members were interviewed by a male interviewer and vice versa. In case of the non-availability of the first respondent, the next candidate was selected from the list to be interviewed. Non-availability of a candidate for an interview means the person was out of the city for more than the duration of team's stay in the area or severely ill and unable to respond to the questionnaire.

In this way 74 LHWs and 292 support group participants (women) were interviewed and a total of 52 support group meetings were observed in all 5 districts. The women were interviewed in their homes and LHWs were interviewed at the health house. Since the team stayed for a period of one week in the vicinity of each health facility, therefore in case of absence of the subject, the team revisited her. This is worth mentioning here that non member of the support group, were not interviewed for this evaluation. This could have provided us information about the effect on their knowledge. 
Table 1.2: Sampling frame $\&$ sampling subjects

\begin{tabular}{lcccccccc}
\hline District & $\begin{array}{c}\text { Sampling } \\
\text { frame HF }\end{array}$ & $\begin{array}{c}\text { No. of } \\
\text { sample } \\
\text { HF }\end{array}$ & $\begin{array}{c}\text { Sampling } \\
\text { frame } \\
\text { LHWs }\end{array}$ & $\begin{array}{c}\text { No. of } \\
\text { sample } \\
\text { LHWs }\end{array}$ & $\begin{array}{c}\text { Sampling } \\
\text { frame SG }\end{array}$ & $\begin{array}{c}\text { No. of } \\
\text { sample } \\
\text { SG }\end{array}$ & $\begin{array}{c}\text { Sampling } \\
\text { frame } \\
\text { women }\end{array}$ & $\begin{array}{c}\text { No. of } \\
\text { sample } \\
\text { women }\end{array}$ \\
\hline Buner & 7 & 2 BHUs & 10 & 10 & 37 & 20 & 380 & 40 \\
Rawalpindi & 8 & 2 RHCs & 27 & 16 & 64 & 32 & 480 & 64 \\
Khanewal & 17 & 2 BHUs & 40 & 16 & 61 & 32 & 799 & 64 \\
Dadu & 6 & $\begin{array}{l}1 \text { RHC } \\
\text { 1 BHU }\end{array}$ & 50 & 16 & 60 & 32 & 568 & 64 \\
Lasbella & 3 & 2 RHCs & 60 & 16 & 57 & 32 & 539 & 64 \\
Total & $\mathbf{4 1}$ & $\mathbf{1 0}$ & $\mathbf{1 8 7}$ & $\mathbf{7 4}$ & $\mathbf{2 7 9}$ & $\mathbf{1 4 8}$ & $\mathbf{2 7 6 6}$ & $\mathbf{2 9 6}$ \\
\hline
\end{tabular}

\section{Process Evaluation Tools:}

Four quantitative assessment tools (three structured questionnaires and one observation check list) were developed for assessing health committees and support group meetings.

\section{a) Questionnaire for Lady Health Workers}

It was used at the community level by the team of female interviewers to collect information from LHWs about conducting support groups and male health committee meetings.

\section{b) Questionnaire for women}

It was used at the community level by the team of interviewers to collect information from the members of the support group i.e. women of community.

\section{c) Checklist for Support Group Observation}

This was used by an observer to assess actual implementation of support group meetings in the community. This checklist was prepared using the module "Guide for lady health workers on support-groups" and was marked by observers during direct observation of support-groups meetings.

\section{d) Questionnaire for members of facility based health committee:}

This was used to collect information from members of FBHC regarding process of formation and meeting of the committee.

The study protocols and tools were shared with relevant partners of the M\&E thematic group and their suggestions were incorporated to improve the overall strategy of the evaluation. 


\section{Data Collection Team:}

A team of two female interviewers carried out data collection in each district. In all, 8 female interviewers were hired (locally where available) to carry out the data collection in 5 districts. A male coordinator conducted the interviews with male members of facility based health committees. He also coordinated the data collection activities in five districts during the data collection period. A 4-day training of the data collection team was carried out in Islamabad which also included a one-day pre-testing of the study instruments in District Rawalpindi (see annex 1, data collection teams).

\section{Data Collection Process:}

Prior correspondence and liaison was done with concerned quarters for implementation of field data collection. Districts Buner, Rawalpindi and Khanewal had separate data collection teams each comprised of 2 female interviewers. The team that collected data in District Dadu also carried out the data collection in District Lasbella afterwards. Data collection was carried out for a duration of two weeks. In this way data collection for four districts (Buner, Rawalpindi, Khanewal and Dadu) was completed over a period of 2 weeks, while data collection in Lasbella required another two weeks. Each team completed the process of data collection in the area of one health facility during a week's time.

\section{Final Status of questionnaires:}

The total number of interviews conducted at each level is as under:

Table 1.3: Number of data collection instruments applied in each of five districts

\begin{tabular}{lccccc}
\hline District & $\begin{array}{c}\text { LHW } \\
\text { Questionnaire }\end{array}$ & $\begin{array}{c}\text { Women } \\
\text { Questionnaire }\end{array}$ & $\begin{array}{c}\text { FBHC Member } \\
\text { Questionnaire }\end{array}$ & $\begin{array}{c}\text { Observation } \\
\text { Checklists }\end{array}$ & Total \\
\hline Buner & 10 & 40 & 12 & 10 & 72 \\
Rawalpindi & 16 & 64 & 3 & 8 & 91 \\
Khanewal & 16 & 60 & 18 & 5 & 99 \\
Dadu & 16 & 64 & 14 & 14 & 108 \\
Lasbella & 16 & 64 & 13 & 15 & 108 \\
Total & $\mathbf{7 4}$ & $\mathbf{2 9 2}$ & $\mathbf{6 0}$ & $\mathbf{5 2}$ & $\mathbf{4 7 8}$ \\
\hline
\end{tabular}





\section{CHAPTER II Support Group Meetings}

\section{Background}

A memorandum of understanding (MOU) was signed between the PAIMAN and National Program (NP) for Family Planning and Primary Health Care (FP \& PHC) whereby an LHW as a community outreach worker for health shall incorporate PAIMAN key MNH messages ${ }^{5}$ through an interactive and participatory technique with lactating mothers, pregnant and newlywed women, mothers-in-law, sisters-in-law, TBA and/or other women of child bearing age in her catchment area. According to the criteria set by the NP, an LHW belonging to the local area, with formal education of grade 10 provides preventive services to $150-200$ households in her catchment area, through visits and group meetings. The population may vary due to access to population and mobility of the LHW. Following steps were adopted in the implementation of support group meetings:

1. The LHWs were initially trained through PAIMAN to formulate support groups (SG) and conduct Support Group (SG) Meetings of the women in the community.

2. Later on, these trained LHWs had to formulate 4 support groups in their respective areas. Each support group comprised of 8 to 15 women.

3. As a final step of implementation, each LHW had to organize support group meetings in which women, who were members of the support group of that community, participated and became aware of $\mathrm{MNH}$ issues.

\section{Process of Support Group Meetings:}

SG Meeting is a meeting where pregnant women, lactating mothers, women of child bearing age, mothers-in-law, TBAs, formal health care providers, councilors as well as other influential women of the area with similar interests, assemble together in an amiable environment. Each LHW had to organize 2 meetings in a month. This way, each support group meets on alternate months. The support group meeting is supposed to be organized at a conveniently located house of any support group member, influential or any women of the community. They exchange ideas, share experiences and information. In addition this group provides emotional support and strengthening so that mothers/women could come to terms with ways of

5 See Annex 3- CAM Message Matrix for Women 
improving the conditions related to their own health and the health of their children; interpersonal growth in formal and informal interaction between spouses, family members, and healthcare workers. Support Group (SG) methodology could help in building a relationship of trust and linkages between the community members and health facility staff. The mode of organization of these support groups was proposed as follows:

1. Provides a safe environment of respect, attention, trust, sincerity, and empathy

2. Allows women to:

- Share information and personal experiences

- Mutually support each other through their own experiences

- Strengthen or modify certain attitudes and practices

- Learn from each other

- Obtain support from other women of the community

3. Allows women to reflect on their experiences, doubts, difficulties, popular beliefs, myths, information, and adequate breastfeeding practices. In this safe environment, the mother acquires the knowledge and confidence needed to decide to either strengthen or modify her breastfeeding practices.

4. Provides a persuasive environment for other family members e.g. mothers-in-law to support daughters-in-law for better decision making with regards to seeking skilled birth attendant.

5. Involves inviting and encouraging role models within the community to help and influence behavior change

6. Is not a lecture or class. All participants play an active role.

7. Focuses on the importance of mother-to-mother communication. In this way all the women can express their ideas, knowledge, and doubts, share experiences and receive and give support to the other women who make up the group.

8. Has a seating arrangement that allows all participants to have eye-to-eye contact.

9. Varies in size from 8 to 15 participants. 
10. Is facilitated by an experienced facilitator who listens and guides the discussion.

11. Is open, allowing the admission of all interested pregnant women, mothers who are breastfeeding, women with older toddlers and other interested women.

12. The facilitator and the participants of the support group decide on the length of the meeting and the frequency of the meetings (number per month).

To evaluate the process of support group meetings, we interviewed both LHWs and women of those communities who were members of support groups. We also observed the support group meetings that were being conducted in the communities across five districts.

\section{Characteristics of Respondents}

\section{Lady Health Workers}

A total number of 74 lady health workers were contacted and all were interviewed. There were no refusals or incomplete interviews. The average time for one interview was around 40 minutes. Ten LHWs were interviewed in district Buner while 16 LHWs were interviewed in each of the remaining four districts. Five LHWs were attached with each of the two sampled health facilities in Buner; hence we interviewed all 10 available LHWs.

Majority (58 percent) of interviewed LHWs had completed 10 years of education, while slightly more than a quarter ( 28 percent) received 8 years of education. Only 14 percent had completed 12 or more years of education.

Of all the LHWs, the majority were currently married (64 percent), while 28 percent were unmarried and 6 LHWs (8 percent) reported to be divorced, widowed or separated.

Of the ever married LHWs ( $N=53$ ), 43 percent had three to five living children, while slightly less than one third had one to two children. Another 17 percent of these LHWs had more than five children. Remaining 8 percent LHWs reported that they had no living children.

Out of all currently married LHWs $(\mathrm{N}=47)$, only 4 LHWs reported that their husbands are not currently working i.e. doing job or business. The husbands of a majority of LHWs were either farmers (30 percent) or Government servants ( 28 percent). 
Table 2.1: Background profile of LHWs ( $N=74)$

\begin{tabular}{lcc}
\hline Level of Education & Number & Percent \\
\hline 8 years of schooling & 21 & 28 \\
10 years of schooling & 43 & 58 \\
12 \& more than 12 years of education & 10 & 14 \\
Marital status & & \\
Currently married & 47 & 64 \\
Un married & 21 & 28 \\
Divorced/widow/separated & 6 & 8 \\
Number of children* & & \\
No children & 4 & 8 \\
1 to 2 & 17 & 32 \\
3 to 5 & 23 & 43 \\
More than 5 & 9 & 17 \\
Work experience & & \\
(Years) & & 5 \\
$1--2$ & 4 & 34 \\
$3--5$ & 25 & 23 \\
$6-10$ & 17 & 38 \\
\hline More than 10 & 28 & \\
\hline * $=53$ & & \\
\hline
\end{tabular}

Of all the LHWs ( $\mathrm{N}=74)$, more than a third had been in this profession for more than 10 years, while another one third reported having an experience of three to five years, and slightly less than a quarter had an experience of 6 to 10 years. For only 4 (5 percent) LHWs, it had been less than two years. This shows that majority of LHWs had an experience of more than 5 years as an LHW. The mean number of years for working as an LHW is approximately 8 years $(S D=4.1)$. Out of all respondents, only 5 LHWs reported that they had worked in the health sector before joining as an LHW.

Mean number of households $(\mathrm{HH})$ registered by each LHW was 136, while mean number of eligible couples registered by an LHW was 123. This shows an average number of less than 1 eligible couple per HH registered by an LHW. Slightly more than three quarters of the LHWs registered up to $150 \mathrm{HH}$, while the remaining registered between 150 and $237 \mathrm{HH}$. One LHW reported to have registered $515 \mathrm{HH}$ while another registered $703 \mathrm{HH}$.

\section{Support Group Members (Women)}

A total number of 292 women were interviewed in 5 districts. These women were the members of support groups and were sampled out of the list provided by the LHW on the day of the research team's visit to the community. Mean duration of each interview was 25 minutes. The support groups formed by one of the LHW in district Khanewal were presently inactive; 
therefore none of her SG women could be found for an interview. For this reason only 60 women were interviewed in Khanewal.

A large number of interviewed women (39 percent) were between 30 to 39 years of age. Slightly more than a quarter of women were up to the age of 29 years, while interestingly one third (34 percent) of the women were in the relatively older group of 40 years and above.

Except for 6 women, all were married. A large number of interviewed women ( 37 percent) had more than 5 children. More than one third of the women had 3 to 5 living children while 20 percent of women had 1 to 2 children. Remaining 8 percent of the women did not have a child. The mean number of living children among the married women $(N=286)$ was $4.5(S D=2.7)$.

A majority (66 percent) of the women interviewed were not educated. Only 5 percent of the women received more than 10 years of education while the remaining 29 percent had 10 years of education or less.

Table 2.2: Background Profile of women ( $\mathrm{N}=292)$

\begin{tabular}{lcc}
\hline $\begin{array}{l}\text { Age groups } \\
\text { (Years) }\end{array}$ & Number & Percent \\
\hline Up to 29 & 78 & 27 \\
$30-39$ & 114 & 39 \\
40 \& above & 100 & 34 \\
Level of Education & & \\
No schooling & 193 & 66 \\
1 - 5 years of schooling & 31 & 11 \\
6 - 10 years of schooling & 55 & 18 \\
More than 10 years of education & 13 & 5 \\
Profession of husbands* & & \\
Unemployed & 14 & 5 \\
Labors, skilled/unskilled & 79 & 29 \\
Farmers/cattle rearing/poultry & 55 & 20 \\
Govt. Servant & 48 & 18 \\
Business/shopkeeper & 31 & 11 \\
Pvt. employee /in another country & 46 & 17 \\
\hline${ }^{*}$ N=273 & &
\end{tabular}
${ }^{*} \mathrm{~N}=273$

As shown in table 2.2, husbands of almost half of the married women interviewed were either laborers or farmers ( 29 percent and 20 percent respectively), while the husbands of 18 percent respondents were government employees. The husbands of the 5 percent of the respondents were unemployed. 
Slightly more than a third (34 percent) of married women said that their husbands had received no formal education. More than a third (38 percent) responded that their husbands had received 6 to 10 years of schooling. A lesser proportion (17 percent) reported that their husbands completed 1 to 5 years of schooling. Only 11 percent of women said that their husbands received more than 10 years of education.

Slightly more than a quarter of the women were involved in paid work other than household work. Among those women reportedly being paid for their work, a majority were involved in tailoring/cutting/sewing work, while slightly less than a quarter were involved in crops harvesting/cutting/picking work. Approximately 12 percent of the women were in government service. 


\section{Findings}

\section{Training of LHWs in Support Group Methodology:}

According to the implementation plan, all LHWs involved in forming and conducting the support group meetings, were trained by the implementing partners in support group methodology. These trainings were planned to be held at the First Level Care Facilities (FLCF) nearest to the residences of the LHWs. The training strategy was in accordance to the guidelines and procedures described in "PAIMAN Training Strategy" document. The strategy and process planned for this training are as follows:

Objective: The main objective of the training was to improve knowledge and skills of LHWs regarding maternal \& newborn care and interpersonal communication and group methodology. Selection procedure: Social Mobilization officers in each district were to liaise with district coordinators of National Program (NP) for FP and PHC and prepare a Detailed Implementation Plan (DIP) for training of LHWs and LHS. The notification was to be issued by respective district coordinators of NP.

Duration: Eight-day orientation package; 5 day of classroom training and 3 days of hands on training to organize women groups and apply communication and counseling skills.

Trainers: The district LHW trainers i.e. doctors and Lady Health Visitors (LHV) were to conduct these training. These trainers were to be previously trained by the district master trainers (MTs), who in turn were trained by the resource staff of PAIMAN.

\section{Training Contents:}

The training was imparted on the following topics:

- Antenatal care

- Safe delivery methods

- Three delays

- Risky behavior

- Ideal behavior

- Counseling

- Community Mobilization

- Support group methodology

- Use of IEC material 
- Revitalization of health committees

- Reporting

- Practice in field

Findings of the process evaluation show that all the LHWs had attended the PAIMAN training to conduct and organize the support group meeting. A majority (85 percent) of LHWs got the information to attend this training through their supervisor (LHS). An overwhelming majority (93 percent) of respondents had received the information verbally, while the remaining reported receiving a formal invitation letter for this purpose. A majority (78 percent) of LHWs had received the training during 2007, while 14 percent reported having received the training in SG methodology in 2008. The remaining ( 8 percent) LHWs were either unable to recall the year in which they had received the training or were trained in 2006 or earlier. Almost all the LHWs reported that these trainings were conducted either at RHC or at $\mathrm{BHU}$ (54 percent and 46 percent respectively).

Figure 2.1: Percent LHWs by year of receiving training in SG methodology, as reported by LHWs

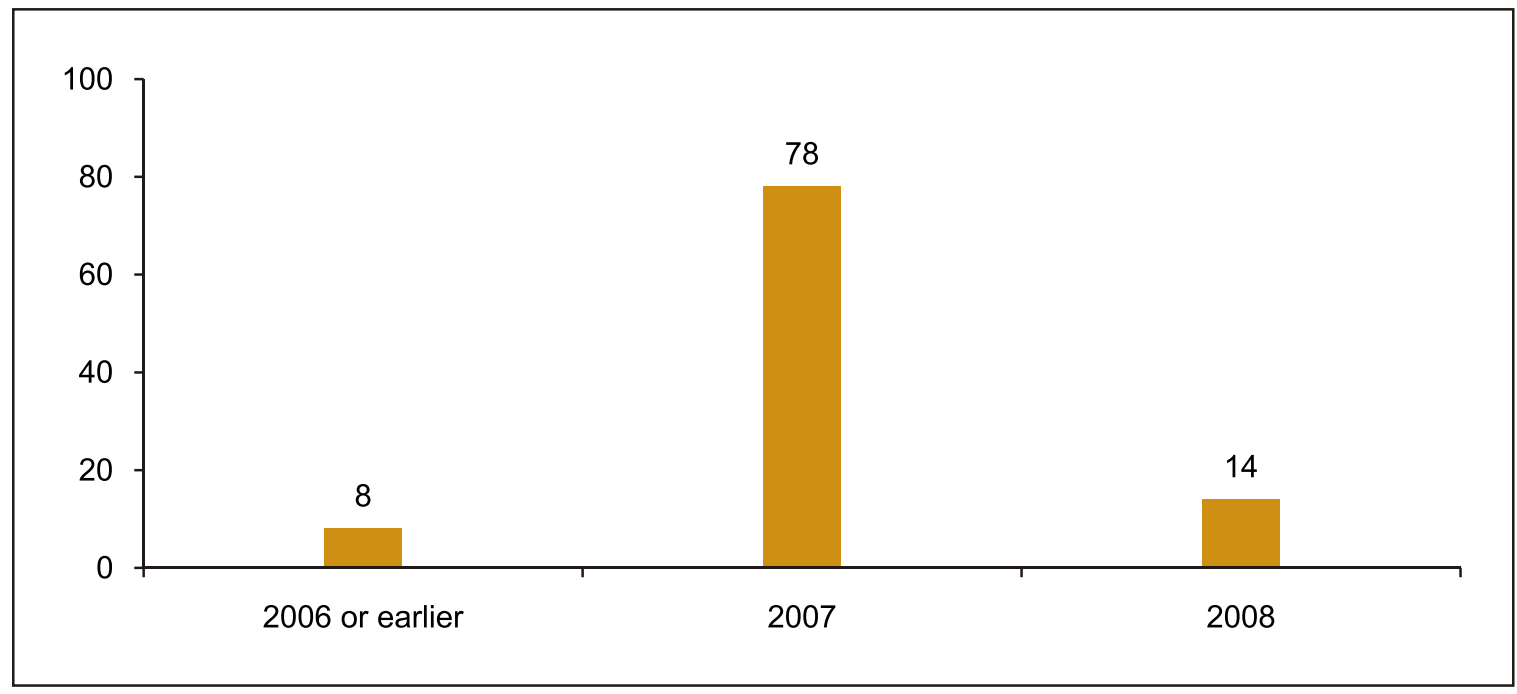

Half of the respondents reported that the duration of this training was 5 days, while more than a third (36 percent) of interviewed LHWs thought that duration of training was 6 days or more than 6 days. The remaining LHWs (14 percent) reported that the duration of training was even less than 5 days. According to the training strategy, the duration of this training was supposed to be 8 days. The discrepancy in responses might be due to the fact that the training was divided into 5 days class room training and 3 days of hands on training. 
Figure 2.2: Duration of training as reported by LHWs

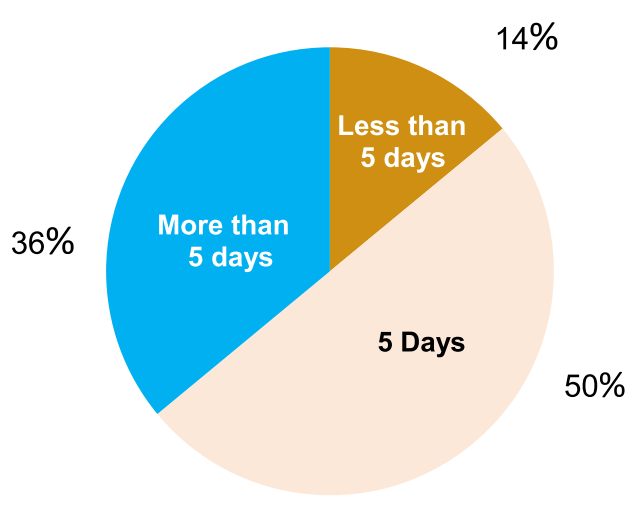

As mentioned in the previous section, the district LHW trainers i.e. doctors and Lady Health Visitors (LHV) were to conduct these training. A majority of the LHWs said that they were trained by a PAIMAN official (a person from implementing partner). Some also reported being trained by a medical officer (doctor), LHS or/and LHV. As mentioned in the training strategy.

The topics that were discussed during the training are shown in figure 3. Most of the LHWs mentioned spontaneously that ANC, safe delivery methods and SG methodology were included in the topics during training, whereas very few LHWs reported that the use of IEC material, $\mathrm{MNH}$, reporting mechanism and field practice were part of their training.

Figure 2.3: Topics discussed during the LHW's support group training, as reported by LHWs*

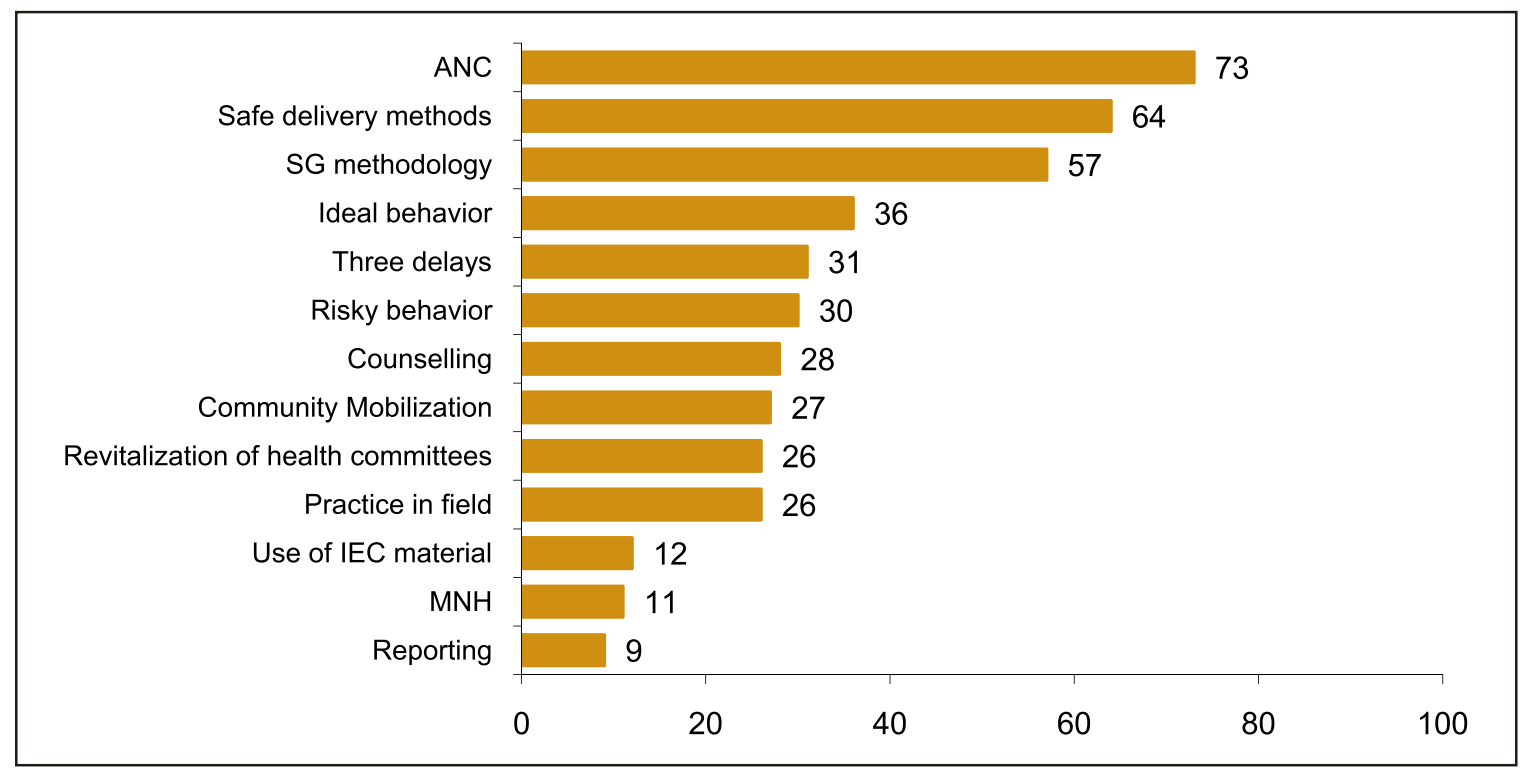

*Multiple responses 
A majority of the LHWs (85 percent) did not face any problem during training on support group methodology. More LHWs in Lasbella (33 percent) and Khanewal (33 percent) had faced a problem, as compared to Dadu (15 percent) and Rawalpindi (18 percent). In Buner, no LHW had faced a problem during the training. Most frequently faced problems by the LHWs included the long distance of the training place, lengthy duration of the training and/or difficult language of instruction/technical words. Majority of the LHWs, who had faced problems during training reported having discussed these problems with the trainer and were satisfied with their responses.

During the training on support group methodology, LHWs were given the following training materials:

1. Sehat Ki Dastak (a booklet)

2. Family booklet

\section{Guidebook for LHW}

\section{PAIMAN brochure}

Sehat Ki Dastak booklet was received by a majority of LHWs, followed by Guidebook for LHW and Family booklet. When LHWs were asked to show the material they were able to show the material in the same order as they had mentioned. Very few $(n=10)$ were unable to show any training material.

\section{Support Groups Formation by LHWs:}

As mentioned in the background section, each LHW was supposed to form 4 support groups in her respective area (communities). Each support group comprised of 8 to 15 women. For this purpose, the LHW was to divide the geographical area of her assigned population into four parts. In each part of the divided areas, she forms a support group of women.

More than three quarters of LHWs (82 percent) had formed 4 support groups in their respective areas. Very few $(n=7)$ reported having formed more than 4 support groups while even less $(n=6)$ of LHWs responded that they formed less than 4 support groups. The mean number of support group members in each support group was 11.82 ( $S D=0.38$ ). This shows that formation of SG was done according to design. 


\section{Organizing a Support Group Meeting:}

\section{Initiation of support group meetings:}

After receiving the training LHWs were supposed to initiate the conduction of SG meetings within a month. A majority of the LHWs had started organizing and conducting SG meetings within a month of receiving the training in support group methodology. A large proportion (40 percent) of LHWs stated that they initiated SG meetings in their communities after one month of training in SG methodology.

\section{Venue for meeting:}

The plan of support group meetings encourages organizing a meeting at a place which is accessible, acceptable and comfortable for the women. Preferably, these meetings should be conducted at the residence of any of the SG members. According to two thirds of the LHWs, the meetings were conducted at the SG member's house whereas slightly less than a third said that the meetings were held at the health house. On the other hand slightly more than half of the women reported that the meetings were conducted at SG member's home, while 40 percent were of the view that meetings were conducted at health house of LHW. This shows that a majority of the meetings were conducted at the residence of some SG member. Most commonly considered issues by the LHWs in selecting a place for meeting were:

- Accessibility

- Comfort

- A familiar place for women

More than two third of the women, who had ever attended a meeting said that the LHW decided about the place/venue of the meeting. Twenty-nine percent were of the view that members of support group were the decision makers. According to the norms of the meeting, this should be a joint decision rather than of the LHW.

\section{Frequency of SG meetings:}

LHWs were supposed to organize two support group meetings in a month. In this way each support group meets in alternate months. When asked how frequently they conduct a SG meeting, a majority (59 percent) of the LHWs reported doing that once in two weeks i.e. twice a month. However, 27 percent of LHWs said that they conduct one meeting in a month, and 11 percent $(n=8)$ organized one meeting in two months. This showed that 38 percent of LHWs were not following the norm of two meetings in a month. All the LHWs of Buner and Khanewal and 
slightly less than two-thirds of Dadu reported organizing meetings twice a month, whereas slightly less than a quarter from Rawalpindi and only one fifth from Lasbella did the same.

Participants of support group meetings i.e. women who ever attended a meeting $(N=223)$, were also asked about how frequently SG meetings were held in the past. A large proportion (43 percent) said that a SG meeting was held once every month. On the other hand, a quarter of the women reported that the time period between the subsequent meeting was either more than a month or there was no specific time interval between the two meetings. This showed that a majority of the LHWs were conducting two meetings each month, so that each group met after a month's time. That is why the responses of LHWs and women were different but appropriate from their own perspective.

Figure 2.4: Frequency of SG meetings as reported by LHWs and women

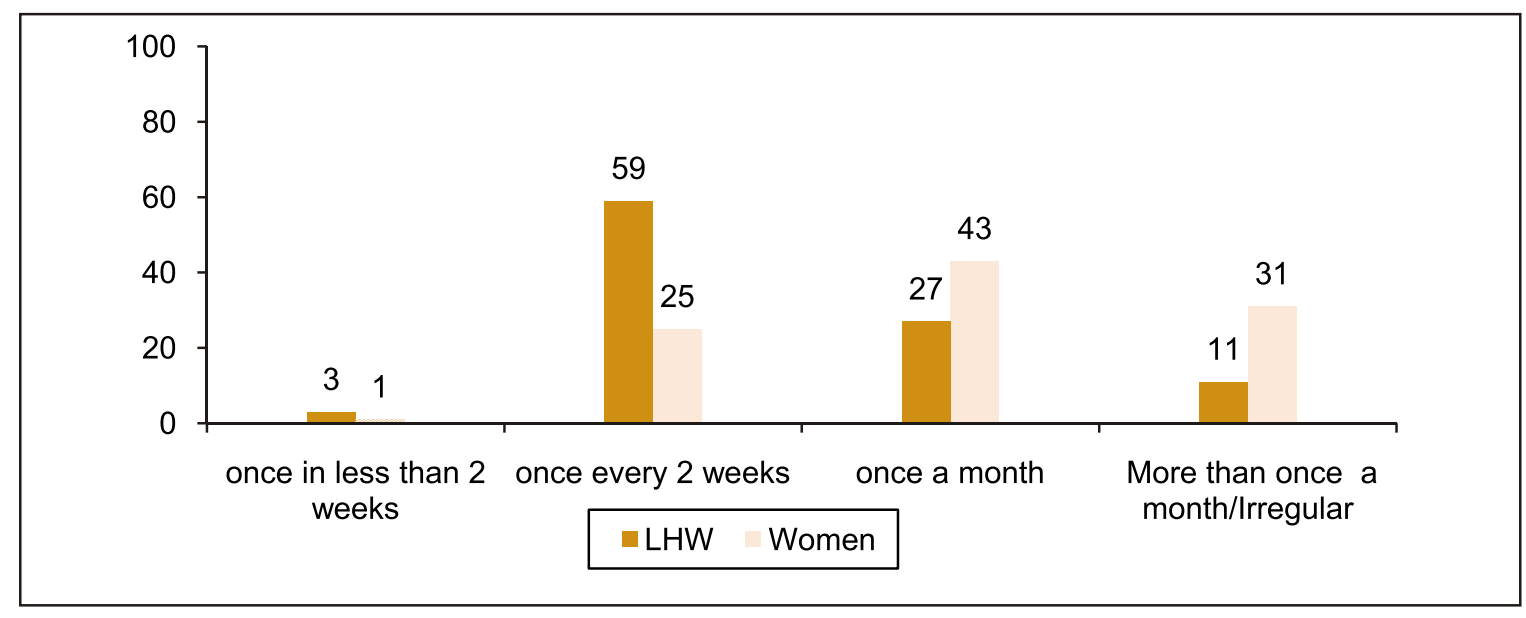

\section{Time Since last meeting:}

According to a majority of the LHWs (66 percent), the last SG meeting was conducted 1 to 2 weeks before the time of the interview. One quarter of LHWs reported that they conducted the last SG meeting 3 to 4 weeks back and for the remaining 9 percent, it had been more than a month since they had their last SG meeting. 
Table 2.3: Frequency of last SG meetings as reported by LHWs and women

\begin{tabular}{lcccc}
\hline & \multicolumn{4}{c}{ Last attended SG meeting } \\
\cline { 2 - 5 } Responses & Number & Percent & Number & Percent \\
\cline { 2 - 5 } 1-2 weeks back & 74 & 33 & 49 & 66 \\
3-4 weeks back & 49 & 22 & 19 & 25 \\
1-2 months back & 56 & 25 & 5 & 7 \\
More than 2 months back & 44 & 20 & 1 & 2 \\
Total & $\mathbf{2 2 3}$ & $\mathbf{1 0 0}$ & $\mathbf{7 4}$ & $\mathbf{1 0 0}$ \\
\hline
\end{tabular}

On asking the same question, one-third of the support group women members said that meeting was held 1 to 2 weeks back. Another quarter of women perceived that the last meeting of their support group was held 1 to 2 months back, while less than a quarter (22 percent) remembered having attended the last meeting 3 to 4 weeks back. The remaining 20 percent of women said that the last meeting was conducted more than two months back. Therefore, majority of meetings were held according to the design of 2 meetings per month.

\section{Participation by SG members:}

All the members of a support group were expected to attend the SG meetings. Out of all interviewed women ( $\mathrm{N}=292)$, who were a member of the support groups formed by the LHWs, three quarters reported that they had ever attended a meeting. Surprisingly, the remaining one quarter of the women responded that they had never attended a support group meeting. All the women from Buner and Rawalpindi, three-fourths from Dadu and two-thirds from Khanewal had attended a SG meeting. Interestingly slightly more than half of the women from Lasbella had attended a minimum of one meeting.

Table 2.4: Percent women who reported to have ever attended SG meeting by District ( $N=292)$

\begin{tabular}{lcc}
\hline \multirow{2}{*}{ District Name } & \multicolumn{2}{c}{ Ever attended SG meeting } \\
\cline { 2 - 3 } & Number & Percent \\
\hline Buner & 40 & 100 \\
Rawalpindi & 64 & 100 \\
Khanewal & 40 & 67 \\
Dadu & 45 & 76 \\
Lasbella & 34 & 54 \\
Total & $\mathbf{2 2 3}$ & $\mathbf{7 8}$ \\
\hline
\end{tabular}

According to the implementation plan, a woman had to attend 8 to 10 SG meetings before she got acquainted with all intended MNH messages. Out of those women who had ever attended a meeting ( $\mathrm{N}=223$ ), slightly less than a quarter had only attended 1 to 2 meetings. More than a 
third (37 percent) responded that they had attended 3 to 5 meetings, while slightly less than a third reported that they attended 6 to 10 meetings. Only 8 percent of the women thought that they attended more than 10 support group meetings. Overall this reflects a relatively low participation of the SG members in the meetings. This could also be due to the fact that the evaluation was conducted approximately after one year of initiation of SG meetings in the communities. Women from Rawalpindi and Buner reported participating in the highest number of meetings, followed by women from Dadu. In Lasbella and Khanewal women reported attending the least number of meetings.

Figure 2.5: Percent women by number of meetings attended, as reported by women ( $\mathrm{N}=286)$

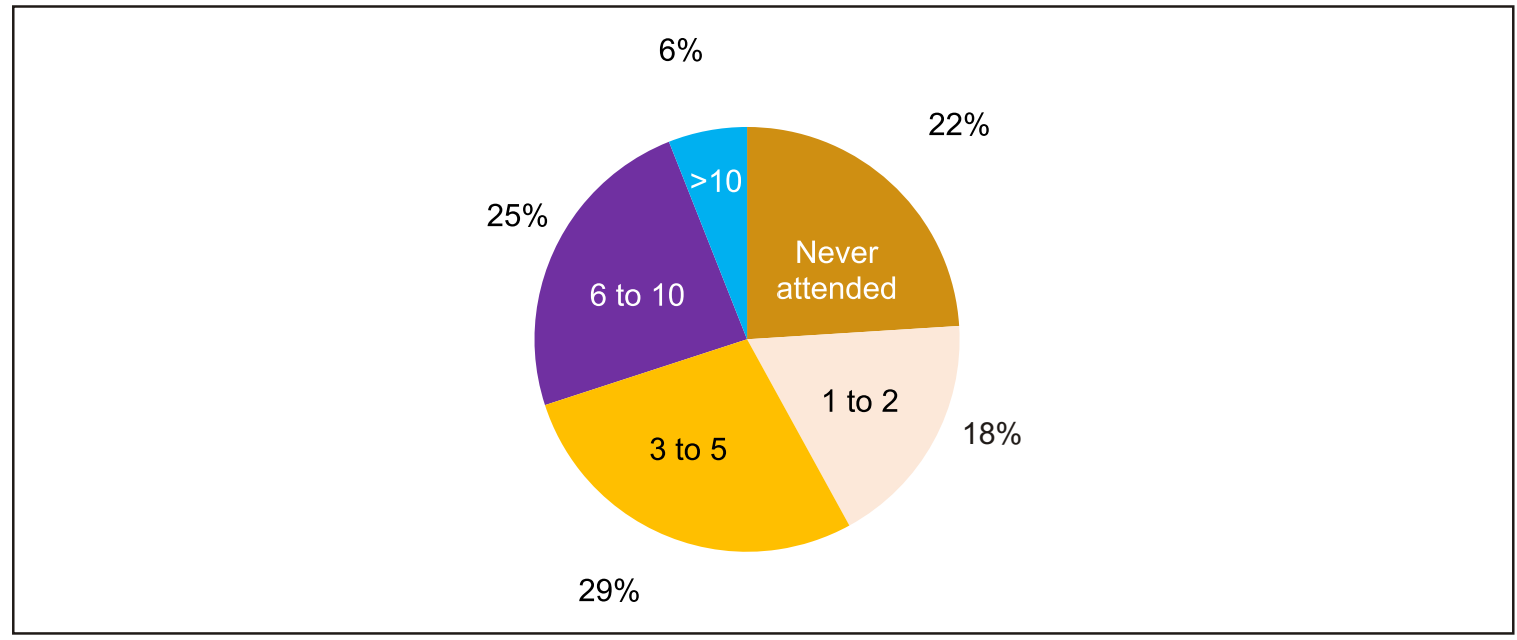

Women were also asked since how long were they attending the support group meetings. Slightly more than a quarter reported attending the meetings for the last 5 months, while a large proportion (40 percent) had been attending for the last 6 to 11 months. For the remaining women, it had been over a year since they started attending the meetings.

\section{Number of participants:}

It was expected that at least 10 to 15 women will attend a support group meeting.

During previous meetings: During the interviews with women, who had ever attended a meeting, half of the women replied that (usually) 10 to 15 women attend the meeting, whereas a third of them had the opinion that more than 15 women used to attend the meeting. A lesser (15 percent) number of women perceived that the number of participants was usually less than 10 (Mean number of participants was 15 with $S D=7)^{6}$.

${ }^{6}$ Data not shown 
During Last meeting: When asked the same question from the LHWs about the number of women who had attended the last meeting conducted by them, slightly less than half of the LHWs (47 percent) mentioned the number as 11 to 15 women, whereas the other half of the LHWs said that there were less than 10 participants.

Figure 2.6: Number of participants in the last attended meeting, as reported by LHWs, women and observed

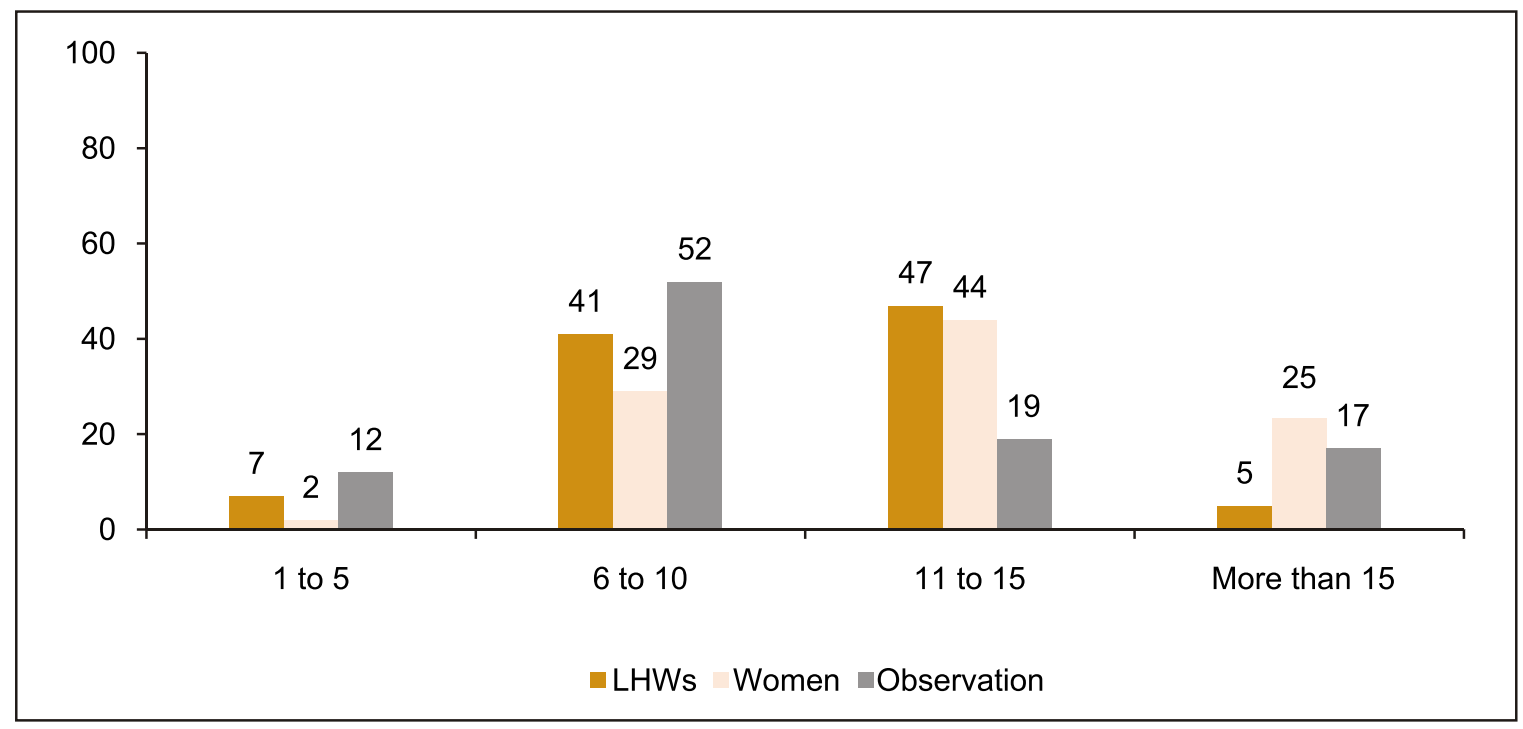

The women were also asked about the number of participants in the last meeting. A large number of women (44 percent) reported that 11 to 15 women were present in the last meeting. A quarter of women perceived that the participants were more than 15, while slightly less than a third of them (31 percent) thought that less than 10 women participated in the last SG meeting held (Mean=14 with SD=6).

On the other hand, the findings during the observation of 52 support groups were slightly different. In half of the meetings, there were 6 to 10 participants, while in a third of the meetings the number of women was more then 10. During these meetings ( $n=52)$, a majority of women (81 percent) came on time to attend the meeting, and most of the meetings (62 percent) also started on time. Out of those meetings which were delayed, most of the meetings started half an hour late than the set time. 


\section{Conducting a Support Group Meeting:}

The LHWs were trained to conduct the support group meetings according to the following steps, described during their training.

- Recitation of Holy Quran

- Self-introduction of LHW

- Self-introduction by SG members

- Objectives of SG meeting

- Norms setting (adaab, moahida)

- Introduction of topic for discussion

- Generate discussion

- Use of cards

- Collecting women's experience

- Problem solving discussion

- Summarizing today's discussion

\section{Steps of a SG meeting:}

The support group meeting can be divided into 3 sessions:

Introductory session: During the introductory session, an enabling environment of the meeting is to be created by the LHW through a warm welcome to the participants of the meeting, which includes introducing her and asking the participants for their introductions, followed by informing the participants about the goals and objectives of the meetings and its setting norms. For introduction, the LHW was supposed to ask:

- Name of member

- Marital status

- Number of children

- Age of children

- If pregnant, month of pregnancy

According to observations ( $N=52$ ), a majority of the LHWs were following most of the steps during the introductory session of the support group meeting. However, only approximately 40 percent of the LHWs were setting the norms of the meeting and informing the participants about the duration of the meeting. 
Figure 2.7: Steps followed by LHWs during the introductory session of SG meeting, as observed

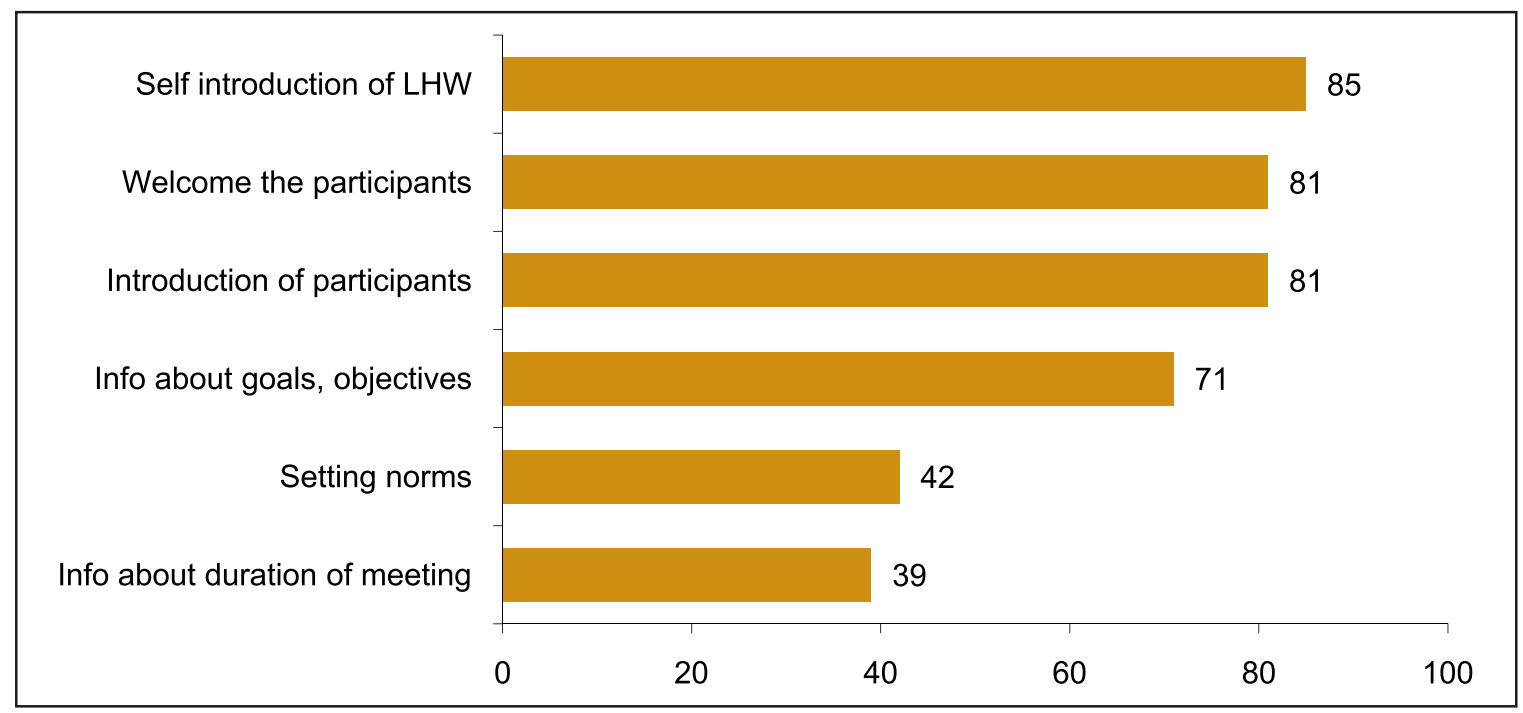

Support group members $(\mathrm{N}=223)$ were also asked how they were introduced in a meeting they had attended. A majority of them said that the LHW asked their name. In some cases questions about the number of children and marital status were asked. However, age of children, pregnancy status and duration were rarely asked by the LHWs. The LHWs $(\mathrm{N}=74)$ also gave the same information as the SG members when asked the same question.

Main session- Discussion on the topic: After the introductory session the LHW was to engage in facilitating the main session of the meeting. During this session discussion on a topic related to MNH was to be initiated by the LHW using the pictorial booklet, Sehat Ki Dastak, and asking perceptions of the women regarding the pictures. Pictures were to be used according to the topic while asking open ended questions. The LHWs have been trained in support group methodology to follow the rules of interpersonal communication and positive behavior towards the participants. These norms included encouraging and involving the participants, especially shy participants, initiating the discussion and giving women enough time to think and reply. The facilitator should appreciate the participant's answers, repeat the answers of participants, ask confirmatory questions, exhibit a positive attitude and should maintain an atmosphere of equality. This ensures a participatory adult learning session. Following is the summary of principal an LHW should consider while conducting a support group:

- Keep eye contact

- Always keep a smiling face

- Sit in a relaxed mode

- Ask open-ended question 
- Repeat the answers of participants

- Try to actively engage shy/silent women in discussion

- Using photo-booklet before summarizing meeting

- Ask literate women to read the card

- Summarize the discussion in meeting

During the SG observations, the research teams found that a majority of the LHWs were following the set protocols of the main session. However, some important steps were not followed by some of the LHWs e.g. encouraging shy participants, appreciating the participants, handing over the pictorial booklet to participants and repeating their answers.

Figure 2.8: Steps followed by LHWs during the main session of SG meeting, as observed

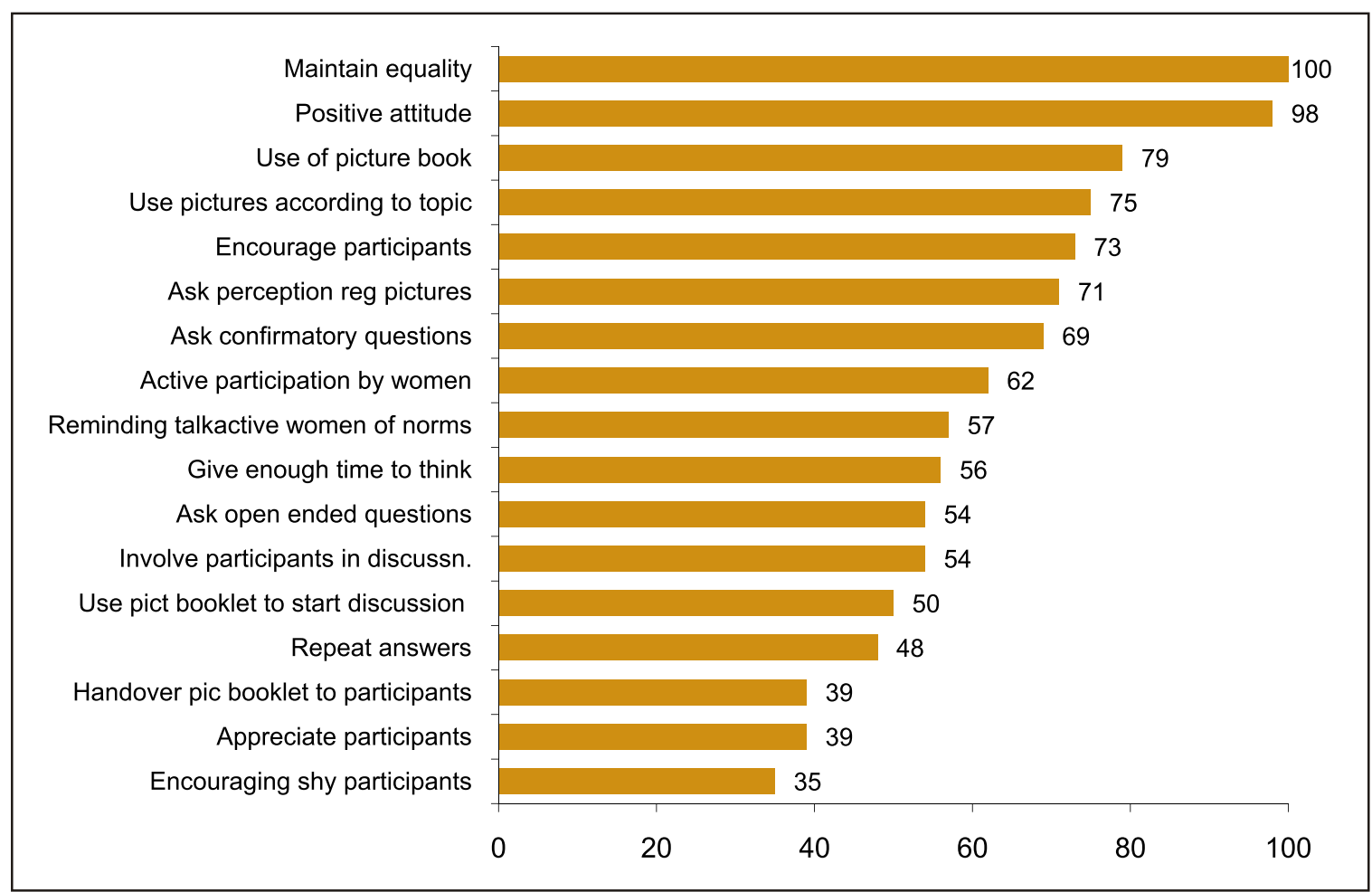

Closing session: According to the LHW training guidelines, following steps were planned for closing the meeting:

- Ask members what did they learn from this meeting

- Decide date and day of next meeting

- Decide place of next meeting 
- Decide topic of next meeting

- Review decisions made during this meeting for next meeting

- Thank participants

Most of the LHWs were following standard protocols during the closing session of the meeting e.g. deciding the date, place and topic for next meeting, summarizing the discussion and thanking the participants. However, the decision to support pregnant women, record keeping and making an attendance sheet were steps not followed by a majority of the LHWs.

Figure 2.9: Steps followed by LHWs during the closing session of SG meeting as observed

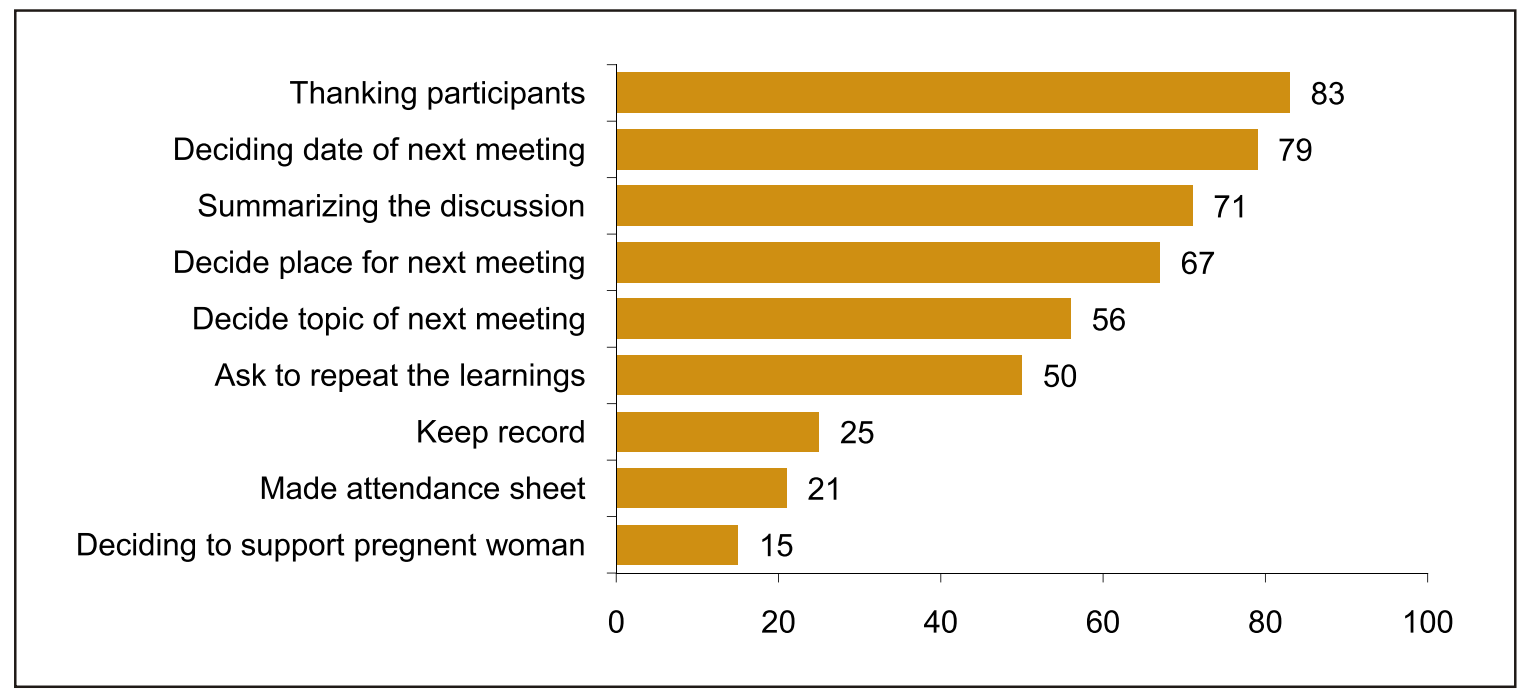

Support group members $\mathrm{N}=223$ were also asked that if they had ever asked a question regarding $\mathrm{MNH}$ during the meetings. Only a fifth of the women responded negatively, whereas all remaining (80 percent) replied that they had asked such questions. All these members responded that the LHW gave them satisfactory answers to their queries. Of these, 80 percent said that the attitude of LHW was good while responding to these questions; whereas for 20 percent the LHW's attitude was satisfactory.

Overall, most of the LHWs were following the set norms and standards of the SG methodology, with few exceptions. Some of these SG meetings were specially organized ahead of their scheduled time; therefore there could be an element of selection bias in these observations. Nevertheless, these observations yielded important information regarding the implementation of SG meetings. The mean duration of observing a support group meeting was around 30 minutes $(S D=20)$. 


\section{Messages Received by Women through SG Meetings:}

LHWs were supposed to deliver messages related to ANC, Delivery, PNC, Newborn care and FP. According to the LHWs the most frequently discussed topic during the support group meetings was antenatal care, followed by newborn care and delivery care. Family planning and post natal care were discussed in very few instances. Interestingly, a similar response was received from the SG members when they were asked the same question as well. This shows that in most support group meetings ANC, newborn care and delivery care were discussed, but PNC and family planning were not so frequently discussed. (A comparison of the responses of the LHW and SG members is given in annex 4)

Figure 2.10: Topics of discussion, as reported by LHWs and women*

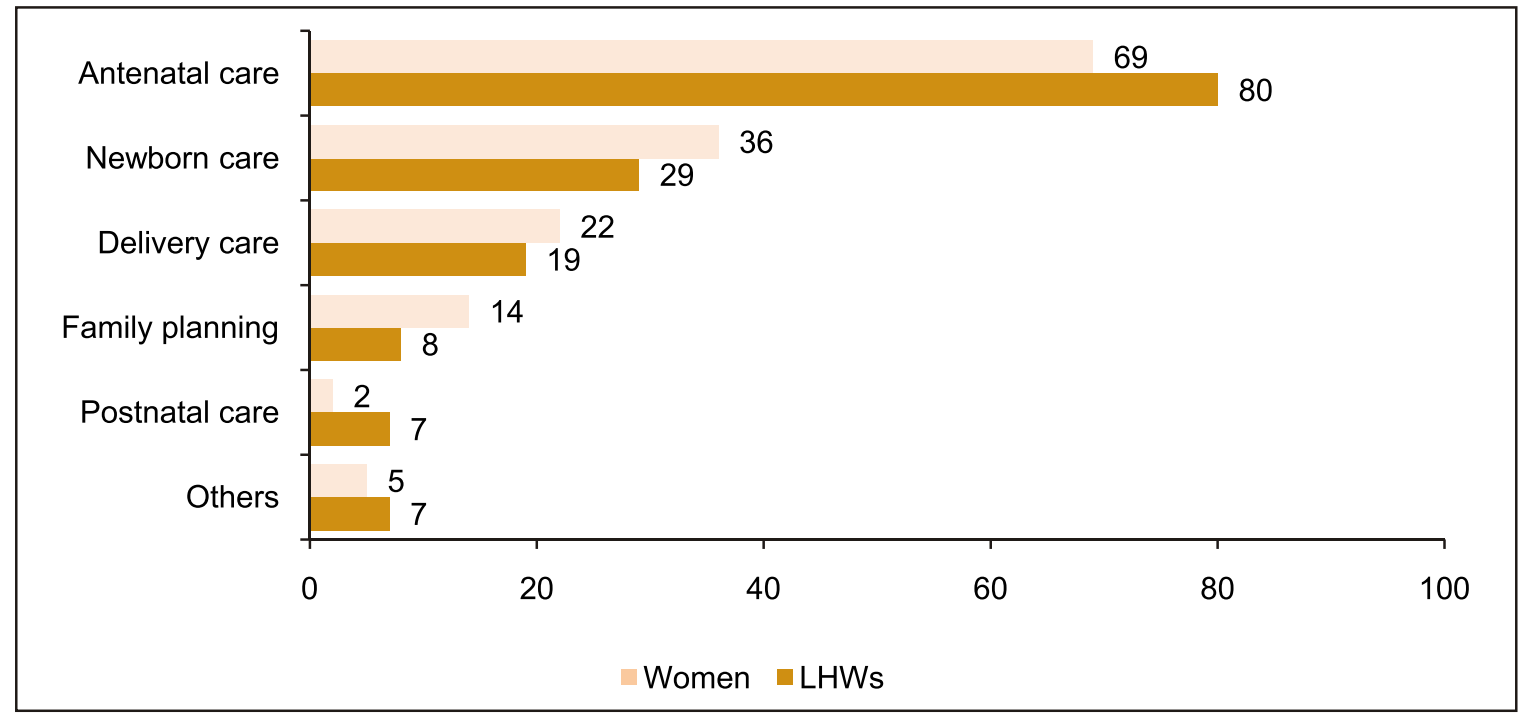

${ }^{*}$ Multiple responses

The following information was derived from the women interviews.

\section{Antenatal Care Messages (ANC):}

According to the SG members the most common ANC messages given to them during the meetings were regarding the diet, rest during pregnancy, at least 4 ANC visits and Tetanus Toxoid vaccination. The least discussed topics were danger signs of pregnancy, arrangement for skilled birth attendant (SBA), use of iron/folic acid tablets and arrangement of transport and money. According to PAIMAN's objectives, these are very important messages to be propagated. 
Figure 2.11: ANC messages received by women of community, as reported by women*

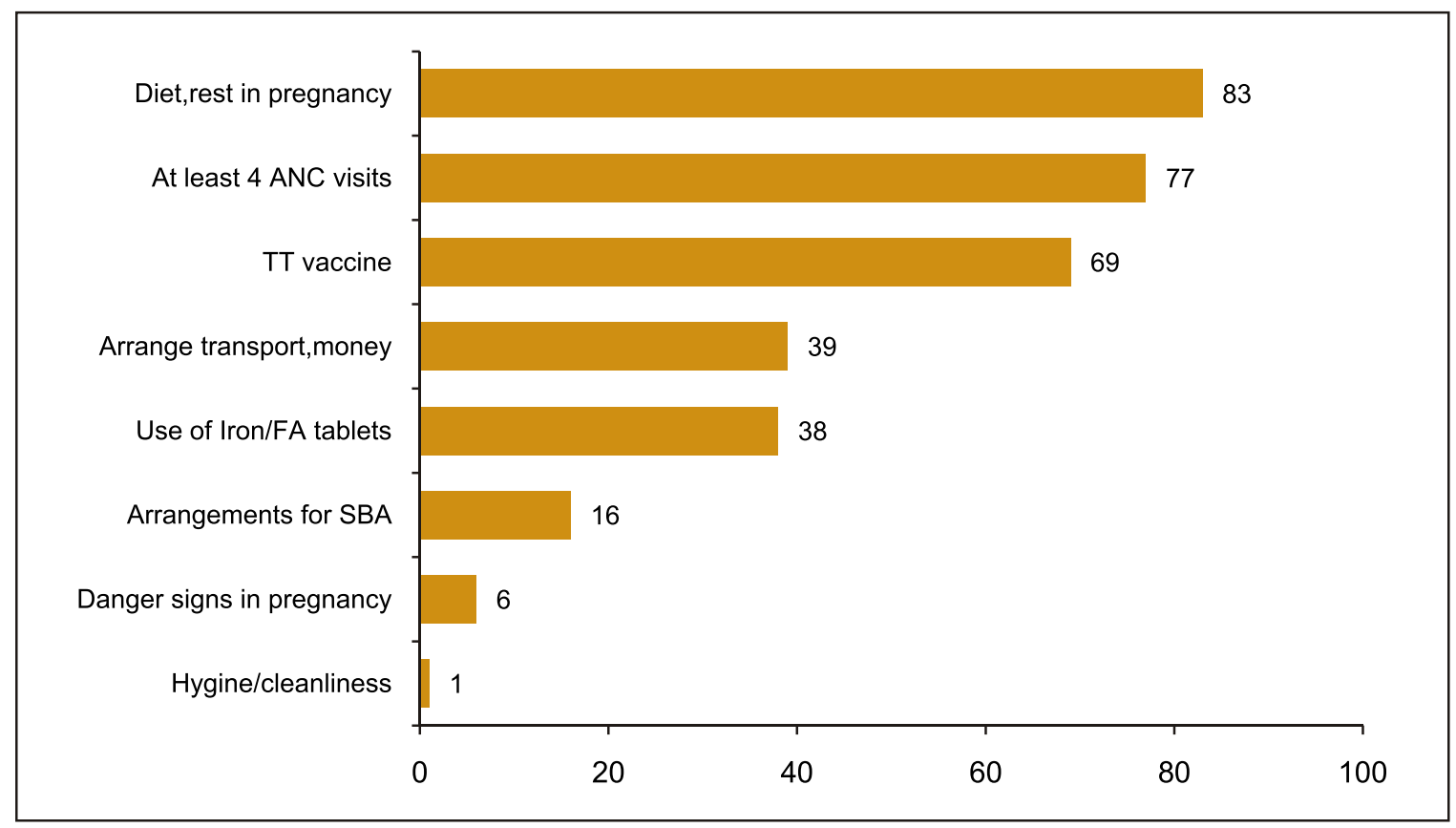

*Multiple responses

\section{Delivery Care Messages}

SG members informed that they most commonly received the messages regarding clean delivery practices and the place to go to in case of an emergency, but messages regarding delivery by SBA and arrangement of transport and money for delivery were less frequently received by them. In future meetings, these messages can be emphasized.

Figure 2.12: Delivery Care messages received by women, as reported by women*

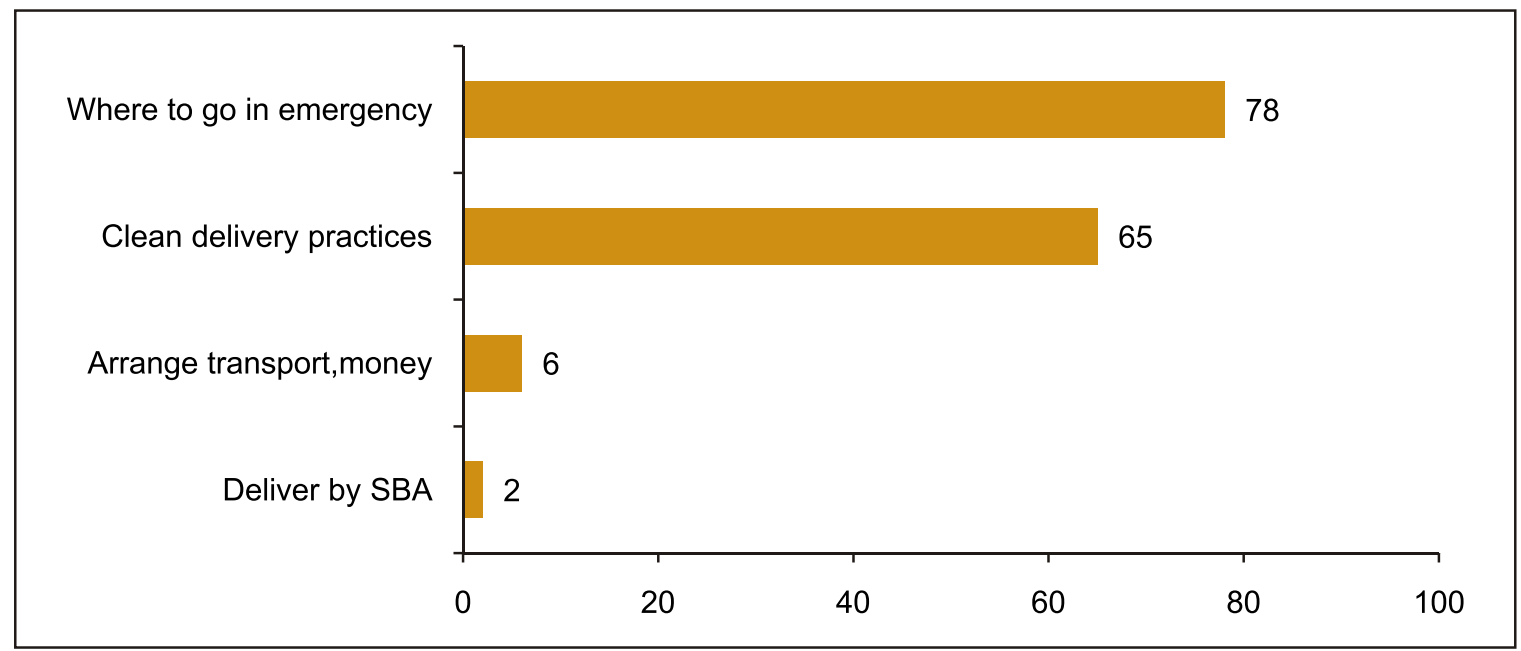

*Multiple responses 


\section{Postnatal care (PNC) messages received by women}

As mentioned in the earlier section on topics of discussion, messages regarding PNC were generally less frequently received by women. PNC messages least discussed include post natal check up and hygienic practices during PN period and FP during post natal period.

Figure 2.13: Postnatal care messages received by women, as reported by women*

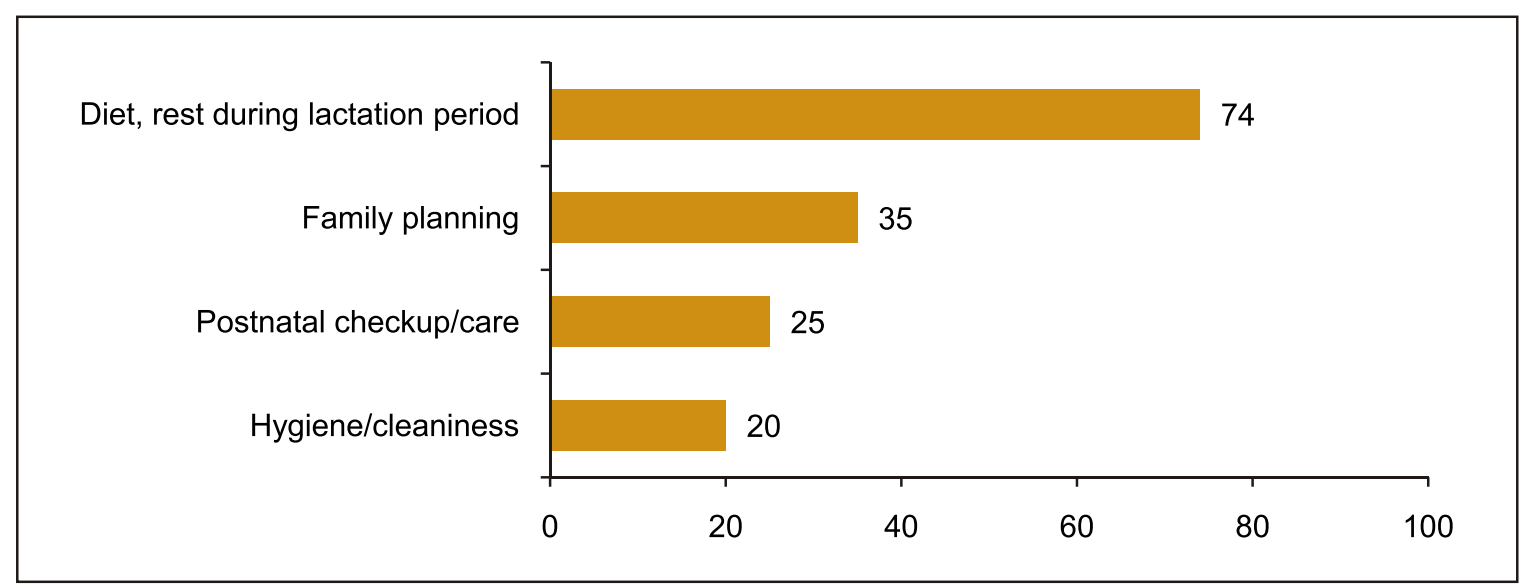

*Multiple responses

\section{Newborn care messages received by women}

Most commonly received newborn care messages by the support group members were about wrapping the newborn in a clean cloth, initiation of early breast feeding (within half an hour of birth) and delaying first bath for at least 6 hours. The least mentioned messages included; protecting the newborn from heat and cold, danger signs of newborn's ill health, care of the umbilical cord, exclusive breast feeding for the first 6 months and immunization. The gaps in these messages can be filled during the future implementation of support groups. 
Figure 2.14: Newborn care messages received by women, as reported by women*

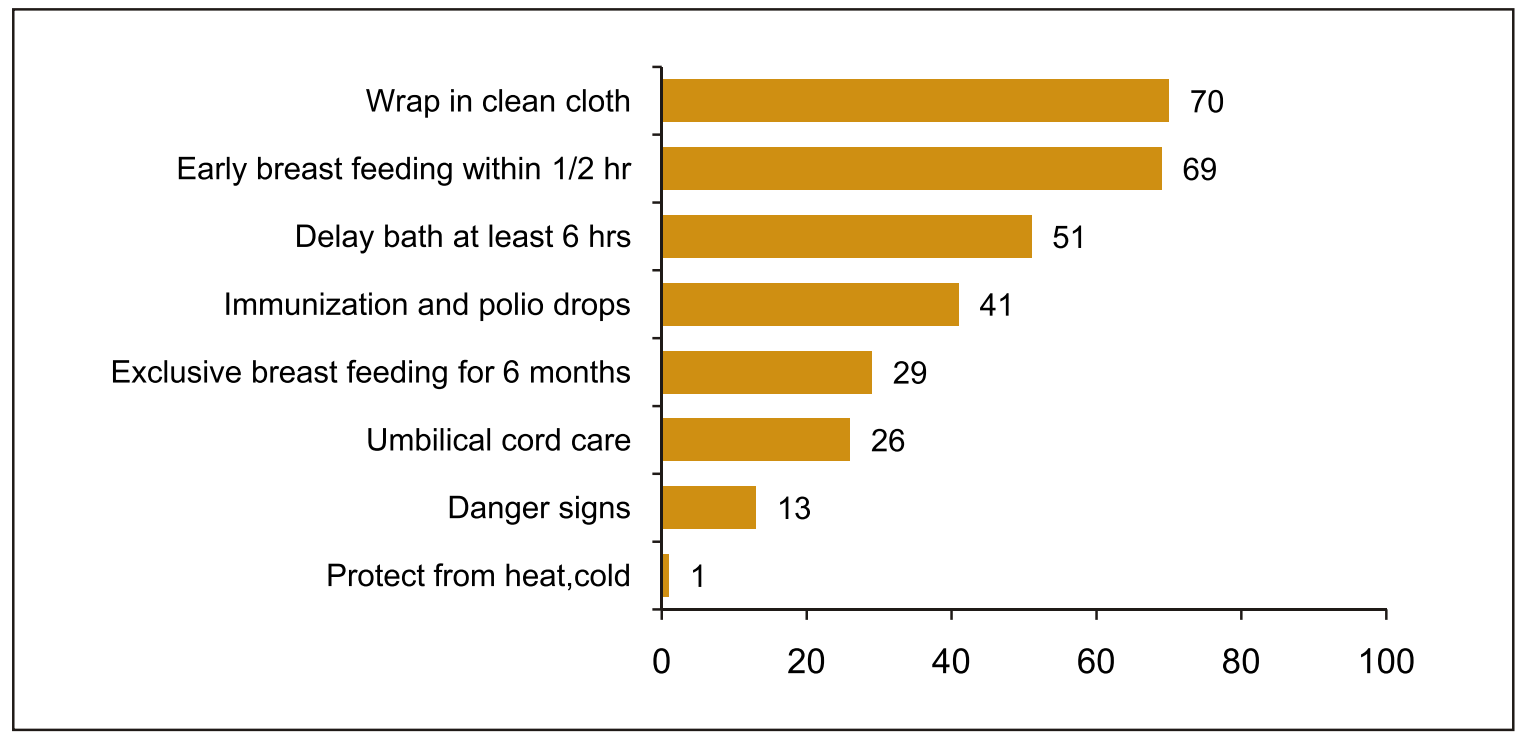

*Multiple responses

According to the information received from the LHWs, a majority of them also gave messages regarding other topics, such as FP, general health and child health, in a descending frequency.

\section{Supervision and Record Keeping:}

Supervision: SG meetings are supposed to be supervised mainly by two supervisors; Lady Health Supervisor (LHS) and Assistant District Coordinator (ADC). The supervisors were supposed to observe the meeting process, without interruption. They had to assess the proceedings according to the supervisory checklist developed by PAIMAN and NP (See Annex 8). At the end of the meeting, they would give feedback to the LHW.

According to observations, only 19 percent of support group meetings were supervised by a supervisor (mostly by LHS). A great majority of supervisors exhibited a positive attitude towards the facilitator and participants. Moreover the supervisor provided support and feedback to the facilitator.

When asked if the LHS ever came to a support group meeting, an overwhelming majority (90 percent) of the LHWs responded positively. Of these, only a third responded that their LHS attended the last SG meeting. Most of the feedback given by the supervisor was related to interaction with participants and communication skills and to a lesser extent on sehat ki dastak booklet, and on steps and topics of the meeting. Although it was not possible for the LHS to 
supervise all the support group meetings facilitated by their LHWs, nevertheless, this pointed towards a potential area for improvement.

The research team also asked the LHWs $(\mathrm{N}=74)$ whether anyone else, beside LHS, ever attended the meetings. Over two thirds of the LHWs responded positively. In most cases, they mentioned that a PAIMAN official was present in the meeting. In very few cases, Assistant District Coordinator (ADC) was mentioned, whereas Field Program Officer (FPO), person from provincial office, and a person from some other NGO were only mentioned by one respondent each.

Record Keeping: LHWs were trained on making the attendance sheet and keeping the record of the meeting on a register. Almost all the LHWs acknowledged keeping a record of SG meetings. A majority of them kept records in their diary while very few used a register, loose charts or pages provided by PAIMAN. Contrary to this, during the observation of support group meetings only a quarter of the LHWs kept record of participants and even less than that (21 percent) prepared an attendance sheet.

\section{Challenges in organizing and conducting meetings:}

LHWs ( $\mathrm{N}=74)$ were also asked about the problems they encountered during organizing and conducting the SG meetings. Of all LHWs, slightly less than half (46 percent) responded that they did encounter problems in organizing the meeting, while only 12 percent reported that they encountered a problem in conducting the meetings.

Main problems faced by the LHWs were that women did not come on time, women did not attend the SG meeting or did not cooperate, difficulties in finding a suitable place for meetings, other duties and responsibilities of LHWs and non-availability of funds for refreshments for the participants of the support group meetings.

Figure 2.15: Problems encountered in organizing the SG meetings as reported by LHWs*

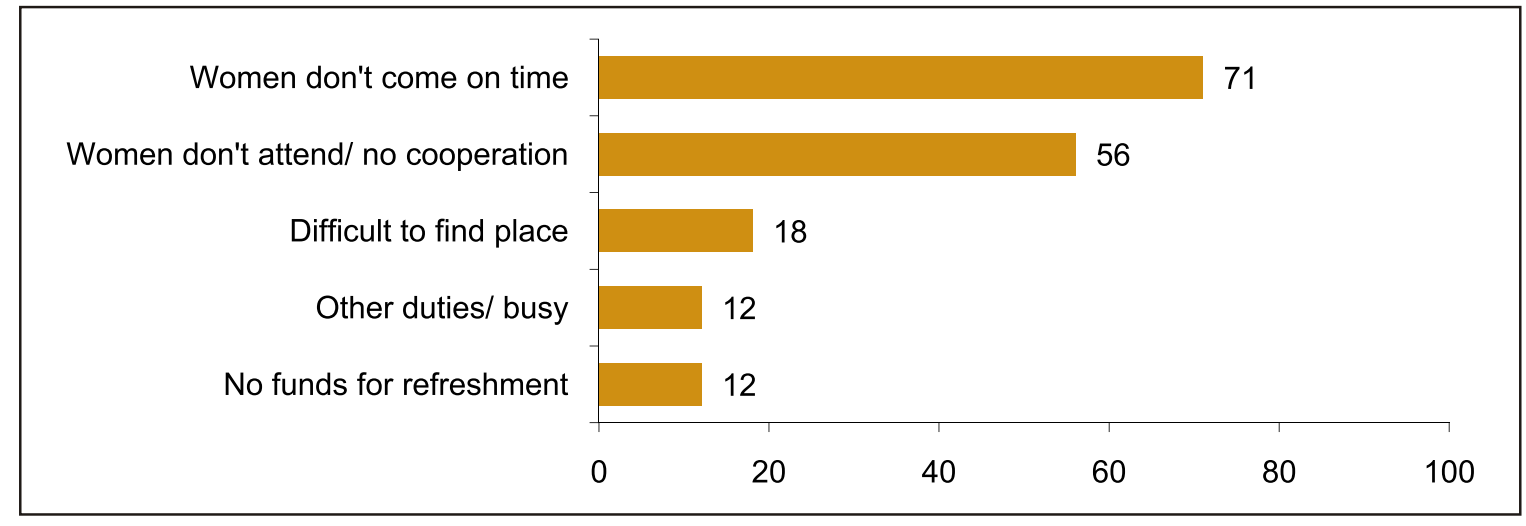

*Multiple responses 
Out of those who had encountered any problem in organizing the meeting, a majority (59 percent) responded that they were helped in resolving these issues mostly by other LHWs, a SG member, the LHS or a PAIMAN official.

Of the few, who encountered problems in conducting the meeting $(N=9)$, the most frequently mentioned problem was 'to make the women understand the issue'. Other problems included 'to answer the women's questions' and 'lack of technical knowledge'. Most of these LHWs said that they were helped out by the LHS on these problems.

\section{Refreshment/Cost of SG Meetings:}

According to the MOU, PAIMAN has to pay Rupees 100 to the LHWs, as a refreshment amount, for holding a single meeting. A majority of the LHWs (84 percent) responded that they arranged refreshments during the meetings. When the women were asked about refreshments, an overwhelming majority (80 percent) reported receiving refreshments during the SG meetings, whereas 20 percent had the opposite view. Of the LHWs who responded that they arranged refreshments during the meeting, less than half said that they got funds for the refreshments. Of all the interviewed LHWs ( $N=74), 60$ percent responded that they did not receive any funds to arrange refreshments. When the LHWs were asked the average cost of refreshment for a single SG meeting, more than half thought that Rs 101 to 200 was required to provide refreshments to the participants of a single SG meeting. Slightly less than a third (29 percent) perceived that the cost was Rs 100 or less to provide refreshments. Compared to this, only 18 percent of the LHWs thought that the amount was more than Rs 200. Probably this also depends upon the district and rural/urban location, for example, cost may be high in Rawalpindi.

\section{Figure 2.16: Cost of refreshment per SG meeting as reported by LHWs}

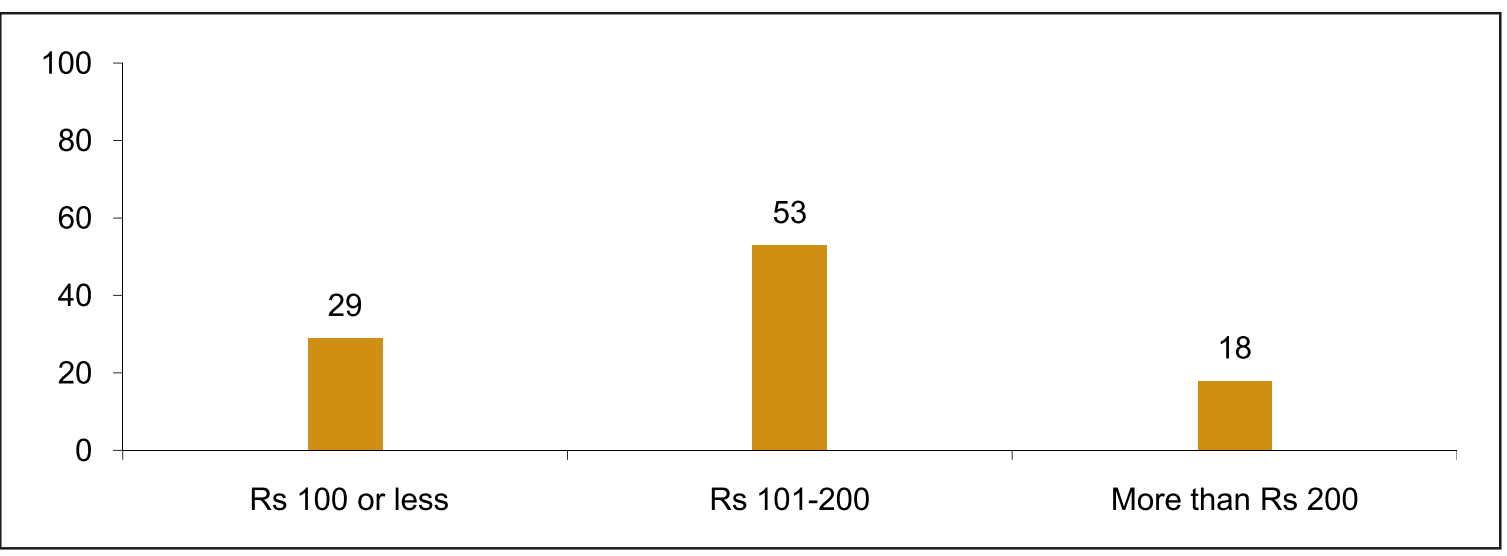




\section{Constraints to women:}

Women were also asked about the constraints they faced in attending the SG meetings. According to the responses of women, a majority did not face any constraints or problems in attending the meeting or during the meeting. Very few said that they did not have time to attend the meeting.

\section{Sharing information with others:}

Though the sharing of information by SG members with other women who were not members of the SG was the main objective of these meetings, it was also important for the SG members to share this information with family and selected individuals in the community. An overwhelming majority of women reported that they did share the information received through SG meetings with others. The most frequently mentioned category with whom women shared this information was other family members, followed by sahaili/family friend, women in neighborhood, husband and, in very few cases, information was shared with the mother in law.

Figure 2.17: Persons with whom women share MNH information, as reported by women*

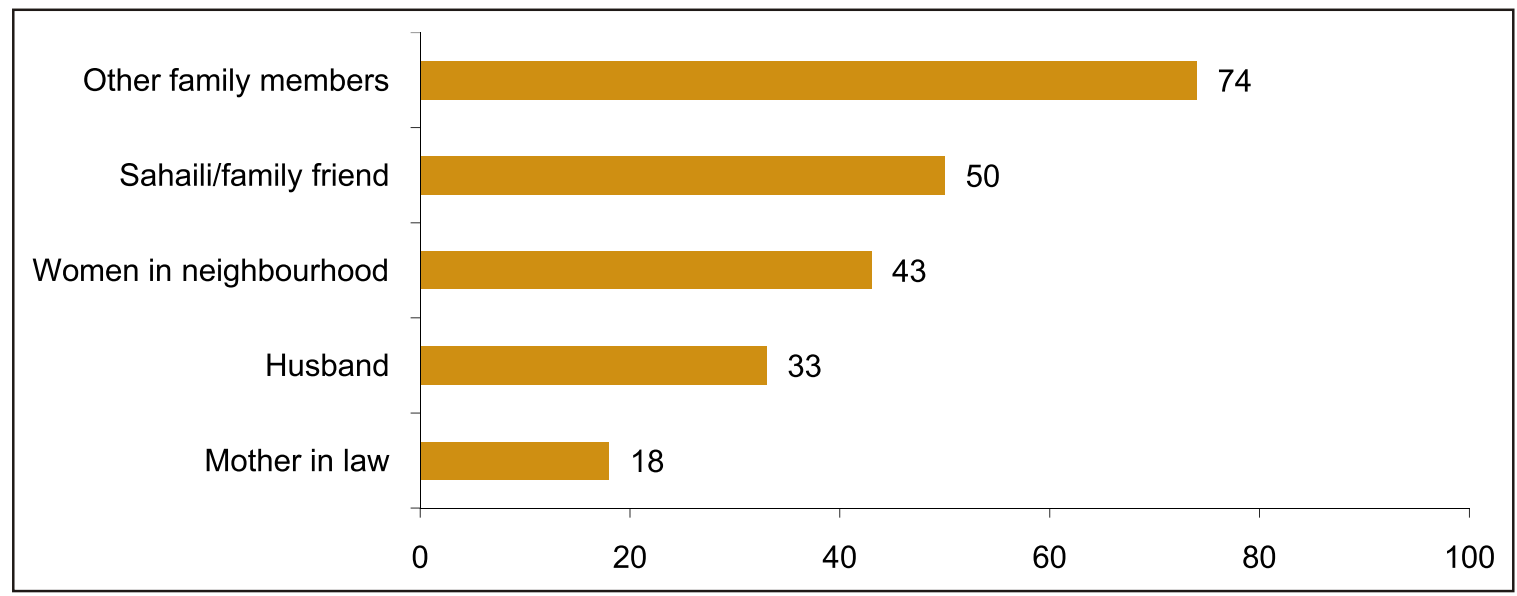

*Multiple responses

Those women, who did not spontaneously mention sharing of information with their husbands $(\mathrm{N}=137)$, were specifically asked the question, if they had ever shared the information with their husbands. Three quarters responded positively, while a quarter reported not sharing the information with husbands. The women, who did not share the information with their husbands $(\mathrm{N}=33)$ mentioned husbands' lack of interest as the main reason for not doing so. Other reasons included 'he has no time to listen' and 'there is no reason at all'.

SG members who had shared information with others ( $N=206)$, were asked if they had shared the information with other females of the village. An overwhelming majority (93 percent) 
responded positively. Of those, who had ever attended a meeting, slightly less than a third (30 percent), reported that they involved their mother in law in SG meetings. The most reported reason for not involving mother in law by these SG members was that she was not alive/sick/too old, followed by the reason that she did not live with them or that the mother in law did not like such activities.

\section{Views of women and LHWs about community and SG meetings}

The LHWs were asked about the MNH problems in the community and their views regarding support group meetings. A large majority of them (72 percent) said that there were maternal health problems in their communities. Most frequently mentioned problems by the LHWs were 'poor health of mothers', 'high rate of complications during pregnancy and delivery', 'low rate of antenatal checkups' and 'prevalence of anemia among the mothers'. When the same question was posed to the SG members, again a majority (60 percent) replied that there were maternal health problems in the community. There was great similarity in the responses of LHWs and women regarding the prevalent maternal health problems in the community.

Figure 2.18: Maternal Health Problems in the community as perceived by the Women and LHWs*

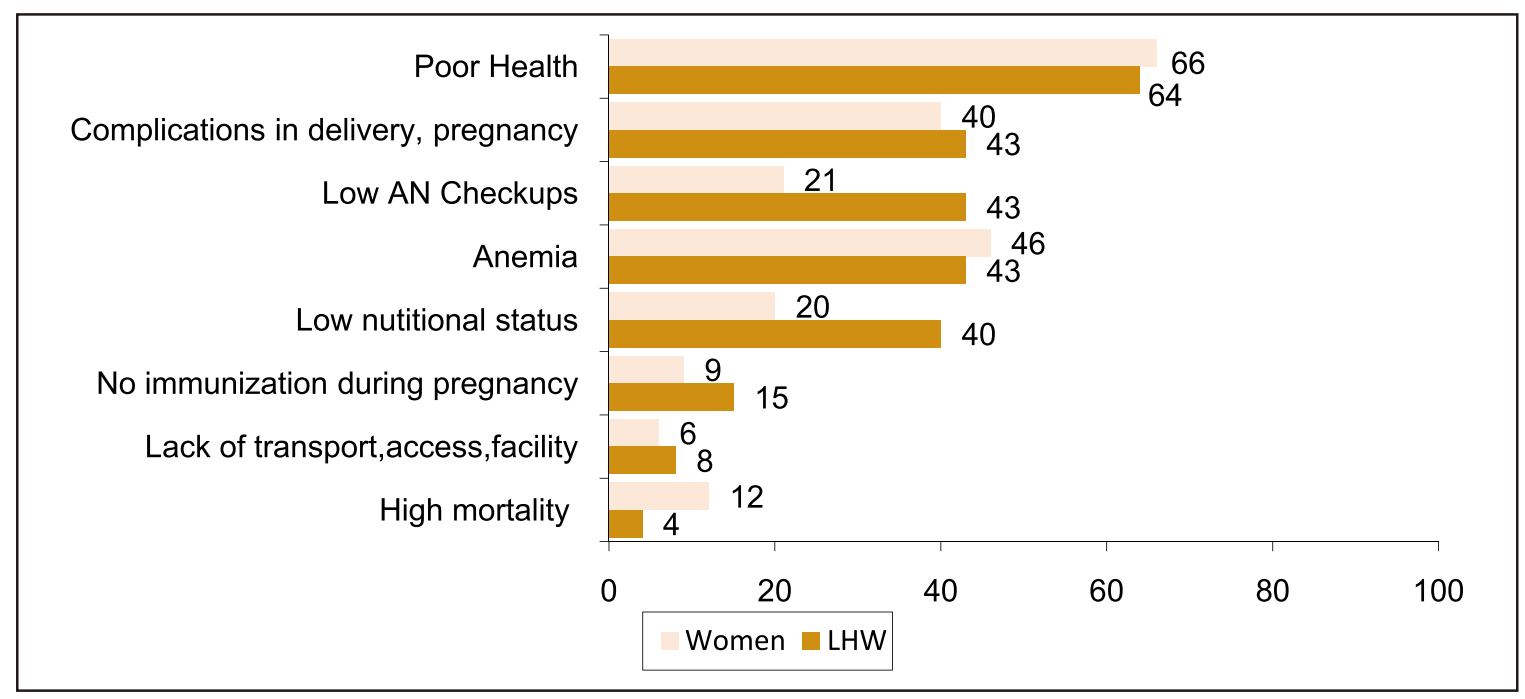

*Multiple responses

A large majority (62 percent) of the LHWs also perceived that there were newborn health problems in the community. The most common newborn health problems mentioned by the LHWs were 'low birth weight' 'poor knowledge of mothers to manage newborn', 'poor immunization status', 'high mortality' and 'low prevalence of breast feeding'. Most of these 
newborn health problems were less frequently mentioned by the SG women compared to the LHWs.

Figure 2.19: Newborn Health Problems in the community as perceived by the women and LHWs*

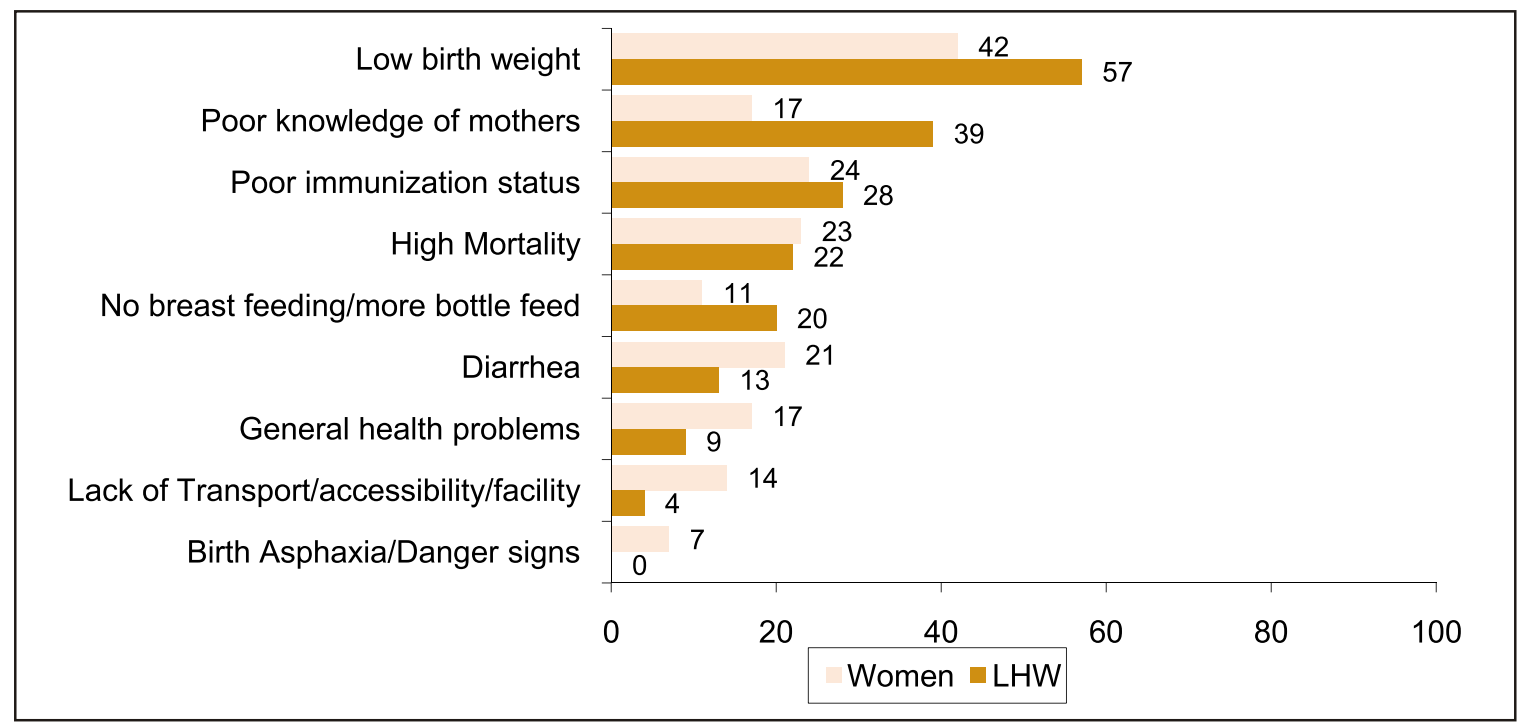

*Multiple responses

Almost all of the LHWs and SG women considered the SG meetings useful and according to them these meetings had made improvements in the community practices regarding maternal and newborn health. Both, LHWs and the women, thought that mutual learning from each other's experience, methodology of the meetings and freedom of speech were the main reasons for the usefulness of SG meetings. The LHWs perceived that the most prominent improvement in maternal health was increased ANC awareness and practices in the community. The other improvements mentioned by the LHWs were an increased awareness and practice about birth preparedness and lowered maternal death rate. There were huge similarities in the responses of women and LHWs when asked similar questions. 
Figure 2.20: Improvements made by SG meetings in maternal health, as perceived by LHWs and women*

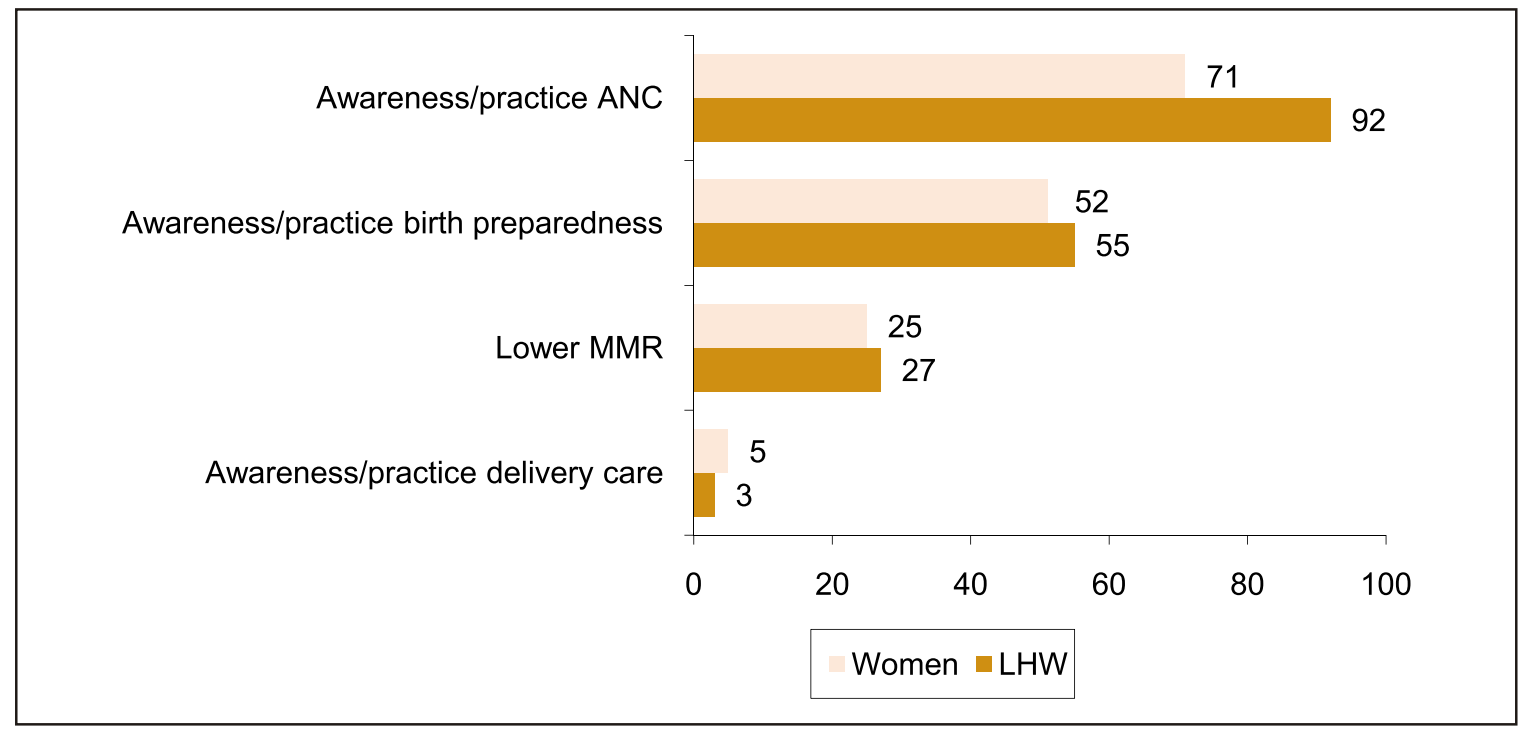

*Multiple responses

With regard to improvements in newborn health as a result of SG meetings, most of the LHWS thought that there had been an increase in the immunization rate. Some of them also thought that a lower neonatal mortality rate, increased awareness/practice about newborn care and births of healthy babies were the improvements owing to the knowledge and awareness imparted by the SG meetings. Once again, there were great similarities in the perceptions of LHWs and women regarding the improvements in newborn health due to the SG meetings. 
Figure 2.21: Improvements made by SG meetings in newborn health, as perceived by LHWs and women*

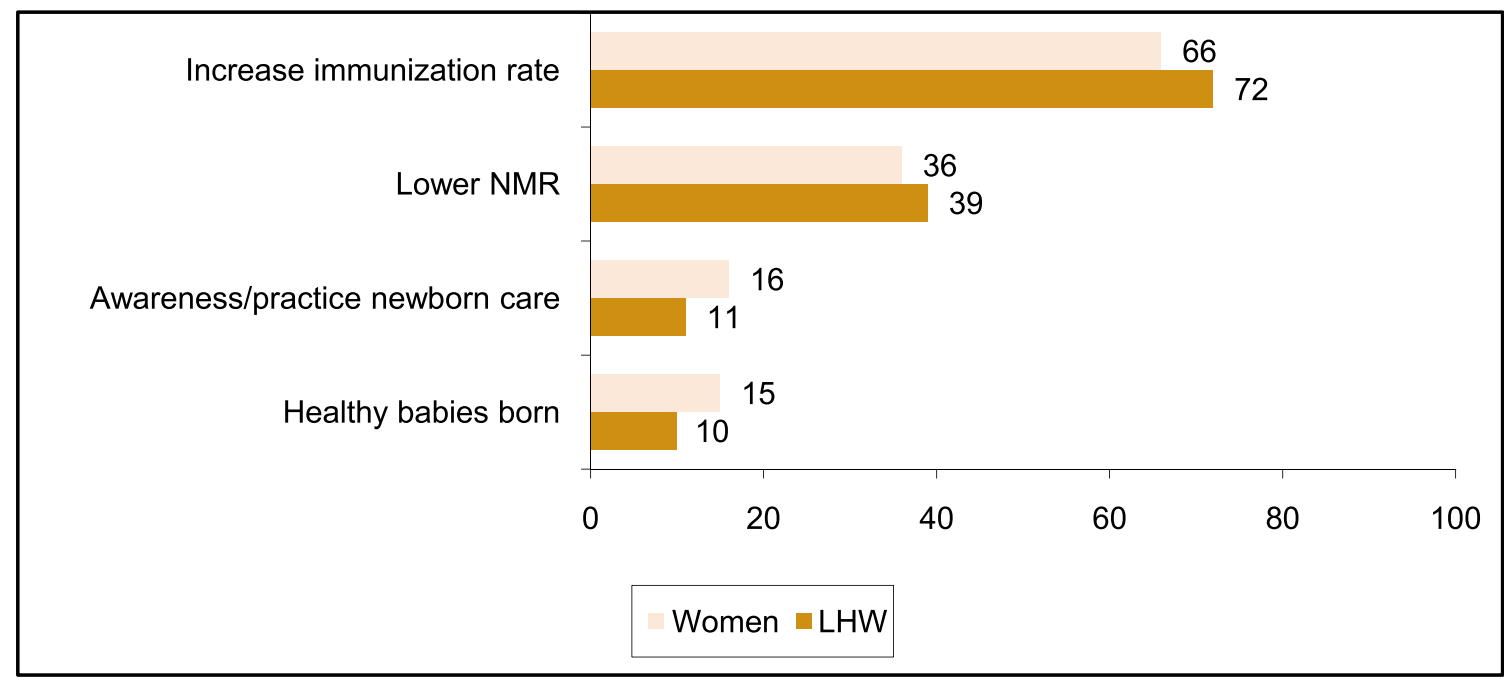

*Multiple responses

\section{Conclusions}

Support group meetings are a key activity of PAIMAN, implemented under the community mobilization component. The process evaluation of support group meetings has revealed that support group organization and meetings are being implemented in PAIMAN districts. However, several important gaps in the implementation process have been identified through this evaluation. Most of the gaps pertain to the areas of overall organization, management and logistics. However, limited but important, deficiencies were also seen in the conduction and quality of support group meetings.

A good foundation was laid by training all the LHWs in support group methodology. Results show that the implementation protocols for training the LHWs in SG methodology were followed in a majority of the cases e.g. training venue, trainers, duration, and training contents. After receiving the training in SG methodology, an overwhelming majority of LHWs formed 4 support groups in their communities, each comprising of 15 women. However, in majority of the cases, there was a delay of one month in the initiation of SG meetings by the LHWs. Although a majority of the LHWs were conducting the support group meetings twice a month, more than a third of LHWs held one meeting per month or after more than a month. A small proportion was also having irregular meetings with no specific gaps between meetings. This inconsistency can be readily addressed according to the guidelines stated. According to set criteria, a support group member must attend 8 to 10 meeting to receive all the intended messages on $\mathrm{MNH}$. After sometime, the membership should rotate to include other members in the community. The 
findings of the process evaluation point towards a low participation of women in the meetings. A quarter of the interviewed women had never attended a support group meeting. These women were members of support groups formed by the LHWs. Another approximately one-fifth of the women attended only 1 or 2 meetings.

The technical skills of the LHWs for conducting the support group meetings were generally appropriate according to their training in SG methodology. There were a few steps which were not followed by all facilitators; implementers need to look closely at these steps in each session of SG meeting. The behavior of LHWs towards the participants of the meeting was positive. However, majority of LHWs were not keeping record of or making an attendance sheet for the participants. LHWs also described difficulties in organizing support group meetings rather than conducting the meetings. The research team found supervision as a weak area of SG meetings as only less than a fifth of meetings were supervised (mainly by LHS). Supervision can be strengthened by supporting LHS and also involving ADC in the process. Monitoring visits by the FPO, district health office, and provincial office also need to be increased.

The main objective of the SG meetings was to give messages to the women regarding $\mathrm{MNH}$. Research showed that the most frequently discussed topics during the support group meetings were antenatal care, followed by newborn care and delivery care. Family planning and post natal care were discussed in very few cases. Antenatal care messages, e.g. danger signs of pregnancy, arrangement for skilled birth attendant (SBA), use of iron/folic acid tablets and arrangement of transport and money need to be discussed more in the future. Similarly, delivery care messages e.g. delivery by SBA and arranging transport/money for delivery, should reach more women. Gaps were found in post natal messages e.g. post natal check up, hygienic practices and FP during post natal period. Several messages related to newborn care need to be more emphasized, which include protecting the newborn from heat and cold, danger signs in newborn, care of umbilical cord, exclusive breast feeding for first 6 months and immunization. Research also revealed that SG members shared the information, received through SG meetings, with their family members and neighbors. This was very encouraging because the support group methodology is based on propagation of messages in the community. The women share this information with other family members, sahaili/family friends, women in the neighborhood, husbands and, in very few cases, with mothers in law. Efforts should be made to disseminate messages to husbands and mothers in law since they are the decision makers in most cases. Despite sharing the information within the family and neighborhood, women were generally reluctant to share the information with the husbands and mothers in law. 
Generally the attitude of LHWs and women was positive towards the support group and they found it very useful for improving MNH. The main difficulties or problems mentioned by the LHWs were low attendance/participation and non-cooperation by women, beside difficulties in finding a suitable place for meetings, other duties and responsibilities of the LHWs and nonavailability of funds for refreshment for participants of the support group meeting. The results show that in a majority of the meetings, refreshments were given to the participants; however, a majority of the LHWs did not receive funds for refreshment. It was also found that a majority of the LHWs asked for an increase in the refreshment amount being paid by PAIMAN and they consider the current rate of Rupees 100 to be insufficient. Generally there was cohesion in the perceptions of the LHWs and women regarding prevalent MNH situation in the community.

The overall results show that, despite some grey areas, support group meetings were being implemented in PAIMAN districts. There were also some differentials across 5 districts. The SG methodology is very efficient and effective in mobilizing the community towards creating a demand for seeking MNH services. The gaps identified through the process evaluation are very fundamental and vital for the effective implementation and replication of community mobilization programs and getting desired outcomes and impact. If these shortcomings are addressed, support group meetings can become the centre of community mobilization activities to bring about a positive change in the communities of Pakistan. 


\section{CHAPTER III Male Health Committees}

\section{Introduction}

As mentioned in the previous chapter, LHW as a community outreach worker for health would orient the fathers of newborns, husbands of pregnant women, influentials, religious leaders, teachers etc on PAIMAN key MNH messages through the meeting of a Health Committee $(\mathrm{HC})$. According to the criteria set by the NP, an LHW belonging to the local area, with formal education of grade 10, selects a focal person for herself. The same focal person seeks the advice of the LHW and revitalizes the LHW's Health Committee. There are 6-12 male members in each Health Committee (or male health committee) representing her whole catchment population. As these members are representatives, they then communicate the messages discussed during the meeting to other men who need the information. The population size of the catchment area of the LHW may vary from 800 to 1200 due to her access to population and mobility of the LHW. The LHW is trained through PAIMAN to revitalize Health Committees in the area.

Meeting of Health Committee is a meeting where members of the Committee exchange ideas, share experiences and information related to any issue regarding $\mathrm{MNH}$ issues. Mostly these issues are pointed out by the LHWs and Health Committee ensures support of male community to LHWs where ever she needs it. In addition, this group provides emotional support and strength so that the fathers of newborn and husbands of pregnant women could come to terms with ways for improving the conditions related to the health of their wives, children and/ or daughters in laws. It also helps in interpersonal growth in the interaction between parents, family members, and healthcare workers, both formal and informal. The methodology of a Health Committee meeting is participatory; as that of a Support Group (SG) meeting, which is one of the most effective methodologies for extending the information and awareness to the communities, along with building self-esteem and bringing positive behavior change. It helps in building trust and linkages of the community members with health facility staff.

\section{Formation of male health committees (HC)}

Information regarding health committees was gathered from the 74 LHWs, who were also interviewed for the support groups. Three quarters of interviewed LHWs reported that they had formed the health committee in their area, as opposed to the remaining quarter who had not formed any health committee. All the LHWs of the Rawalpindi district reported that they had formed the $\mathrm{HC}$ and an overwhelming majority from Districts Khanewal and Buner (94 percent 
and 80 percent respectively) also reported the same. On the other hand 63 percent from Dadu and 44 percent from Lasbella had formed health committees.

Slightly more than half ( 55 percent) of the LHWs who had formed health committees, reported that there were more than 5 members (maximum=15) in the health committee. The remaining 45 percent replied that there were 5 or less than 5 members in their health committee. The mean number of health committee members was $5.8(\mathrm{SD}=1.9)$. This reflects that only half of the LHWs followed the criteria of 6 or more male members in a health committee.

\section{Organizing the Health Committee meeting}

\section{Frequency of Health Committee Meetings:}

All the LHWs, who had formed a MHC $(\mathrm{N}=56)$, responded that there had been at least one meeting of the HC. There were varied responses from LHWs about the total number of HC meetings held. Slightly more than a fifth (21 percent) of the LHWs perceived that a total number of 1 to 5 meetings were held, while more than a third (36 percent) of the LHWs were of the view that 6 to 10 meetings were held. 16 percent of the LHWs reported that they held 11 to 15 meetings, and more than a quarter (27 percent) perceived that more than 15 meetings were held. Overall it seems that reasonable number of $\mathrm{HC}$ meetings had been held. The highest numbers of meetings were held in Rawalpindi, followed by Dadu, Khanewal, Lasbella and least in Buner.

Figure 3.1: Number of male health committee meetings, as reported by LHWs ( $\mathrm{N}=56)$

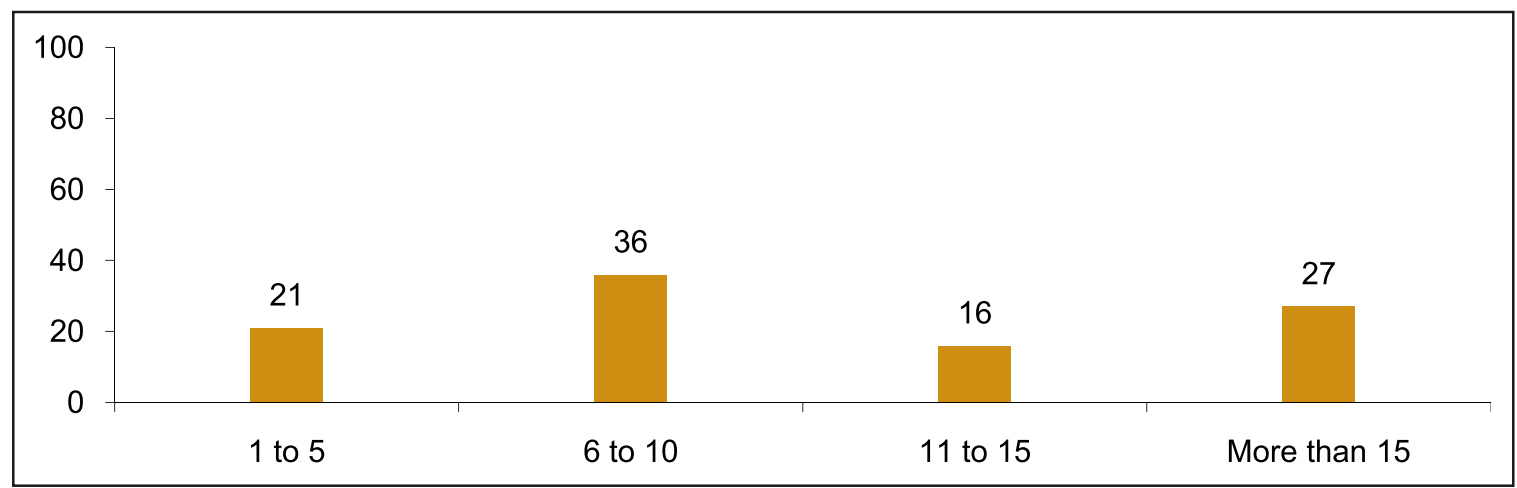

LHWs were also asked about the timing of the last meeting. Slightly less than half of the LHWs responded that the last meeting was held 1-2 weeks back. More than a quarter (29 percent) perceived that it was held 3-4 weeks back while 21 percent reported that the last HC meeting 
was held 1-2 months back. Most recent meetings were held in Rawalpindi and Dadu, followed by Khanewal, while more time had elapsed since a meeting was held in Lasbella and Buner.

Figure 3.2: Time since last meeting was held as reported by LHWs ( $N=56)$

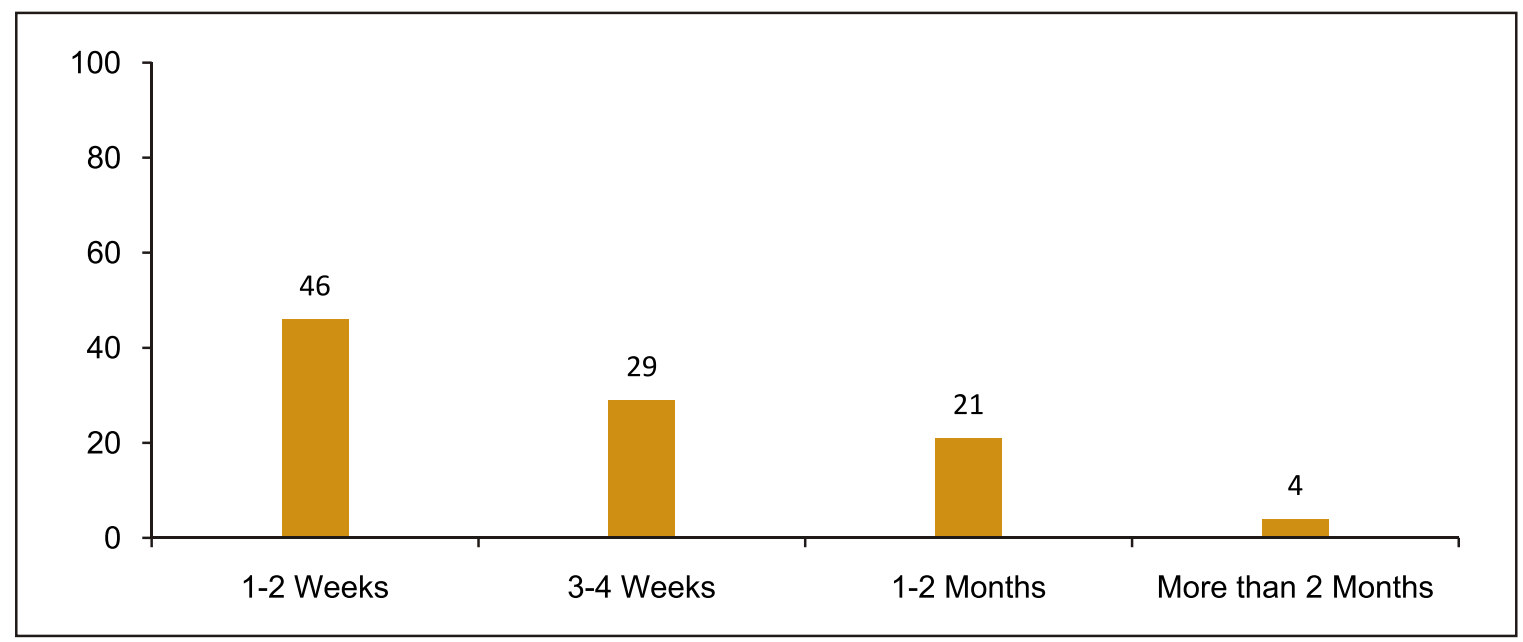

\section{Participation of LHWs in HC Meetings:}

When the LHWs were asked if they had attended any of the health committee meetings, more than three quarters (79 percent) responded positively. This was very encouraging because usually it was perceived by different quarters that a woman could not attend a male meeting. An overwhelming majority from all the districts reported that they attended the HC meeting, except in District Buner, where only 25 percent of the LHWs who formed the HC, responded positively. A majority (55 percent) of the LHWs responded that they attended more than 10 meetings, while 16 percent perceived that they attended 6 to 10 of these meetings. More than a quarter (29 percent) reported that they had attended 1 to $5 \mathrm{HC}$ meetings.

Most of the LHWs reported that they themselves facilitated the HC meetings, while the remaining reported that a relative or their husband facilitated the meetings. Most of the LHWs who were facilitating the meetings were from Rawalpindi, followed by Khanewal, Dadu and Lasbella while no LHW in Buner reported to be facilitating an $\mathrm{HC}$ meeting. 
Figure 3.3: Facilitator of HC meetings as reported by LHWs *

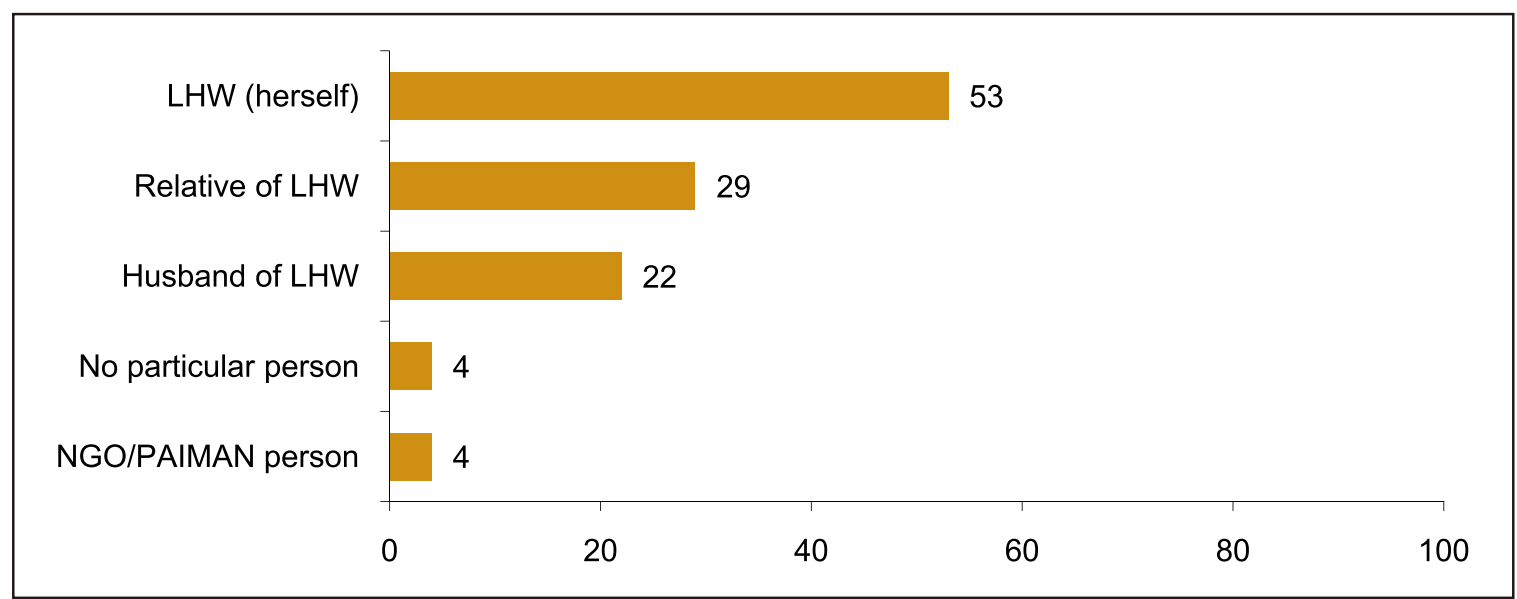

*Multiple responses

\section{Participation of community in HC Meetings:}

A majority of the LHWs (60 percent) reported that 5-10 members participated in the last meeting while a third of the respondents perceived that the number of members was less than 5. Only 7 percent reported this number to be more than 10 . Most of the LHWs reported that married men attended the HC meetings, whereas other participants mentioned by LHWs (descending order) were local influential people, elders and unmarried males. As mentioned in the previous section, most of the committees comprised less than 6 members. This demands an improvement in the participation of members.

Figure 3.4: Number of participants in last held meeting as reported by LHWs

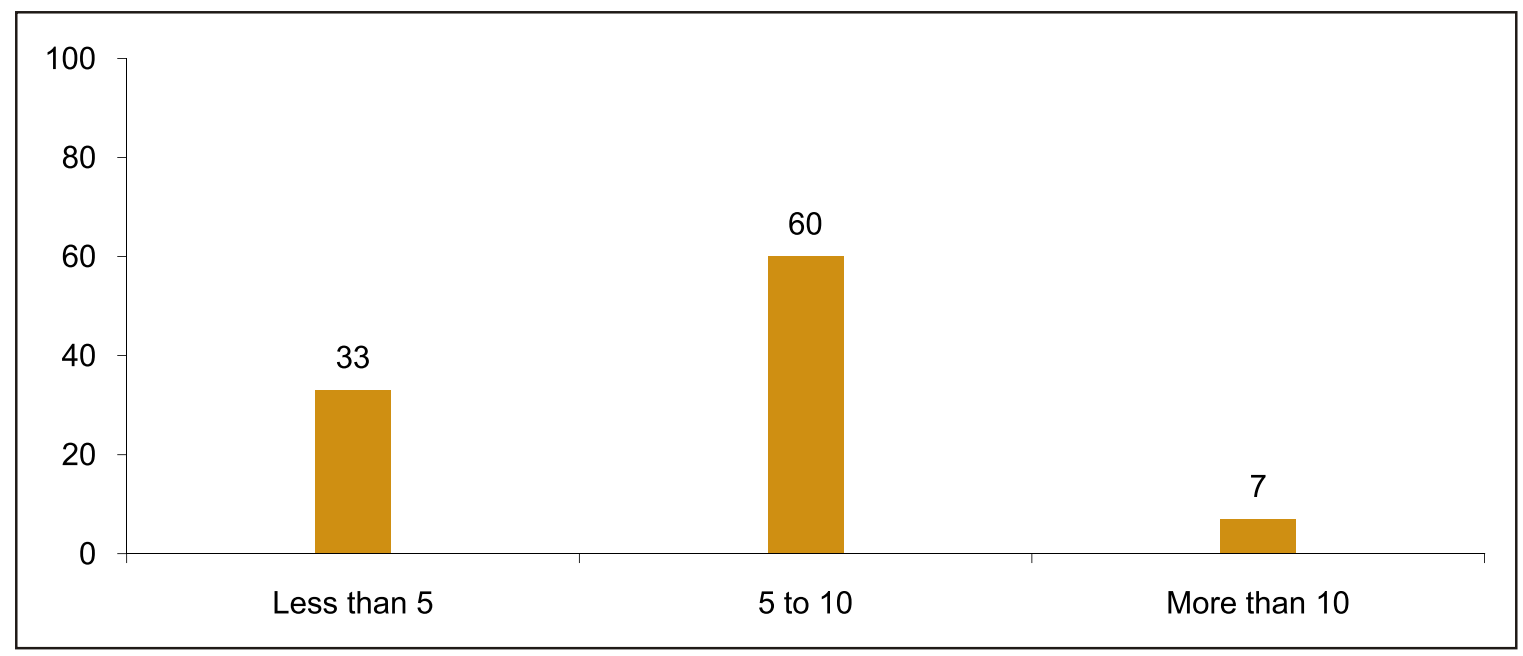




\section{Process of conducting a meeting}

To learn about the process of the $\mathrm{HC}$ meetings conducted, questions were also asked about the place of meeting, duration, topics of discussion and problems in conducting these meetings.

\section{Venue of HC meetings:}

The place of meeting is very important and it should be accessible and comfortable for the participants of the meeting. Slightly less than half of the LHWs reported that these meetings were held at the Health House, while 43 percent thought that meetings were held at one of the member's residence. The remaining 10 percent replied that the venue of the meetings was some government office.

Figure 3.5: Venue of MHC meetings, as reported by LHWs

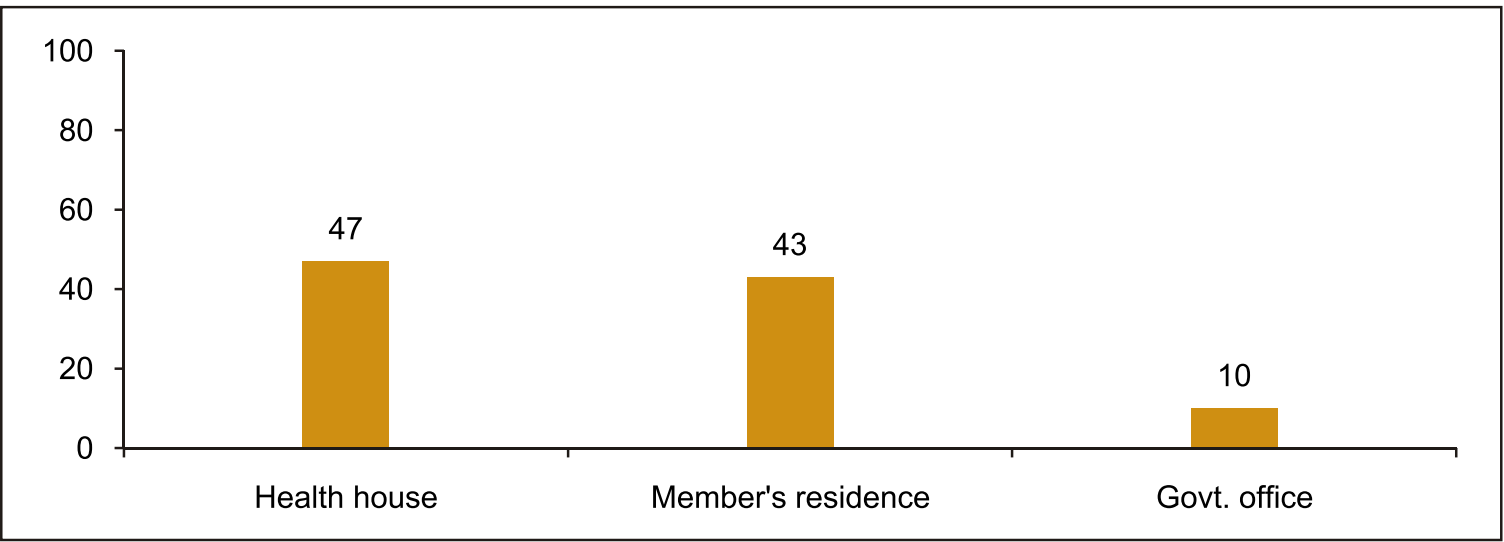

\section{Duration of HC meetings:}

Half of the LHWs thought that the duration of $\mathrm{HC}$ meetings ranged from 30 minutes to one hour while a third responded that the duration was less than 30 minutes. Only 14 percent reported that the duration was more than 1 hour. Almost similar responses were reported when we asked about the duration of the last held $\mathrm{HC}$ meeting.

Table 3.1: Duration of last male HC meeting, as reported by LHWs

\begin{tabular}{lcc}
\hline Duration of meeting & Number & Percent \\
\hline Up to 30 minutes & 18 & 32 \\
$31-60$ minutes & 30 & 54 \\
More than 60 minutes & 8 & 14 \\
Total & $\mathbf{5 6}$ & $\mathbf{1 0 0}$ \\
\hline
\end{tabular}




\section{Topics discussed in $\mathrm{HC}$ meetings:}

According to the LHWs, antenatal care, cleanliness in the community and newborn care were frequently discussed topics. Other topics that came under discussion during these meetings were polio/vaccination campaigns, family planning, delivery care and postnatal care.

Figure 3.6: Topics discussed in Health Committee meetings*

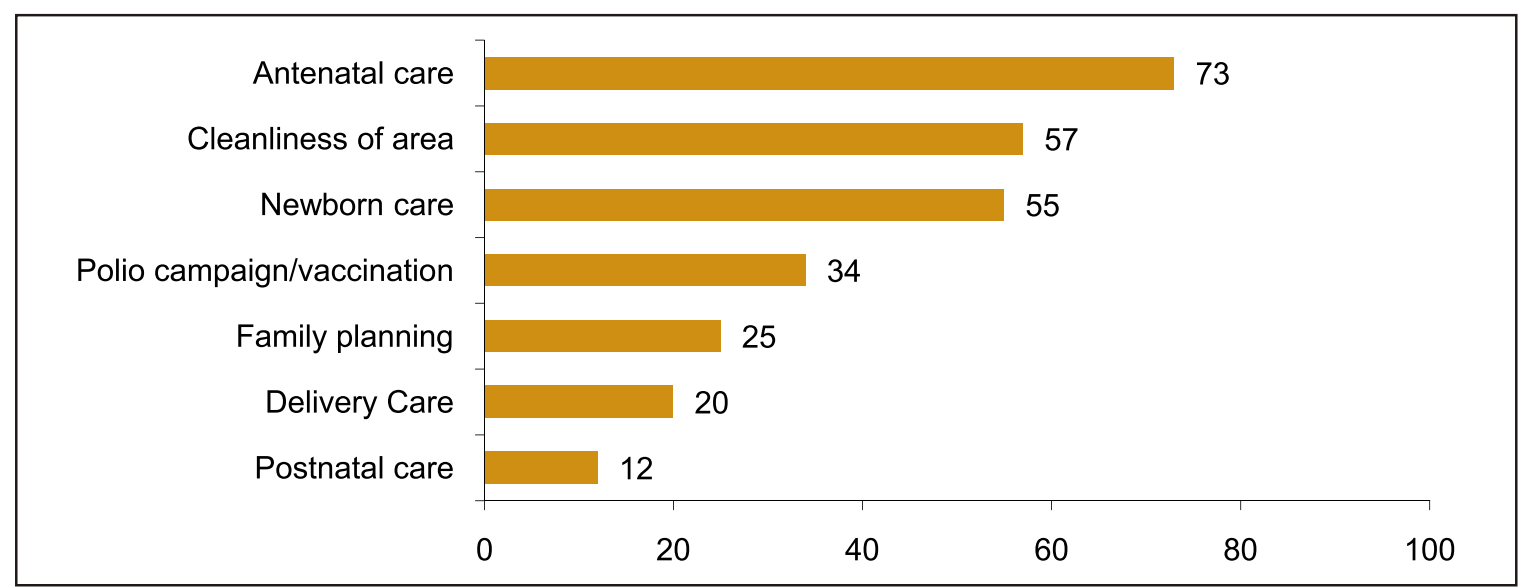

*Multiple responses

When the LHWs were asked about the problems they faced during HC meetings, a large number of them responded that no problem was encountered. However, important problems pointed out were shyness on part of the LHW and that female attendance of male meetings was against the norms/culture of society.

Almost all the LHWs were of the view that the Health Committee was beneficial to the community. Responding to a question on how the $\mathrm{HC}$ was helpful for the community, most of the LHWs said that through HC, men could communicate with other men. LHWs also perceived that males were usually the decision makers in the family and they could influence women to make correct decisions regarding their health.

\section{Conclusions}

The overall implementation process of male health committees was not as satisfactory as that of support group meetings. There are several areas which need improvement. Nevertheless, male health committees had provided some opportunities to mobilize the male proportion of the community, which is very vital. A quarter of the LHWs never formed/revitalized the male health committee in their area. This shows a low coverage of health committees in PAIMAN districts. Although a majority of the established committees had 6-10 members, slightly less than half of the committees had less than 5 members, as against the set norm of 6-12 members in each committee. This was another major gap in the implementation process of male health 
committees. In the majority of cases, more than 10 meetings were reported to be held, which indicates a satisfactory frequency of meetings. There were appreciable differences among the study districts regarding the above indicators.

More than two thirds of the LHWs had attended at least one MHC meeting. This is quite encouraging that a male meeting is being attended by a female. Most of the LHWs also facilitated the committee meeting, showing signs of a progressive outcome. Although in a majority of the last held meetings, participation was 5 or more than 5 members, in a third of the previously held meetings, less than 5 members participated. This proportion needs improvement with increased participation of the members. The venue and duration of meetings were appropriate. Although ANC, newborn care and immunization were discussed in most of the meetings, the focus on FP, PNC and delivery care needs to be enhanced. Almost all the LHWs exhibited a positive attitude towards the health committees. If the above mentioned gaps are filled with close monitoring and supportive supervision, health committees can become effective enough to mobilize the male section of the community. 



\section{CHAPTER IV Facility Based Health Committees (FBHC)}

\section{Introduction}

As part of the community mobilization process, Facility Based Health Committees (FBHCs) were formed at each health facility that had been selected for Improvement/upgradation in each district by PAIMAN. Similar committees were also formed at several well functioning basic health facilities around the district. These HCs have been referred to as leadership teams in certain geographic areas pertaining to the political involvement of the community representatives. There is a common understanding of nomenclature of Advisory Committee/team at the RHC level and Core team at the BHU level. These committees are comprised of local notables, elected representatives, and community and religious leaders, TBAs, health care providers of the facility and other volunteers. FBHC members themselves determine the organizational structure and functions of these committees.

Committee meetings play an important role throughout the community mobilization process. The committee is supposed to meet quarterly. Small, focused meetings as well as larger awareness raising meetings held at different junctures help to motivate community leaders to take responsibility for the improvement of $\mathrm{MNH}$ facilities in their area and thereby make their village/union council/district a model for MNH. Furthermore, the FBHCs have responsibility for guiding the health facility upgradation process, involving the community members and other organizations when needed, providing support to facilities, and mobilizing communities in various ways. For example mobilization activities include: generating emergency transport systems, emergency MNH funds (such as for obstetric emergencies), partner organizations for referral and transport of pregnant mother and /information sharing sessions, male committees of the LHWs etc and more.

\section{Characteristics of respondents}

A total of $60 \mathrm{FBHC}$ members were interviewed in 5 sampled districts. In District Khanewal, 18 members were interviewed, while in Dadu, Lasbella and Buner, 13 members were interviewed in each district. Only 3 members could be interviewed from Rawalpindi district, mainly due to the non-availability of members on the day of the visit of the research team and replacement of FBHC with 'partner's defined quality (PDQ)' at one of the sampled health facilities. The average length of each interview was 18 minutes. Around 3 quarters of the respondents were male. 
Table 4.1: Distribution of respondents across districts by gender

\begin{tabular}{|c|c|c|c|c|c|}
\hline \multirow[b]{3}{*}{ Name of Districts } & \multicolumn{4}{|c|}{ Gender } & \multirow[b]{3}{*}{ Total } \\
\hline & \multicolumn{2}{|c|}{ Male } & \multicolumn{2}{|c|}{ Female } & \\
\hline & Number & Percent & Number & Percent & \\
\hline Buner & 9 & 69 & 4 & 31 & 13 \\
\hline Rawalpindi & 3 & 100 & 0 & 0 & 3 \\
\hline Khanewal & 8 & 44 & 10 & 56 & 18 \\
\hline Dadu & 11 & 85 & 2 & 15 & 13 \\
\hline Lasbella & 11 & 85 & 2 & 15 & 13 \\
\hline Total & 42 & 70 & 18 & 30 & 60 \\
\hline
\end{tabular}

A large number (43 percent) of respondents were health care providers, while teachers and social workers were 17 percent respectively. A few (8 percent) were Zamindar/Nazim/Councilor and remaining (15 percent) were housewives, or office /BHU, RHC workers. Respondents had fairly varied educational backgrounds, as shown in figure 4.1.

Figure 4.1: Distribution of respondents by education (FBHC)

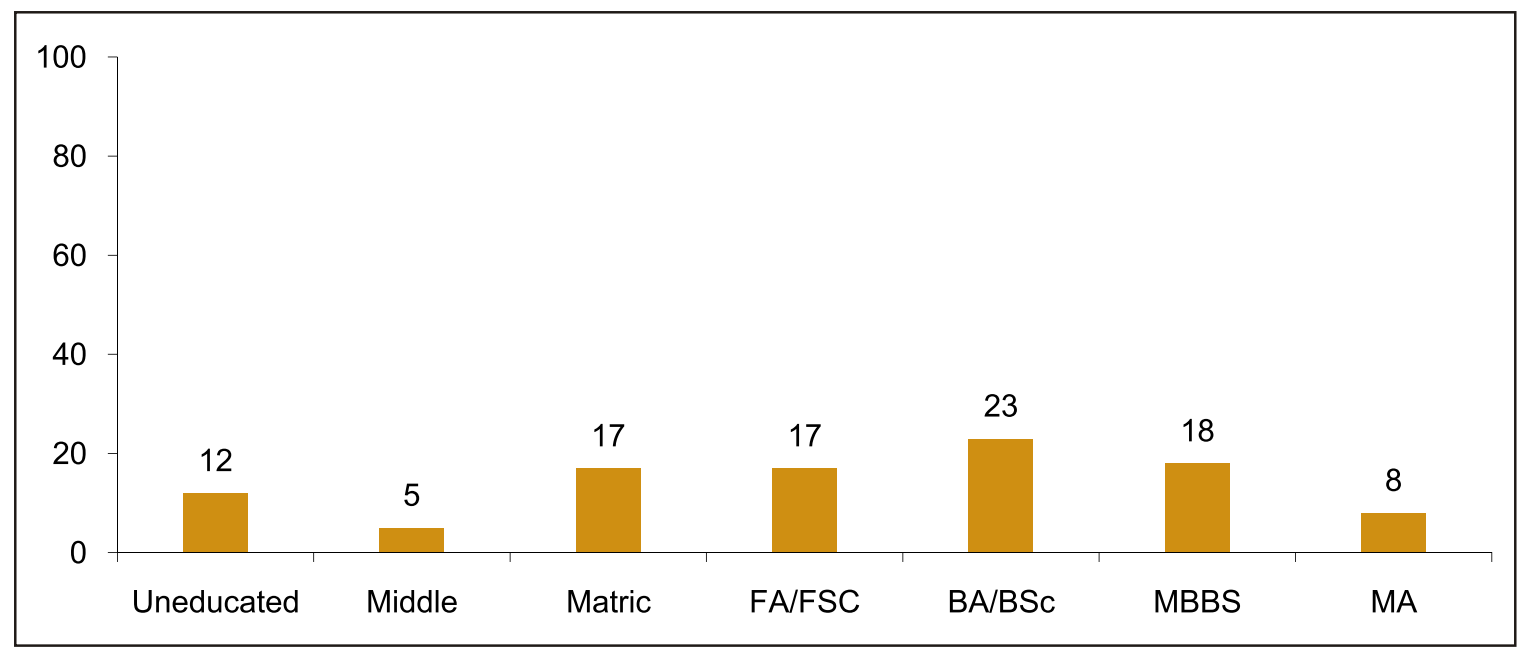

The respondents belonged to all age groups, although a majority of them were relatively younger (up to 40 years of age). Only 10 percent of the respondents were unmarried. A majority (57percent) of the respondents had 3 to 5 children, and slightly more than a third had more than 5 children. Only 7 percent had 1 to 2 children and one respondent was reported to be childless. 
Table 4.2: Distribution of respondents by age group and number of children

\begin{tabular}{lcc}
\hline Age group $\mathbf{( N = 6 0 )}$ & Number & Percent \\
\hline Up to 30 & 10 & 17 \\
$31-40$ & 24 & 40 \\
$41-50$ & 16 & 27 \\
More than 50 & 10 & 16 \\
Number of children $(\mathbf{N}=\mathbf{5 3})$ & & \\
No child & 1 & 2 \\
1 to 2 & 4 & 7 \\
3 to 5 & 30 & 57 \\
More than 5 & 18 & 34 \\
\hline
\end{tabular}

\section{Organization of facility based health committee}

\section{Number of FBHC members}

When the respondents were asked if they were members of FBHC, all replied positively except one member who did not know whether he was a member of the committee. The mean number of members in each FBHC was $13(S D=6.8)$, as reported by the respondents. A fifth of respondents were unable to tell the number of members in their committee. Out of those who gave a number $(\mathrm{N}=48)$, more than a third responded that the number of members in their FBHC was less than 10 , whereas a third reported the number as 10 to 15 . Slightly less than a quarter mentioned 16 to 20 members in their FBHC and very few ( 8 percent) told that there were more than 20 members in the committee. The district wise mean number of members in FBHC has been given in Annex 10.

Table 4.3: Number of members in FBHC, as reported by respondents

\begin{tabular}{lcc}
\hline No. of members & Number & Percent \\
\hline Less than 10 & 17 & 35 \\
$10-15$ & 16 & 33 \\
$16-20$ & 11 & 23 \\
More than 20 & 4 & 8 \\
Total & $\mathbf{4 8}$ & $\mathbf{1 0 0}$ \\
\hline
\end{tabular}

On average, there were 5 female members in each FBHC ( $S D=5.4)$, as reported by the respondents. Again, slightly more than a fifth of the respondents did not know the number of 
female members in their committees. Out of those who knew $(N=47)$, a third reported the number of female members as 1 to 2 , whereas 15 percent mentioned the number as 3 to 5 . Another one third of the respondents thought that there were 6 to 10 female members and 13 percent quoted the number as more than 10 . Only 5 percent mentioned that there were no female members in their committees.

Orientation of FBHC members: An overwhelming majority (88 percent) knew that the PAIMAN project was a maternal and newborn health program. However, 12 percent of respondents didn't know about PAIMAN. In response to the question pertaining to the basis on which they were selected as a member of FBHC, a large number (38 percent) responded that they were selected on the basis of their health background. Slightly more than a quarter ( 27 percent) of the respondents thought that they were selected by virtue of their influence in the community, whereas 15 percent were of the opinion that they were randomly selected. Another 15 percent of members mentioned the basis of their selection as being a village leader, respected and valued by the people, while a few ( 5 percent) were unable to give any reason for their selection.

A large number ( 40 percent) of respondents perceived that their role in the health committee was to advocate within the community to improve $\mathrm{MNH}$, while 30 percent saw their role as a link between the community and the health department. This showed that majority of members were aware of their basic role in FBHC. However, a quarter of respondents replied that they did not have a specific role and they acted as requested.

An overwhelming proportion of respondents ( 89 percent) reported that there were maternal health problems in the community. The most common problems pointed out were low antenatal checkups, low nutritional status of women, anemia, poor health and lack of knowledge/awareness regarding $\mathrm{MNH}$ issues.

Figure 4.2: Maternal health problems in the community as perceived by the FBHC members*

\begin{tabular}{|c|c|c|c|c|c|c|}
\hline Low AN Checkups & \multicolumn{6}{|c|}{48} \\
\hline Low nutritional status & \multicolumn{6}{|c|}{46} \\
\hline Anemia & \multicolumn{5}{|c|}{41} & \\
\hline Poor health & \multicolumn{4}{|c|}{26} & & \\
\hline Lack of knowledge,awareness & \multicolumn{4}{|c|}{15} & & \\
\hline Transport/accessibility & \multicolumn{4}{|l|}{7} & & \\
\hline Complications during pregnancy & \multicolumn{4}{|l|}{4} & & \\
\hline \multirow[t]{2}{*}{ High maternal mortality } & 2 & & & & & \\
\hline & & 20 & 40 & 60 & 80 & 100 \\
\hline
\end{tabular}

*Multiple responses 
More than three quarters (78 percent) of all respondents agreed that there were problems in their community regarding newborn health. The most commonly mentioned problem by them was low birth weight or premature babies. Other newborn related health problems included poor knowledge, awareness and practices, poor immunization status, lack of breast feeding practices and prevalence of bottle feeding.

Figure 4.3: Newborn health problems in the community as perceived by the FBHC members*

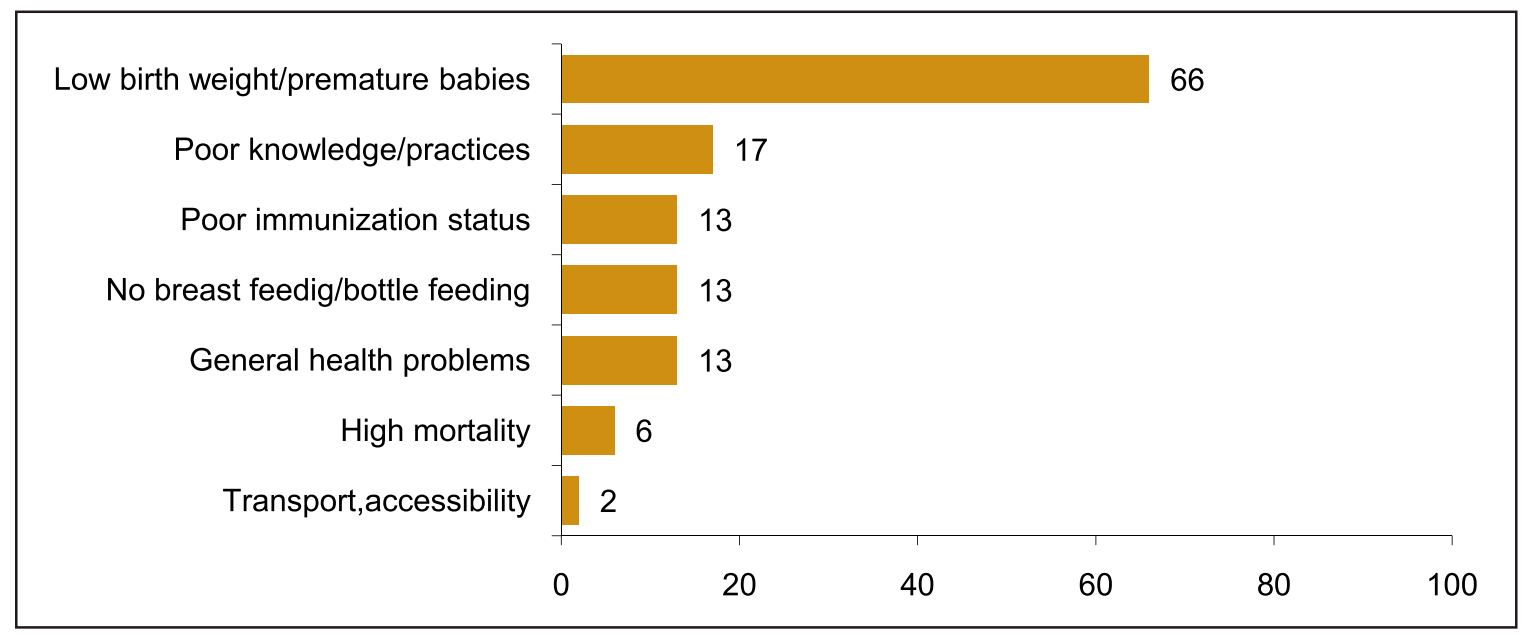

*Multiple responses

\section{Process of FBHC meetings}

\section{Arrangements for the meeting}

The members were asked about the person who had arranged the FBHC meetings. A large number (42 percent) reported that meetings were arranged by the head of the facility (doctor in-charge); whereas a fifth of respondents said that someone from PAIMAN/partners arranged the meetings. According to some respondents, meetings were arranged by specific members of FBHC (8 percent) or they were mutually arranged by PAIMAN and health facility staff (5 percent), however 15 percent of respondents didn't know who arranged the meetings. A large majority ( 82 percent) of respondents reported that the last FBHC meeting was held at the health facility.

It is very vital for FBHC meeting to have an agenda and that should be shared with the members prior to the meeting. Three quarters (76 percent) of the respondents expressed that an agenda was set for the last FBHC meeting held but a majority of these (59 percent) respondents did not receive a formal agenda document before the meeting. Slightly less than a quarter of respondents thought that the head of health facility prepared the agenda, whereas others were of the view that the agenda was prepared by a person from PAIMAN or the head of FBHC (18 
percent and 15 percent respectively). A fifth of the respondents had no idea about who prepared the agenda for meetings.

Table 4.4: Arrangements for FBHC meetings, as reported by members

\begin{tabular}{lcc}
\hline Arranged by & Number & Percent \\
\hline Person from PAIMAN/Partners & 12 & 20 \\
Head of health facility & 25 & 42 \\
Specific member of health committee & 5 & 8 \\
Mutual/both PAIMAN \& head of health facility & 3 & 5 \\
No meeting was held & 6 & 10 \\
Don't know & 9 & 15 \\
Total & $\mathbf{6 0}$ & $\mathbf{1 0 0}$ \\
\hline
\end{tabular}

\section{Participation by members}

A quarter of the respondents had never attended a meeting of FBHC. Of those who had ever attended a meeting, slightly less than half reported having attended only one meeting, whereas a third responded that they attended 2 to 5 meetings. Only a fifth of respondents attended more than 5 meetings. Mean number of meetings attended by the members was 4.5(SD=7). District wise analysis showed that all respondents from Rawalpindi and Khanewal reportedly attended at least one meeting, where as three quarters of the respondents in both Dadu and Buner responded to have ever attended a meeting. Surprisingly only less than a third (31 percent) from Lasbella reported having ever attended a meeting, whereas the remaining more than two thirds (69 percent) stated that they never attended any FBHC meeting.

Among the respondents who had ever attended a meeting, all members in District Lasbella reported that they had attended only one meeting, whereas slightly less than three quarters from Khanewal also reported that they had attended only one meeting. This showed a low participation by the members in these two districts. The proportion, who attended only one meeting, was less in Dadu (10 percent), Buner (20 percent) and Rawalpindi (33 percent). Two thirds of respondents in Rawalpindi and half in Buner attended 2 to 5 meetings, as opposed to Dadu (30 percent) and Khanewal ( 22 percent). The largest proportion that attended more than 5 meetings was from Dadu (60 percent), followed by Buner (30 percent) and Khanewal (6 percent). No member from Lasbella and Rawalpindi was reported to have attended more than 5 meetings. If we rate the districts by number of reported meetings attended by the members, 
Dadu scored the highest, followed by Buner, Rawalpindi, Khanewal and Lasbella being the lowest.

A third of those who had ever attended a meeting, were reported to have attended a meeting within a month, whereas slightly less than a quarter attended 1 to 2 months previously. A large number (44 percent) had attended a meeting more than 6 months back. This showed a relatively low participation by the members of FBHC in the meetings. It could be due to a low frequency of FBHC meetings.

Figure 4.4: Time since last meeting attended as reported by FBHC members

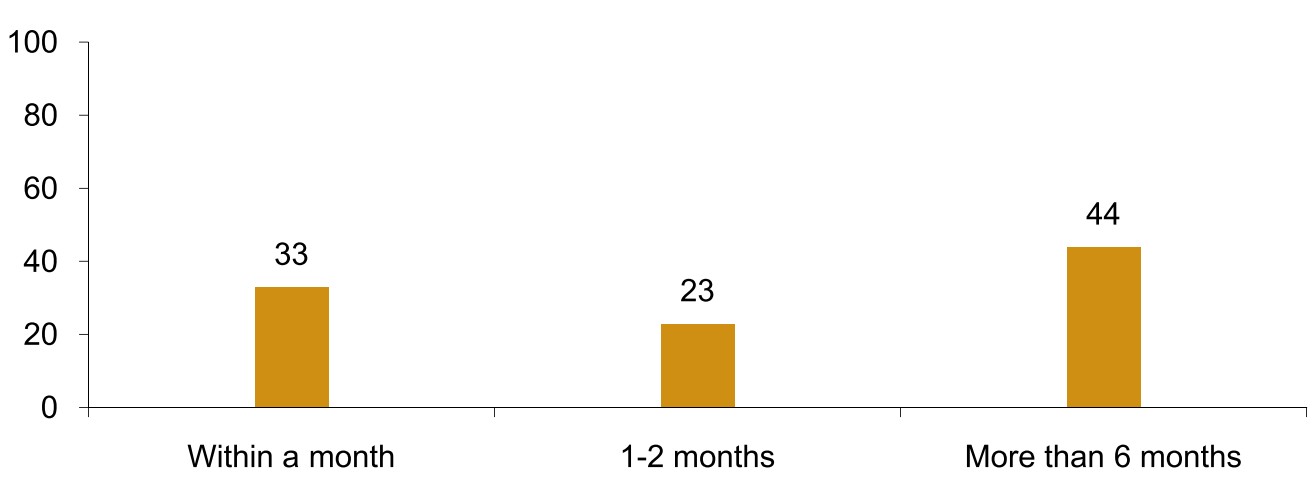

A large number (39 percent) of respondents reported that less than 10 members participated in the last held meeting, whereas slightly less than half (46 percent) replied that 10-20 members were present in the last meeting. Interestingly, 15 percent respondents mentioned that more than 20 members were present in the last FBHC meeting.

\section{Frequency of meetings}

Of those who had ever attended a meeting, slightly less than half reported that so far only one meeting was held and according to a fifth, a meeting was held once every month. Most of the remaining reported even less frequent meetings. This indicated a very low frequency of FBHC meetings. 
Table 4.5: Frequency of meetings as reported by FBHC members

\begin{tabular}{lcc}
\hline Frequency of meetings & Number & Percent \\
\hline Once every two weeks (twice a month) & 2 & 5 \\
Once every month & 9 & 21 \\
Once every two-month & 1 & 2 \\
Once every quarter & 3 & 7 \\
Once every two-quarter & 1 & 2 \\
Only one so for & 20 & 47 \\
Others & 7 & 16 \\
Total & $\mathbf{4 3}$ & $\mathbf{1 0 0}$ \\
\hline
\end{tabular}

\section{Proceedings of the meeting:}

A majority of respondents (62 percent) mentioned that the main issues discussed in the last held meeting were regarding maternal and newborn health and creating $\mathrm{MNH}$ awareness in the community. 16 percent members reported that the up gradation of health facility was among the topics of discussion. A few (7 percent) could not recall the main topic discussed in the last meeting. Two thirds of the respondents reported that they were able to share their views in the last held meeting, as opposed to the remaining one third, who could not share their views.

Two thirds of the members (who ever attended a meeting, $\mathrm{N}=45$ ), reported that the minutes of FBHC meetings were recorded. Of those $(\mathrm{N}=30)$, more than a third (37 percent) responded that the person from PAIMAN recorded the minutes and a fifth replied that a member of FBHC did so. Slightly less than a quarter expressed that there was no particular person to record the meeting minutes. An overwhelming majority ( 87 percent) reported that they did not receive the minutes of the last held meeting.

Overall, a large majority of FBHC members (80 percent) reported that a PAIMAN person ever attended a meeting. Overwhelming proportions from Dadu (90 percent), Khanewal (89 percent) and Buner (70 percent) reported so, compared to two third from Rawalpindi and half from Lasbella.

\section{Views of FBHC members regarding the committee}

Members were asked to express their views regarding the usefulness of $\mathrm{FBHC}$ and to give suggestions to improve its functioning. Of those who had ever attended a meeting $(\mathrm{N}=45)$, slightly less than a third ( 32 percent) responded that there was no benefit to having FBHC, while a large number ( 45 percent) perceived that it had improved awareness in the community regarding $\mathrm{MNH}$ issues. Another 17 percent expressed favorable views, such as the FBHC acted as 
a link between the community and the health facility and that there had been a reduction in maternal mortality in the community etc. In this way, a majority (62 percent) had a positive attitude towards the FBHC. Very few $(n=3)$ members were unable to mention the benefits of FBHC. A large majority of interviewed members ( 80 percent) responded that the management of health facility listened to the recommendations of the committee.

An overwhelming majority (90 percent) of the respondents were of the view that FBHC concept should be continued in their area, although most of them expressed that it must be implemented in an improved form. A similar proportion of respondents (90 percent) were in favor of implementing the FBHCs in other districts because they believed that the other districts were under developed and people of those districts should also benefit from the FBHC. Those who were not in favor of $\mathrm{FBHC}$ replication, thought so because the $\mathrm{FBHC}$ had no legal power and the community did not give importance to the recommendations of the committee.

The most common suggestions given by the respondents were to hold regular meetings, more PAIMAN support/monitoring and inclusion of other members in FBHC for better representation of the community.

Figure 4.5: Suggestions of FBHC members*

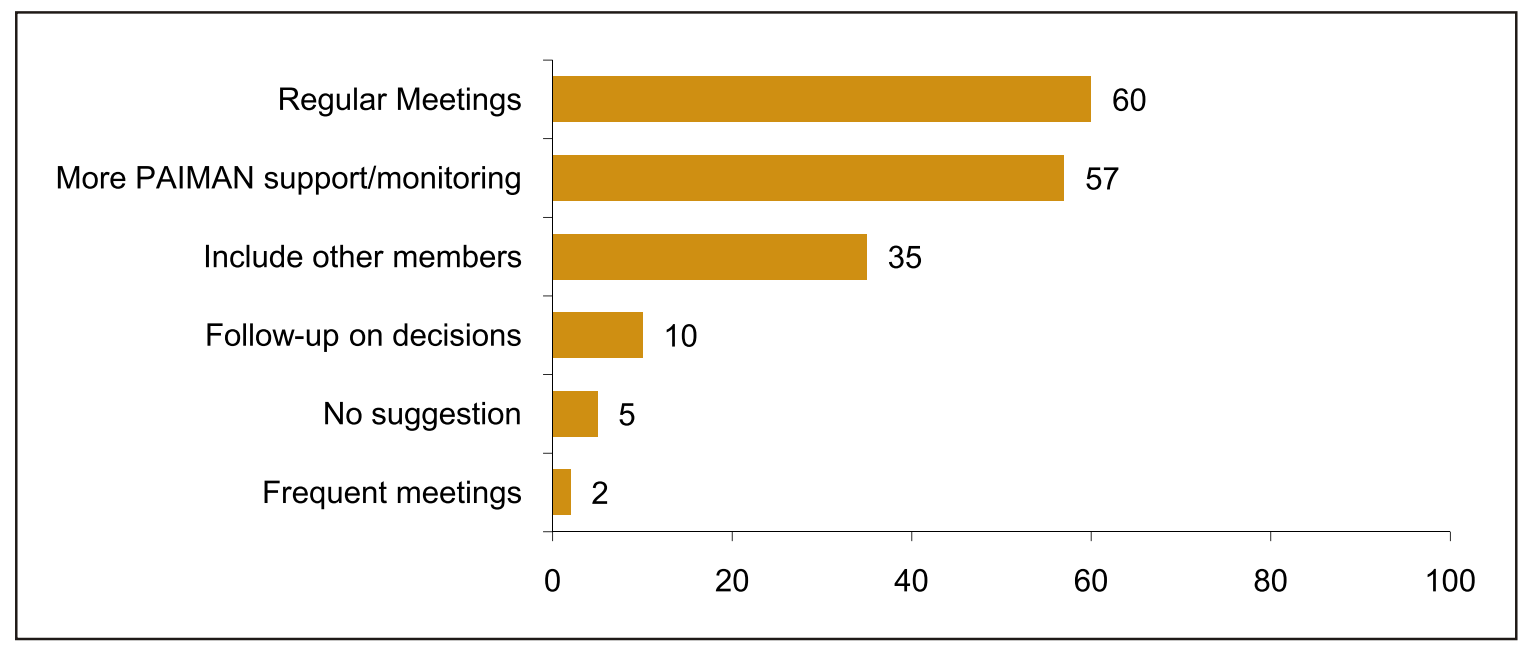

*Multiple responses

During interviews with some $\mathrm{FBHC}$ members, it was pointed out that most of the FBHC members were not residents of the area; rather, they were living in the main town of tehsil or district .They only visited their native area on weekends; hence they were unaware of the local issues. A suggestion was made for inclusion of local residents from different areas for a comprehensive and true representation of the community. 


\section{Conclusions}

Although FBHCs were established in all PAIMAN districts, the process of implementing the steps of FBHC was not carried out as planned, in most of the districts. The coverage of FBHCs was very limited; they were established in 3, 6, 7, 8 and 17 health facilities of district Lasbella, Dadu, Buner, Rawalpindi and Khanewal respectively. The average number of members in each committee was 13, including a mean number of 5 females in each committee. A quarter of the FBHC members had never attended a meeting. Out of the remaining, almost half had attended only one meeting. This shows very limited participation by the members of FBHC. There was also a low frequency of FBHC meetings. The research team also found that in a majority of the meetings, no prior agenda was prepared or sent to the members. Similarly meeting minutes were not sent to the members of FBHC. Maternal and newborn health, creating awareness on $\mathrm{MNH}$ and up gradation of $\mathrm{HF}$ were the topics of discussion in most of the meetings. A majority of the members were able to share their views during the meetings.

Most of the members had a positive attitude towards FBHC, but a third of the members thought that there was no benefit to having the committee. Those who were not in favor of FBHC replication, thought so because the $\mathrm{FBHC}$ had no legal power and the community did not give importance to the recommendations of the committee. The members suggested that there should be regular, frequent, well organized and coordinated meetings of FBHC. They also suggested including more members in the committee to be truly representative.

In the wake of above mentioned deficiencies in the implementation of FBHC, the strategy needs to be reviewed. The research findings suggest that a concerted effort is required to improve the prevailing situation of FBHC in PAIMAN districts. An alternate strategy could be to replace the $\mathrm{FBHC}$ with some innovative community mobilization activity. 



\section{ANNEX 1}

\section{Team formation for fieldwork of process evaluation community mobilization}

\begin{tabular}{|c|c|c|}
\hline \multicolumn{3}{|c|}{ Supervisor : Dr. Zakir Hussain Shah } \\
\hline S.No & Team & Designation \\
\hline 1. & Ms. Lubna Shireen & Deputy Program Officer \\
\hline 2. & Mr. Abdur Rauf Khan & Field Coordinator \\
\hline \multicolumn{3}{|c|}{ District Buner } \\
\hline $\begin{array}{l}3 . \\
4 .\end{array}$ & $\begin{array}{l}\text { Ms. Shagufta Bibi } \\
\text { Ms. Irum Rashid }\end{array}$ & Interviewers \\
\hline \multicolumn{3}{|c|}{ District Rawalpindi } \\
\hline $\begin{array}{l}5 . \\
6 .\end{array}$ & $\begin{array}{l}\text { Ms. Nasreen Akhter } \\
\text { Ms. Samina Abbas }\end{array}$ & Interviewers \\
\hline \multicolumn{3}{|c|}{ District Khanewal } \\
\hline $\begin{array}{l}7 . \\
8 .\end{array}$ & $\begin{array}{l}\text { Ms. Irum Jilani } \\
\text { Ms. Samina Rafiq }\end{array}$ & Interviewers \\
\hline \multicolumn{3}{|c|}{ District Dadu \& Lasbella } \\
\hline $\begin{array}{r}9 . \\
10 .\end{array}$ & $\begin{array}{l}\text { Ms. Afroze Channa } \\
\text { Ms. Farzana Khan }\end{array}$ & Interviewers \\
\hline
\end{tabular}




\section{ANNEX 2}

\section{Health facilities with FBHCs in five sampled districts*}

\begin{tabular}{|c|c|c|c|c|c|}
\hline \multicolumn{6}{|c|}{ Districts } \\
\hline S/No & Buner & Rawalpindi & Khanewal & Dadu & Lasbella \\
\hline 1 & RHC Jowar & RHC Mandra & BHU Mumdal & $\begin{array}{l}\text { BHU Piro Goth, Tehsil } \\
\text { Dadu }\end{array}$ & RHC Bella \\
\hline 2 & BHU Nanser & BHU Kali Mitti & $\begin{array}{l}\text { BHU Mian } \\
\text { Cannu }\end{array}$ & $\begin{array}{l}\text { RHC Sita Road, Tehsil } \\
\text { KN Shah }\end{array}$ & $\begin{array}{l}\mathrm{MCH} \text { Center } \\
\text { Hub }\end{array}$ \\
\hline 3 & BHU Ilai & BHU Kuri Dolal & $\begin{array}{l}\text { RHC Kacha } \\
\text { Khu }\end{array}$ & $\begin{array}{l}\text { BHU Gozo, Tehsil KN } \\
\text { Shah }\end{array}$ & RHC Winder \\
\hline 4 & $\begin{array}{l}\text { BHU } \\
\text { Nawekaley }\end{array}$ & BHU Kontrila & BHU 30/10-R & BHU Pipri, Tehsil Dadu & \\
\hline 5 & $\mathrm{CH}$ Chamla & BHU Susraal & BHU $14 / 8-R$ & $\begin{array}{l}\text { BHU Khanpur, Tehsil KN } \\
\text { Shah }\end{array}$ & \\
\hline 6 & BHU Koga & $\begin{array}{l}\text { BHU Pind } \\
\text { Nosheri }\end{array}$ & BHU 11-A/8-R & $\begin{array}{l}\text { GD Kakar, Tehsil KN } \\
\text { Shah }\end{array}$ & \\
\hline 7 & BHU Koria & $\begin{array}{l}\text { RHC Kalar } \\
\text { Sayedan }\end{array}$ & $\mathrm{BHU} 7 / 9-\mathrm{R}$ & & \\
\hline 8 & & BHU Jatli & BHU 137/16-L & & \\
\hline 9 & & & BHU 129/15-L & & \\
\hline 10 & & & BHU 133/16-L & & \\
\hline 11 & & & BHU 44/15-L & & \\
\hline 12 & & & $\mathrm{BHU} 88-\mathrm{A} / 10-\mathrm{R}$ & & \\
\hline 13 & & & BHU 79/10-R & & \\
\hline 14 & & & RHC Tulemba & & \\
\hline 15 & & & BHU Shamkot & & \\
\hline 16 & & & $\mathrm{BHU} 12 / \mathrm{AH}$ & & \\
\hline 17 & & & $\begin{array}{l}\text { BHU Srai } \\
\text { Sadhoo }\end{array}$ & & \\
\hline Total & 7 & 8 & 17 & 6 & 3 \\
\hline
\end{tabular}

${ }^{*}$ Only RHCs \& BHUs are enlisted 


\section{ANNEX 3}

\section{CAM Message Matrix for Women}

\begin{tabular}{|c|c|c|}
\hline Audience & Messages for phase 1 & Messages for phase $2^{7}$ \\
\hline Women & $\begin{array}{l}\text { 1. Pregnancy is a special condition that } \\
\text { requires preparation, good food and } \\
\text { rest. } \\
\text { 2. Adequate rest and nutritious food } \\
\text { will help you cope with your } \\
\text { pregnancy well. You need to eat } \\
\text { foods that are high in protein and } \\
\text { iron such as eggs, lamb, beef, dark, } \\
\text { leafy green vegetables and fresh } \\
\text { fruits. etc. (need more information } \\
\text { on specific nutrition requirements). } \\
\text { Babies get all their nutrition through } \\
\text { what you eat. If you eat well, you are } \\
\text { more likely to have a healthy baby. } \\
\text { 3. Women need emotional and } \\
\text { physical support during pregnancy. It } \\
\text { is normal to be concerned about } \\
\text { your pregnancy. Talk to your } \\
\text { husband and family about your } \\
\text { condition regularly. Ask for help } \\
\text { when you need it. } \\
\text { 4. During your pregnancy you should } \\
\text { see a health care provider } 4 \text { times. } \\
\text { The provider can help you prepare } \\
\text { for your delivery and make good } \\
\text { decisions about your antenatal care. } \\
\text { Many women have low iron when } \\
\text { they are pregnant which makes } \\
\text { them tired. You need to take iron } \\
\text { supplements during your pregnancy } \\
\text { so you are not as tired. You should } \\
\text { also get } 2 \text { tetanus injections } \\
\text { sometime during the } 9 \text { months. } \\
\text { 5. Make sure you know who is going to } \\
\text { deliver your baby. Find out if they } \\
\text { have access to a clean delivery kit. } \\
\text { Ask for help from someone in the } \\
\text { community to get a clean delivery kit } \\
\text { if the Dai do not have one. }\end{array}$ & $\begin{array}{l}\text { 1. Even a healthy looking pregnancy can } \\
\text { have complications. It is important to } \\
\text { deliver with a skilled birth attendant } \\
\text { who knows what to do in case of a } \\
\text { complication. Make a plan before your } \\
\text { delivery and find out who is trained to } \\
\text { assist you. } \\
\text { 2. Talk to your husband about special } \\
\text { preparations you need for the delivery. } \\
\text { If you have an emergency, you may } \\
\text { need to be transported to a facility. } \\
\text { Make a transportation plan with your } \\
\text { husband. } \\
\text { 3. If you have a complication, you may } \\
\text { need money to pay for treatment, } \\
\text { transportation blood, etc. Start saving } \\
\text { now for any possible complications. } \\
\text { Find out if there are funds available in } \\
\text { your community for pregnant women's } \\
\text { needs. } \\
\text { 4. Find out where the nearest facility is } \\
\text { located in the event you need } \\
\text { emergency care during your pregnancy. } \\
\text { 5. Know the danger signs of pregnancy, } \\
\text { delivery, and post delivery and talk to } \\
\text { your husband about getting care at a } \\
\text { facility should these arise. } \\
\text { 6. If you have a danger sign during your } \\
\text { pregnancy, such as high blood } \\
\text { pressure, make arrangement to deliver } \\
\text { at a facility. }\end{array}$ \\
\hline
\end{tabular}

${ }^{7}$ The messages in this phase will build on messages delivered in phase 1 . Phase 2 however will include more specific messages related to available services and access to skilled birth attendants in the area 


\section{ANNEX 4}

\section{MNH messages given to women during SG meetings, as reported by LHWs and women*}

\begin{tabular}{|c|c|c|}
\hline Responses & LHW \% & Women \% \\
\hline \multicolumn{3}{|c|}{ Antenatal messages } \\
\hline Diet and rest during pregnancy & 81 & 84 \\
\hline At least 4 antenatal visits & 87 & 77 \\
\hline TT vaccinations & 77 & 69 \\
\hline Arrangements for transport, money & 30 & 39 \\
\hline Use of Iron/Foliate tablets & 57 & 38 \\
\hline Arrangements for skilled birth attendant & 31 & 16 \\
\hline Danger Signs & 5 & 6 \\
\hline Hygiene cleanliness & 11 & 1 \\
\hline \multicolumn{3}{|c|}{ Delivery messages } \\
\hline In case of emergency know hospital where & 78 & 78 \\
\hline Clean delivery practices & 82 & 65 \\
\hline Arrangements for money & 3 & 6 \\
\hline Delivery by skilled birth attendant & 5 & 2 \\
\hline \multicolumn{3}{|c|}{ Newborn messages } \\
\hline Early breast feeding within half hour/co & 88 & 70 \\
\hline Wrap newborn in clean cloth/Cleanliness & 62 & 70 \\
\hline Delay bath to newborn at least 6 hours & 66 & 51 \\
\hline Immunization and polio drops & 50 & 41 \\
\hline Exclusive breastfeeding for 6 months & 46 & 29 \\
\hline Cord care & 35 & 26 \\
\hline Danger signs in newborn & 18 & 13 \\
\hline Wrap in warm cloth & 7 & 2 \\
\hline \multicolumn{3}{|c|}{ Postnatal messages } \\
\hline Diet and rest during lactation period & 80 & 75 \\
\hline Post natal check up & 62 & 36 \\
\hline Family planning & 44 & 26 \\
\hline Hygiene/ Cleanliness & 11 & 20 \\
\hline
\end{tabular}

*Multiple responses 


\section{ANNEX 5}

\section{Steps followed during SG meetings as reported by LHWs* \& Observed}

\begin{tabular}{lcc}
\hline Steps & $\begin{array}{c}\text { Observation(N=52) } \\
\text { Percent }\end{array}$ & $\begin{array}{c}\text { LHW*(N=74) } \\
\text { Percent }\end{array}$ \\
\hline Self-introduction of LHW & 85 & 84 \\
Self-introduction by SG members & 81 & 81 \\
Recitation of Holy Quran & 73 & 81 \\
Summarizing today's discussion & 71 & 01 \\
Objectives of SG meeting & 71 & 37 \\
Generate discussion & 54 & 12 \\
Collecting women's experience & 50 & 10 \\
Use of cards & 50 & 12 \\
Norms setting (adaab, moahida) & 42 & 46 \\
Introduction of topic for discussion & - & 84 \\
Problem solving discussion & - & 04 \\
\hline
\end{tabular}

*Multiple responses, percent of cases 


\section{ANNEX 6}

\section{Percent women by number of SG meetings attended, as reported by women}

\begin{tabular}{lcc}
\hline Number of SG meetings & Number & Percent \\
\hline Never attended & 63 & 22 \\
$1-2$ & 52 & 18 \\
$3-5$ & 83 & 29 \\
$6-10$ & 71 & 25 \\
More than 10 & 17 & 6 \\
Total & $\mathbf{2 8 6}$ & $\mathbf{1 0 0}$ \\
\hline
\end{tabular}




\section{ANNEX 7}

\section{Messages Matrix for Husbands, Family Members and Community Leaders}

\begin{tabular}{|c|c|c|}
\hline Audience & Messages for phase 1 & Messages for phase 2 \\
\hline $\begin{array}{l}\text { Husbands and } \\
\text { family } \\
\text { members }\end{array}$ & $\begin{array}{l}\text { 1. Women need help and support when they are } \\
\text { pregnant. Talk to your wife/family member } \\
\text { regularly about her condition. Offer to help her } \\
\text { with her work. } \\
\text { 2. If a woman gets proper rest and good nutrition, } \\
\text { the newborn is more likely to be healthy at } \\
\text { delivery and will have a better chance of } \\
\text { survival. The woman will also fare better with } \\
\text { the pregnancy if she is taking care of herself. } \\
\text { 3. During pregnancy, your wife/family member } \\
\text { requires four antenatal care visits, iron } \\
\text { supplements, and two tetanus injections. Make } \\
\text { sure she is taken to a provider/facility where she } \\
\text { can receive this care. } \\
\text { Whoever delivers the baby (Dai, Family } \\
\text { member) needs to use a clean delivery kit. } \\
\text { Clean delivery kits are available at.... }\end{array}$ & $\begin{array}{l}\text { 1. During the pregnancy the woman should see a } \\
\text { health care provider } 4 \text { times. The provider can } \\
\text { help the family prepare for the delivery and } \\
\text { make good decisions about antenatal care. Many } \\
\text { women have low iron when they are pregnant } \\
\text { which makes them tired. She needs to take iron } \\
\text { supplements during your pregnancy so she is not } \\
\text { as tired. She should also get } 2 \text { tetanus injections } \\
\text { sometime during the } 9 \text { months. } \\
\text { 2. Even a healthy looking pregnancy can have } \\
\text { complications. It is important to delivery with a } \\
\text { skilled birth attendant who knows what to do in } \\
\text { case of a complication. Make a plan before she } \\
\text { delivers and find out who is trained and available } \\
\text { to assist during the delivery. } \\
\text { 3alk to your wife/family member about special } \\
\text { preparations needed for the delivery. If she has } \\
\text { an emergency, she may need to be transported } \\
\text { to a facility. Make a transportation plan. Contact } \\
\text { community leaders to find out what } \\
\text { transportation is available. } \\
\text { 4. If she has a complication, she may need money } \\
\text { to pay for treatment, transportation, blood, etc.. } \\
\text { Start saving now for any possible complications. } \\
\text { Find out if there are funds available in your } \\
\text { community for pregnant women's needs. } \\
\text { Consider starting a committee fund for pregnant } \\
\text { women. } \\
\text { 5ind out where the nearest facility is located in } \\
\text { the event she needs emergency care during her } \\
\text { pregnancy. } \\
\text { Know the danger signs of pregnancy, delivery, } \\
\text { and post delivery and talk to your wife/family } \\
\text { member about getting care at a facility should } \\
\text { these arise. } \\
\text { If you have a danger sign during your pregnancy, } \\
\text { to deliver at a facility. }\end{array}$ \\
\hline
\end{tabular}




\begin{tabular}{|c|c|c|}
\hline Audience & Messages for phase 1 & Messages for phase 2 \\
\hline $\begin{array}{l}\text { Community } \\
\text { leaders }\end{array}$ & $\begin{array}{l}\text { 1. It is the responsibility of every community } \\
\text { leader to take a lead role in helping to } \\
\text { reduce maternal and newborn death. } \\
\text { 2. In order to help save lives, community } \\
\text { leaders need to be well-informed and skilled } \\
\text { modeling appropriate behavior and sharing } \\
\text { important information with community } \\
\text { members. They need to encourage pregnant } \\
\text { women and their families to gather all the } \\
\text { information they need about the } \\
\text { importance of pregnancy, labor, delivery, } \\
\text { and the neonatal period; seek clinical care, } \\
\text { etc. Messages on the importance of support } \\
\text { from loved ones as a key ingredient to } \\
\text { successful birth outcomes should also be } \\
\text { shared by community leaders. } \\
\text { Community leaders can be particularly } \\
\text { useful by encouraging husbands and family } \\
\text { members to: } \\
\text { - Help pregnant women have proper } \\
\text { rest and food } \\
\text { - Have } 4 \text { antenatal check ups } \\
\text { - Have two TT vaccine shots } \\
\text { Take regular iron folate tablets (how } \\
\text { often?) } \\
\text { In addition, it is important to reinforce the } \\
\text { messages to mothers and their husbands } \\
\text { and in-laws on the importance of a } \\
\text { diversified diet for the mother including lots } \\
\text { of fruits and vegetables, sources of protein } \\
\text { (beans, fish, and meat) for a healthy } \\
\text { delivery. Q: Are Zinc and vitamin A being } \\
\text { formally recommended? } \\
\text { and encourage birth preparedness measures } \\
\text { mechanisms when appropriate. }\end{array}$ & $\begin{array}{l}\text { 1. In particular, community leaders should } \\
\text { deliver messages on the importance of } \\
\text { establishing an emergency transport } \\
\text { system; generating an emergency fund for } \\
\text { MNH dire situations; and arranging for } \\
\text { blood donors and appropriate referral } \\
\text { facilities is another. }\end{array}$ \\
\hline
\end{tabular}




\section{ANNEX 8}

\section{Supervisory Checklist}

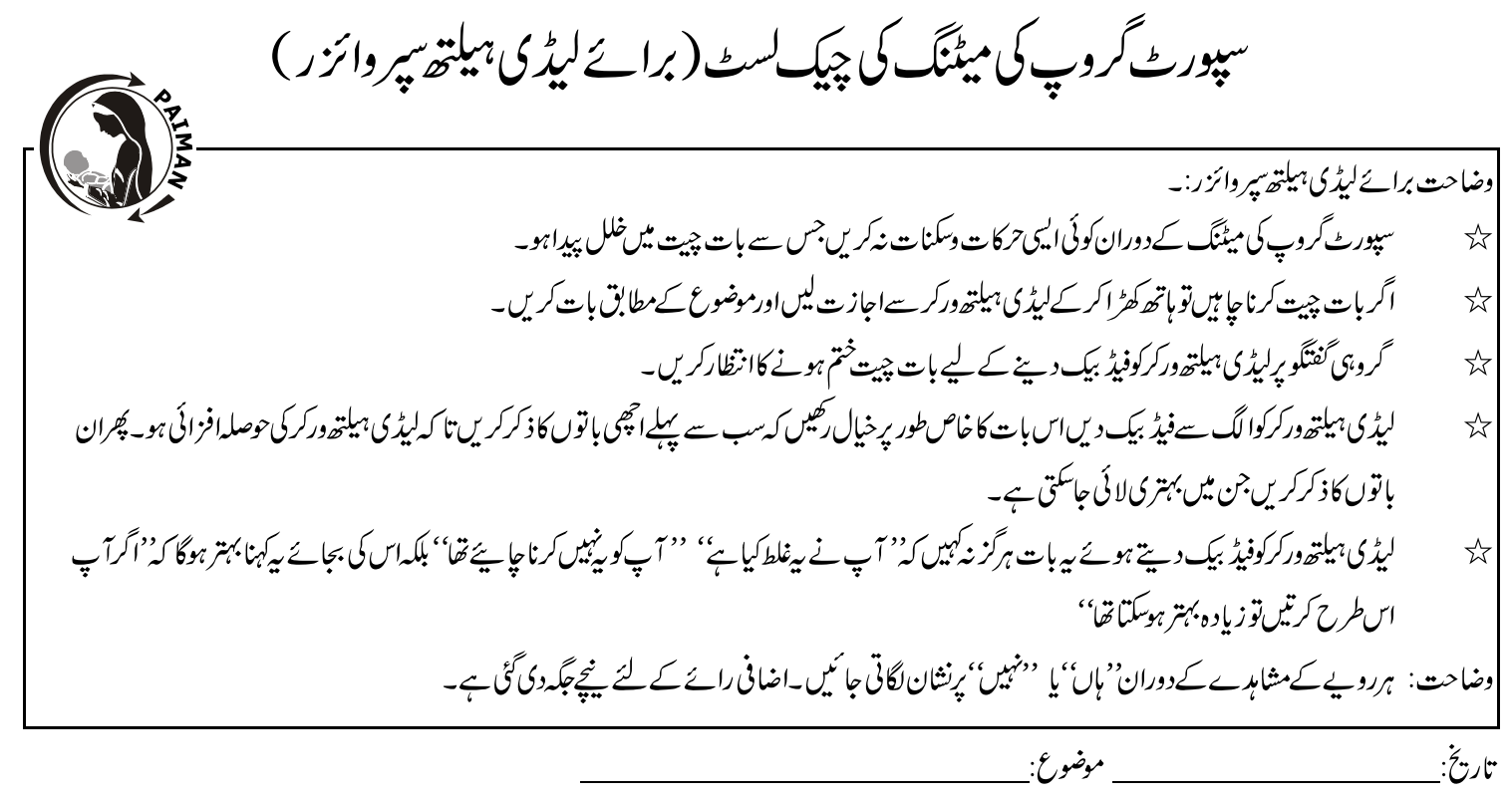

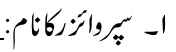

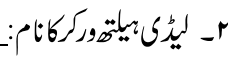

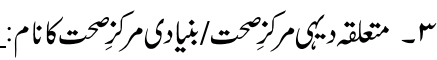

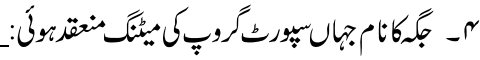

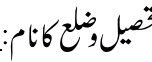

هـ كاؤنكام:

\begin{tabular}{|c|c|c|c|}
\hline i & $u$ & קهارتيّ & نمبرثار \\
\hline & & 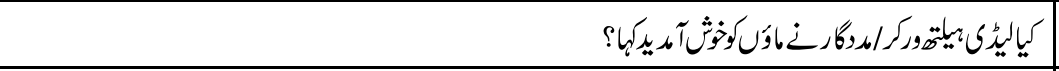 & 1 \\
\hline & & 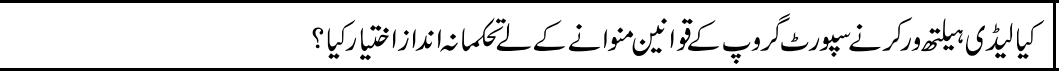 & $r$ \\
\hline & & 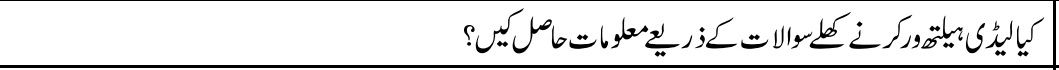 & $r$ \\
\hline & & 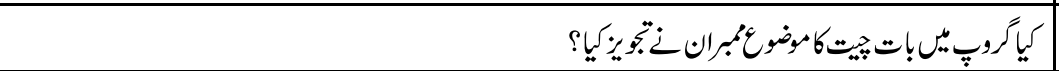 & $r$ \\
\hline & & 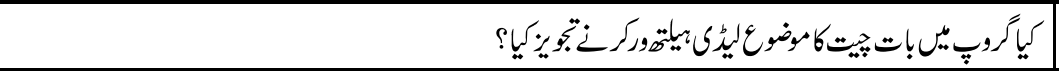 & $\Delta$ \\
\hline & & 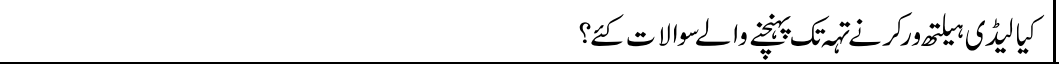 & 4 \\
\hline & & 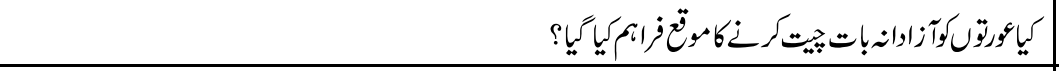 & $\angle$ \\
\hline & & 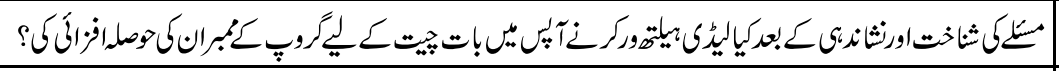 & $\wedge$ \\
\hline & & 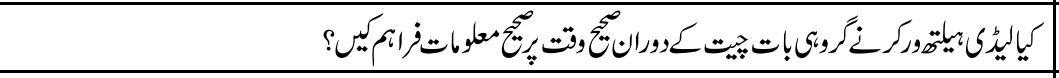 & 9 \\
\hline & & 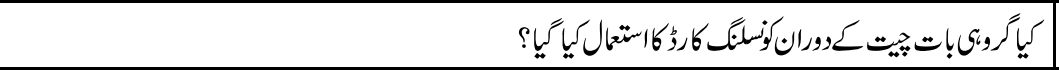 & 1. \\
\hline & & 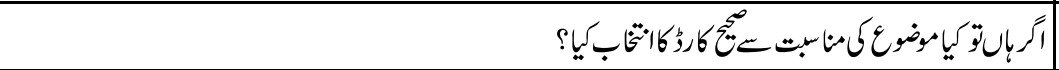 & $\|$ \\
\hline
\end{tabular}




\begin{tabular}{|c|c|c|c|}
\hline ن' & $u$ & هبارثي & فُبرثار \\
\hline & & 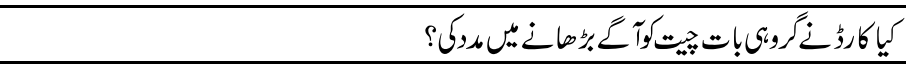 & ir \\
\hline & & 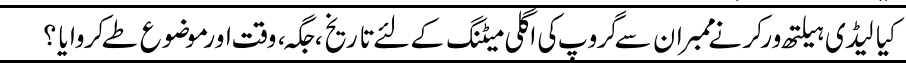 & I" \\
\hline & & 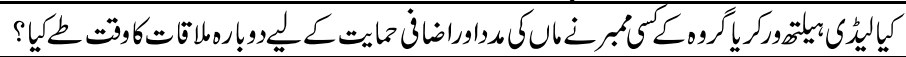 & ir \\
\hline
\end{tabular}

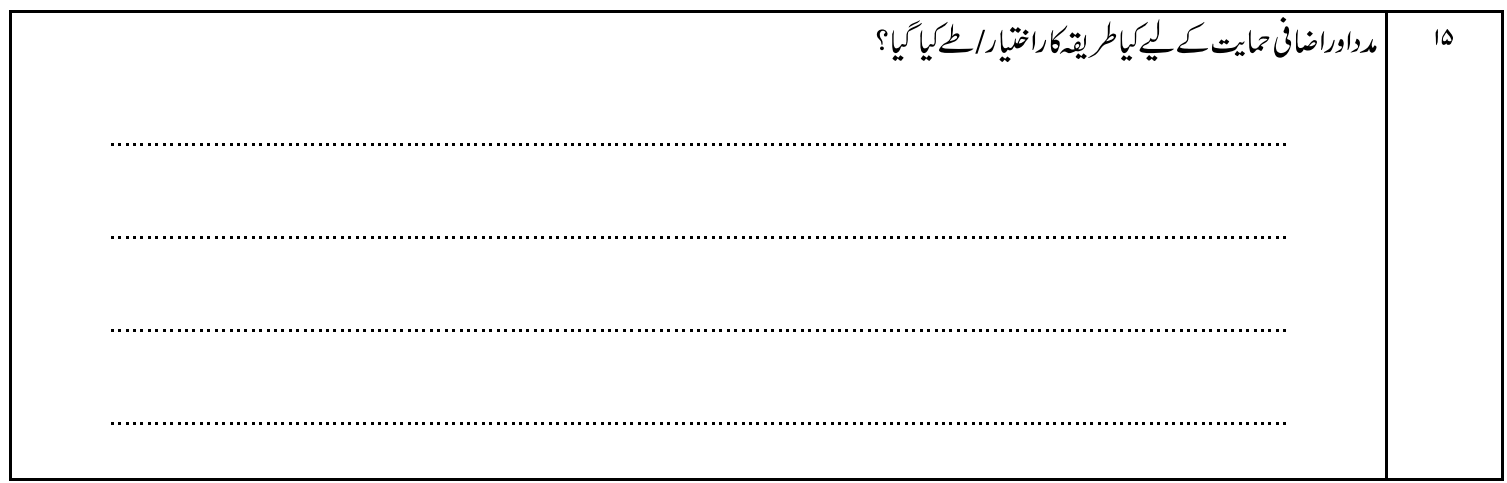

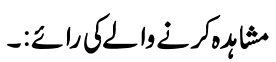




\section{ANNEX 9}

\section{Activity Reference Sheet- Support Group}

\section{Activity Reference Sheet - Support Group}

Name of Strategic Objective: S01- Increase awareness and promote positive maternal and neonatal health behaviors

Name of the CM task : Support National Program in conducting female support groups (SG)

Geographic Focus: 10 target districts: Punjab and NWFP- Lead organization for CM activities; Save the Children US. Balochistan, Mercy Corps is the lead organization for Implementation of $\mathrm{CM}$ activities while in Sindh, PAVHNA leads the CM activities.

Reporting Frequency: Quarterly

\section{DESCRIPTION}

\section{Precise Definitions(s):}

A MOU has been signed with the National Program for FP \& PHC whereby an LHW as a community out reach worker for health shall incorporate PAIMAN key MNH messages through an interactive and participatory technique with lactating mothers, pregnant mothers, newly wed women, mothers-in-law, sisters-in-law, TBA and/or other women of child bearing age in her catchments. According to the criteria set by the NP an LHW belonging to the local area, with formal education of grade 10 provides preventive services to 150-200 households in her encatchement area, through visits and group meetings. The number of the population may vary due to access to population and mobility of the LHW. The LHW is trained through PAIMAN to conduct SG in the area.

Targets: Every quarter

Desegregation: Female primarily of married women and secondarily all women of reproductive age are encouraged to attend.

Significance of the task: It is a meeting where pregnant women, lactating mothers, women of child bearing age, mothers-in-law, TBAs, formal health care providers, councilors as well as other influential women of the area with similar interests, assemble together in a safe atmosphere. They exchange ideas, share experiences and information. In addition this group provides emotional support and strengthening so that the mothers/women could come to terms with ways for improving the conditions related to their own health and the health of their children. It 
also helps in interpersonal growth in the interaction between parents, family members, and healthcare workers, both formal and informal. Support Group (SG) methodology is one of the most effective methodologies for extending the information and awareness to the communities, along with building of self-esteem \& bringing positive behavior change. It helps in building trust and linkages of the community members with health facility staff.

According to support group methodology 8-15 participants should comprise a SG. In relevance to the role of LHW, each LHW is expected to provide services to CBAs specially mothers and rest of the target population; therefore she needs to organize at least 3-4 Support Groups, meeting at regular intervals, with participation of mothers, mothers-in-law, newly wed females and unmarried women. The mode of organization of these support groups is proposed as follows:

\section{Characteristics of a Support Group}

1. Provides a safe environment of respect, attention, trust, sincerity, and empathy

2. Allows women to:

- Share information and personal experiences

- Mutually support each other through their own experiences

- Strengthen or modify certain attitudes and practices

- Learn from each other

- obtain support from other women of the community

3. Allows women to reflect on their experiences, doubts, difficulties, popular beliefs, myths, information, and adequate breastfeeding practices. In this safe environment the mother has the knowledge and confidence needed to decide to either strengthen or modify her breastfeeding practices.

4. Provides a persuasive environment for other family members e.g. mothers-in-law to support daughters-in-law for better decision making with regards to seeking skilled birth attendance.

5. Involves inviting and encouraging role models within the community to help and influence behavior change

6. Is not a LECTURE or CLASS. All participants play an active role.

7. Focuses on the importance of mother-to-mother communication. In this way all the women can express their ideas, knowledge, and doubts, share experiences and receive and give support to the other women who make up the group.

8. Has a seating arrangement that allows all participants to have eye-to-eye contact.

9. Varies in size from 8 to 15 participants.

10. Is facilitated by an experienced facilitator who listens and guides the discussion. 
11. Is open, allowing the admission of all interested pregnant women, mothers who are breastfeeding, women with older toddlers and other interested women.

12. The facilitator and the participants of the support group decide on the length of the meeting and the frequency of the meetings (number per month).

\section{PLAN FOR DATA ACQUISITION FOR PAIMAN}

\section{Data Collection Method:}

LHW sends the report to LHS, who than submits it to the District Coordination Officer NP. The DCO NP prepares a district picture of the SG meetings conducted in an area with the number of LHWs performing and mother attending the sessions. This report is collected by the CM personnel in the district on monthly basis. It is compiled at the district and provincial level and submitted to the National level on quarterly basis.

Data Source(s): DCO monthly report /PAIMAN quarterly reports,

Method of data acquisition by PAIMAN/USAID: DCO NP monthly and Quarterly Reports from SCUS/PAVHNA/MC

Individual responsible at SCUS: National Manager CM

Individual responsible for providing data at Provincial Level: Provincial Manager SCUS/PAIMAN

Individual Responsible for providing data at district level: Senior Community Mobilization Officers, Rawalpindi. LHW, LHS, DCO, NP FP \& PHC.

Location of Data Storage: SCUS Islamabad Officer, Provincial office SCUS, District Office, SCUS. District offices NP, provincial and national PIU NP FP \& PHC

\section{DATA QUALITY ISSUES}

Known Data Limitations and significance (if any): Involving new mothers into the group may not be happening and the same group may be meeting repeatedly leading to high beneficiary count but low coverage.

Actions taken or Planned to Address Data Limitations: A diary is maintained with the LHW, listing names of the participants attending the SG meetings to ensure better coverage. 


\section{ANNEX 10}

\section{Mean Number of members in FBHC by district as reported by members FBHC}

\begin{tabular}{llcc}
\hline S. No & District & $\begin{array}{c}\text { Mean No. of FBHC } \\
\text { members }\end{array}$ & Standard Deviation(SD) \\
\hline 1 & Buner & 10 & 3.4 \\
2 & Dadu & 14 & 4.9 \\
3 & Khanewal & 19 & 7.9 \\
4 & Lasbella & 7 & 1.4 \\
5 & Rawalpindi & 10 & 4.0 \\
\hline Overall & & 13 & 6.8 \\
\hline
\end{tabular}




\section{JSI}

JSI Research \& Training Institute, Inc.

CA\#391 A-00-05-01037 is funded by the United States Agency for International Development and implemented by JSI Research \& Training Institute, Inc.

In conjunction with Aga Khan University, Contech International, Johns Hopkins University / CCP, The Population Council, Save the Children USA 